Marina de Marco e Souza

\title{
Avaliação neuropsicológica de crianças e adolescentes com TOC: comparação com controles saudáveis e desfechos pós-tratamento
}

\author{
Dissertação apresentada à Faculdade de \\ Medicina da Universidade de São Paulo para \\ obtenção do título de Mestre em Ciências \\ Programa de Psiquiatria \\ Orientadora: Profa. Dra. Roseli Gedanke Shavitt
}

(Versão corrigida. Resolução CoPGr 6018/11, de 1 de novembro de 2011. A versão original está disponível na Biblioteca da FMUSP) 
Marina de Marco e Souza

\title{
Avaliação neuropsicológica de crianças e adolescentes com TOC: comparação com controles saudáveis e desfechos pós-tratamento
}

\author{
Dissertação apresentada à Faculdade de \\ Medicina da Universidade de São Paulo para \\ obtenção do título de Mestre em Ciências \\ Programa de Psiquiatria \\ Orientadora: Profa. Dra. Roseli Gedanke Shavitt
}

(Versão corrigida. Resolução CoPGr 6018/11, de 1 de novembro de 2011. A versão original está disponível na Biblioteca da FMUSP) 


\section{Dados Internacionais de Catalogação na Publicação (CIP)}

Preparada pela Biblioteca da

Faculdade de Medicina da Universidade de São Paulo

Creprodução autorizada pelo autor

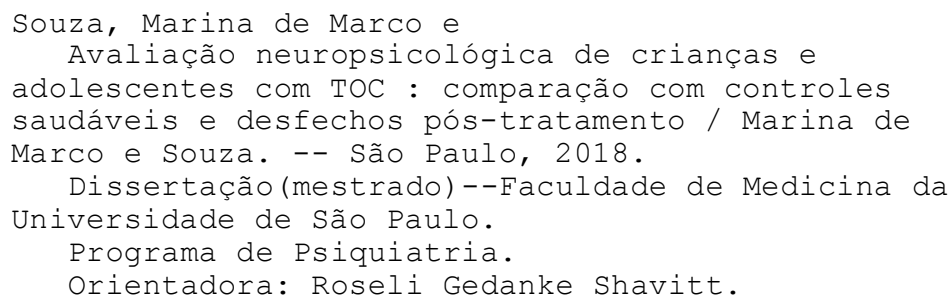

Descritores: 1.Transtorno obsessivo-compulsivo 2.Psiquiatria infantil 3.Neuropsicologia 4.Testes neuropsicológicos 5.Fluoxetina 6.Psicoterapia 7. Criança 8.Adolescente

$\mathrm{USP} / \mathrm{FM} / \mathrm{DBD}-442 / 18$

Responsável: Erinalva da Conceição Batista, CRB-8 6755 
Essa dissertação é dedicada aos meus queridos amigos Carina, Chicão e Rúbia e ao meu tio Jorginho, as pessoas mais cheias de vida que já conheci, mas que se foram antes do final dessa jornada. 


\section{AGRADECIMENTOS}

À querida orientadora Profa. Dra. Roseli Gedanke Shavitt, minha "mãeacadêmica", por acreditar em meu potencial, por todo aprendizado e pelos cuidados cedidos nos momentos mais difíceis.

Aos meus queridos pais, Denise e José Antonio, pela caminhada lado-a-lado e por terem me ensinado que conhecimento é o bem mais precioso que eu poderia adquirir.

Ao meu Rafa, por estar ao meu lado a cada novo desafio e por acreditar em mim. Só amor e companheirismo justificam toda paciência comigo nesses últimos anos. Obrigada por aceitar construir "nossa família" nesse período, no qual tanto de nosso tempo foi tomado por meus investimentos profissionais.

Aos meus irmãos, Letícia e Tiago, por toda cumplicidade e pela companhia. Por me fazerem querer ser uma pessoa e uma profissional ainda melhor.

À minha família, em especial, Vó Matilde, Tia Nelly e Cássia, por estar sempre ao meu lado e por me prover um porto seguro.

Aos meus sogros, Flávio, Lili e Rosinha, por valorizarem minha trajetória profissional e por acreditarem que eu podia ir além.

Às queridas amigas Camilla, Fran, Simone e Fabi, por me fazerem persistir na concretização dessa etapa. 
Às queridas amigas Inês, Nina, Priscilla, Giovanna, Taísa, Deborah, Renata, Cybele, Tati e Karina, pelo companheirismo e por compreenderem minha ausência em tantos momentos.

À querida Adriane Bacellar, por ser responsável pelo início da construção de tantos caminhos em minha vida.

Ao Dr. Marcelo Camargo Batistuzzo, "co-orientador" e parceiro de trabalho no PROTOC desde 2013, por sua generosidade em compartilhar comigo seus conhecimentos e sua curiosidade científica.

Ao Guaraci Requena, por ser tão paciente diante de minhas dúvidas estatísticas e por sempre me orientar da melhor forma possível.

À querida Maria Cecília Toledo ("Cecis"), por cuidar tão bem de mim no PROTOC.

À Dra. Carolina Cappi, por compartilhar comigo seu amor pela pesquisa, por todo acolhimento e por todo companheirismo.

Aos Professores, titulares e suplentes, que compuseram as bancas de defesa e de qualificação desta dissertação, Dra. Cristiana Castanho de Almeida Rocca, Dr. Paulo Jannuzzi Cunha, Dr. Antônio de Pádua Serafim, Dra. Nadia Shigaeff, Dra. Mônica Carolina Miranda, Dr. Orestes Forlenza, Dr. Guilherme Polanczyk, Dra. Juliana Emy Yokomizo e Dra. Tânia Alves, pela disponibilidade e pelas contribuições. 
Aos queridos membros do PROTOC e aos membros do INPD que, de algum modo, colaboraram com a elaboração deste trabalho.

Aos queridos amigos do Serviço de Psicologia e Neuropsicologia, por toda capacitação fornecida no Aprimoramento e na Especialização, por fomentarem meu amor pela Neuropsicologia e por serem exemplos profissionais para mim.

À querida Débora Zambori, que viabilizou toda organização da coleta de dados do projeto SMART e que me aturou por tantas horas no ambulatório e no CEAPESQ.

Às queridas Eliza Fukushima e Isabel Ataide, que tanto me auxiliaram neste processo, fosse com orientações, fosse com colo.

À Coordenação de Aperfeiçoamento de Pessoal de Nível Superior (CAPES), pelos três meses de bolsa cedida.

À Fundação de Amparo à Pesquisa do Estado de São Paulo (FAPESP), pela bolsa concedida e consequente viabilização deste estudo.

Às crianças e às suas respectivas famílias, que acreditaram neste projeto. 
O presente trabalho foi realizado com apoio da Coordenação de Aperfeiçoamento de Pessoal de Nível Superior - Brasil (CAPES) - Código de Financiamento 001 - e financiado pela Fundação de Amparo à Pesquisa do Estado de São Paulo (FAPESP), processo 2016/04595-7. 
Esta dissertação está de acordo com as seguintes normas, em vigor no momento desta publicação:

Referências: adaptado de International Committee of Medical Journals Editors (Vancouver).

Universidade de São Paulo. Faculdade de Medicina. Divisão de Biblioteca e Documentação. Guia de apresentação de dissertações, teses e monografias. Elaborado por Anneliese Carneiro da Cunha, Maria Julia de A. L. Freddi, Maria F. Crestana, Marinalva de Souza Aragão, Suely Campos Cardoso, Valéria Vilhena. 3a ed. São Paulo: Divisão de Biblioteca e Documentação; 2011.

Abreviaturas dos títulos dos periódicos de acordo com List of Journals Indexed in Index Medicus. 


\section{SUMÁRIO}

\section{LISTA DE ABREVIATURAS, SIGLAS E SÍMBOLOS \\ LISTA DE FIGURAS \\ LISTA DE TABELAS \\ RESUMO \\ ABSTRACT}

1. INTRODUÇÃO

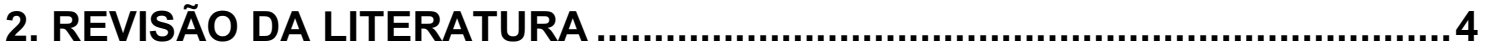

2.1. CARACTERIZAÇÃO DO TRANSTORNO OBSESSIVO-CoMPULSIVO …................ 4

2.2. ASPECTOS NEUROPSICOLÓGICOS DO TOC ...............................................

2.3. TRATAMENTOS Do TOC PEDIÁtRICO E SUA RELAÇÃO COM A COGNIÇÃO .........11

3. JUSTIFICATIVA

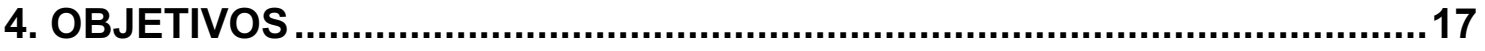

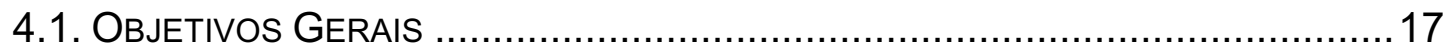

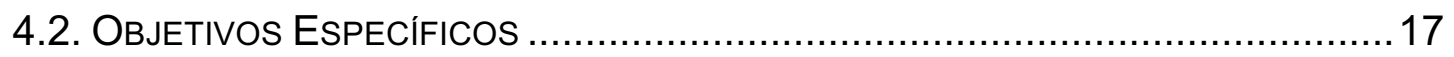

4.2.1. Dados relativos à linha de base (pré-tratamento)..........................17

4.2.2. Dados relativos aos desfechos longitudinais (pós-tratamento)........ 18

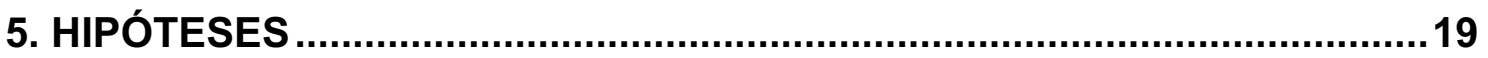

6. MÉTODO

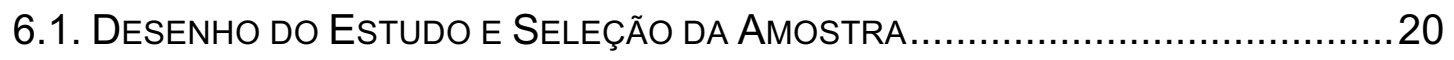

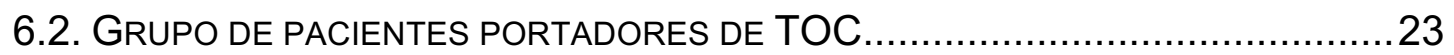

6.2.1. Fluxograma da coleta de dados junto às crianças e adolescentes

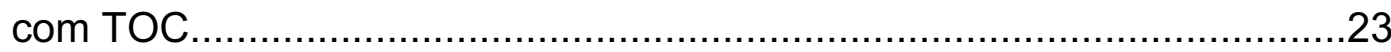

6.2.2. Caracterização da amostra de pacientes portadores de TOC .........26

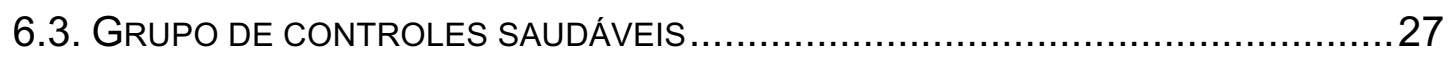

6.3.1. Fluxograma da coleta de dados junto aos controles saudáveis ......27

6.3.2. Caracterização da amostra formada por crianças e adolescentes

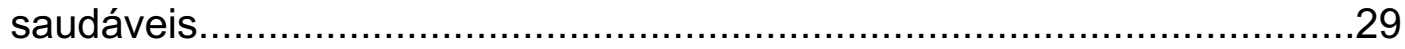

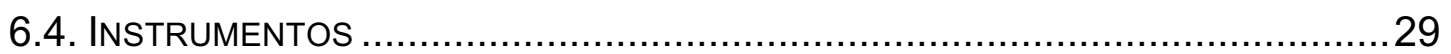

6.4.1. Instrumentos utilizados para a avaliação clínica ...........................29

6.4.2. Instrumentos utilizados para a avaliação neuropsicológica ..............32

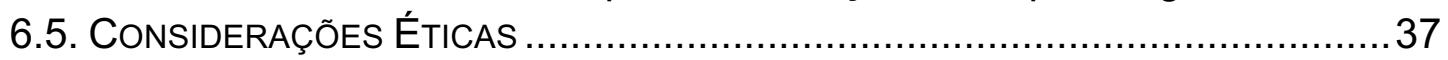

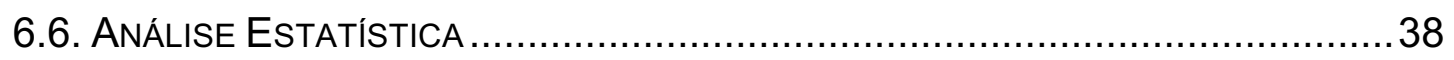

7. RESULTADOS

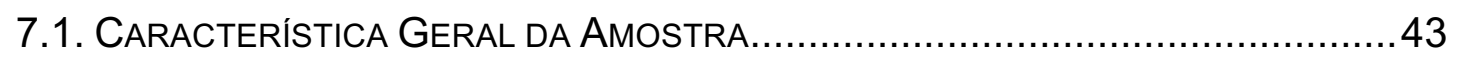

7.2. CARACTERISTICAS CLÍNICAS DO GRUPO DE PACIENTES ...............................45

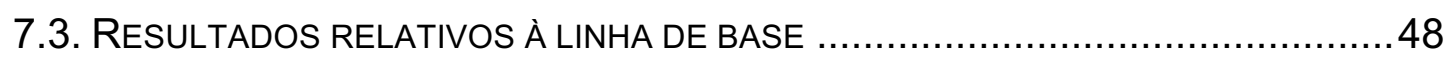


7.3.1. Comparação entre grupos: pacientes versus controles .48

7.3.1.1. Comparação do Quociente de Inteligência entre grupos .48

7.3.1.2. Comparação do funcionamento neuropsicológico de pacientes e controles em diferentes domínios cognitivos .50

7.3.1.3. Associação das variáveis clínicas com o desempenho cognitivo dos pacientes

7.4. DESFECHOS LONGITUDINAIS 53

7.4.1. Comparação do desempenho cognitivo das crianças e adolescentes com TOC antes e depois do tratamento nos diferentes domínios cognitivos

7.4.2. Comparação do desempenho cognitivo das crianças e adolescentes com TOC antes e depois do tratamento nos diferentes testes neuropsicológicos

8. DISCUSSÃO

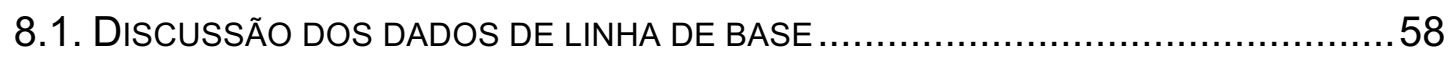

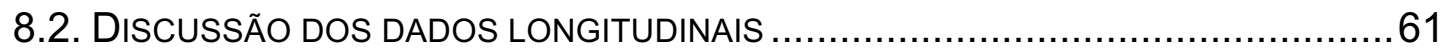

9. LIMITAÇÕES E PERSPECTIVAS FUTURAS ..........................................64

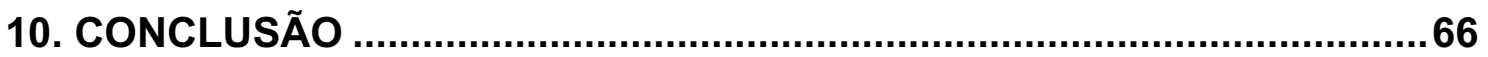

11. ANEXOS

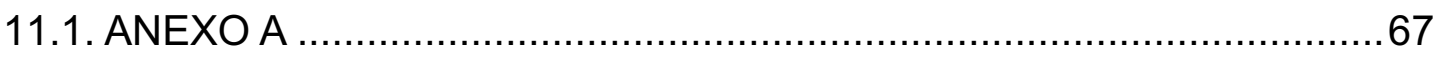

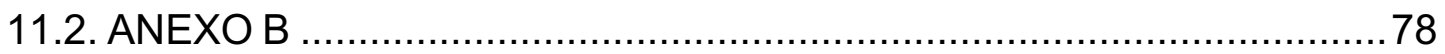

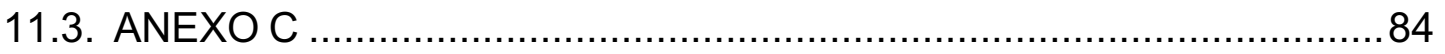

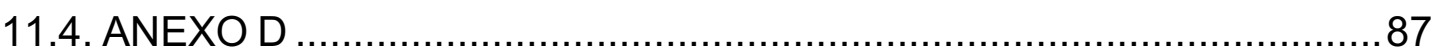

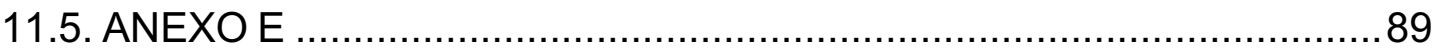

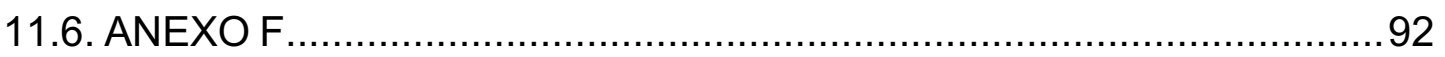

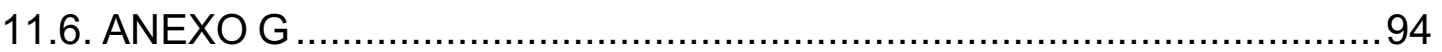

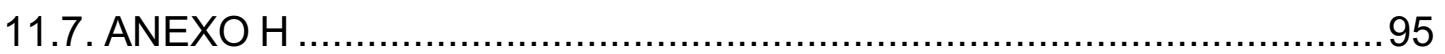

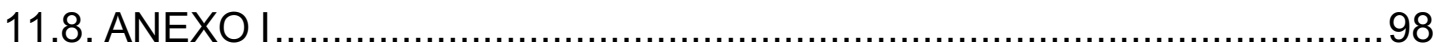

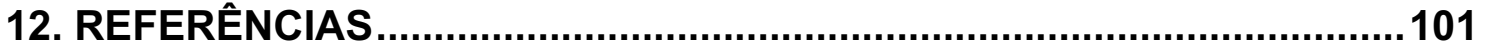




\section{LISTA DE ABREVIATURAS, SIGLAS E SÍMBOLOS}

\begin{tabular}{|c|c|}
\hline ANCOVA & Análise de Covariância \\
\hline ABEP & Associação Brasileira de Empresa e Pesquisa \\
\hline APA & American Psychiactric Association \\
\hline BXT & Brixton Test \\
\hline CEP & Comitê de Ética e Pesquisa \\
\hline CDRS-R & Children's Depression Rating Scale - Revised \\
\hline COR & Cubos de Corsi - WMS-R \\
\hline CRI & Childhood Routines Inventory \\
\hline CUB & subtestes Cubos - WASI \\
\hline CWIT & Color-Word Interference Test \\
\hline DIG & subteste Dígitos - WISC III \\
\hline DFT & Design Fluency Test \\
\hline D-KEFS & Delis-Kaplan Executive Function System \\
\hline DSM-IV-TR & $\begin{array}{l}\text { Diagnostic and Statistical Manual of Mental Disorders, Forth } \\
\text { Edition Revised Manual }\end{array}$ \\
\hline DSM-V & $\begin{array}{l}\text { Diagnostic and Statistical Manual of Mental Disorders, Fith } \\
\text { Edition }\end{array}$ \\
\hline DY-BOCS & Dimensional Yale-Brown Obsessive Scale \\
\hline GPT & Grooved Pegboard Test \\
\hline HC-FMUSP & $\begin{array}{l}\text { Hospital das Clínicas da Faculdade de Medicina da } \\
\text { Universidade de São Paulo }\end{array}$ \\
\hline INPD & $\begin{array}{l}\text { Instituto Nacional de Psiquiatria do Desenvolvimento para } \\
\text { crianças e adolescentes }\end{array}$ \\
\hline IRS & Inibidores de Recaptura de Serotonina \\
\hline ISRS & Inibidores Seletivos de Recaptura de Serotonina \\
\hline
\end{tabular}


Média

MANOVA Análise Multivariada de Variância

MTR

subtestes Matrizes

$\mathrm{mg}$

miligrama

$\mathrm{N}$

Número da amostra

PROTOC

Programa Transtornos do Espectro Obsessivo-Compulsivo

QI

Quociente de Inteligência

QIE

Quociente de Inteligência de Execução

QIV

Quociente de Inteligência Verbal

QIT

Quociente de Inteligência Total

RAVLT

Rey Auditory Verbal Learning Test

RCFT

Rey-Osterrieth Complex Figure Test

SCARED

Screen for Child Anxiety Related Emotional Disorders

SEM

subteste Semelhanças - WASI

SMART

$\mathrm{SOC}$

Sequential Multiple Assigned Randomized Treatment

Sintomas Obsessivos-Compulsivos

TAG

Transtorno de Ansiedade Generalizada

TCC

Terapia Cognitivo-Comportamental

TCCG

Terapia Cognitivo-Comportamental em grupo

TCLE

Termo de Consentimento Livre-Esclarecido

TDAH

Transtorno de Déficit de Atenção e Hiperatividade

TEPT

Transtorno de Estresse Pós-Traumático

TMT

Trail Making Test

TOC

Transtorno Obsessivo-Compulsivo

VOC

subteste Vocabulário - WASI 
WASI

WCST

WISC III

Y-BOCS
Wechsler Abbreviated Scale of Inteligence

Wisconsin Card Sorting Test

Wechsler Intelligence Scale for Children, Third Edition

Yale-Brown Obsessive-Compulsive Scale 


\section{LISTA DE FIGURAS}

Figura 1 - Fluxograma das ligações e das avaliações realizadas junto aos pacientes na linha de base do estudo e após serem submetidos ao tratamento. .25

Figura 2 - Fluxograma das ligações e das avaliações realizadas junto aos controles: o grupo final foi constituído apenas por sujeitos saudáveis que completaram os protocolos clínicos e neuropsicológicos 28 


\section{LISTA DE TABELAS}

Tabela 1 - Agrupamento das variáveis neuropsicológicas em domínios cognitivos 40

Tabela 2 - Características sociodemográficas e lateralidade manual dos participantes do estudo 44

Tabela 3 - Características clínicas de 80 crianças e adolescentes com TOC que receberam tratamento randomizado com fluoxetina ou terapia cognitivo-comportamental em grupo 47

Tabela 4 - Taxa de Resposta a TCCG e a FLX após 14 semanas de tratamento 48

Tabela 5 - Desempenho dos pacientes e controles no teste de QI e nos subtestes do teste WASI 49

Tabela 6 - Comparação do Desempenho Cognitivo de Pacientes e Controles

Tabela 7 - Associação entre os domínios cognitivos e melhora clínica dos sintomas do TOC .54

Tabela 8 - Dados das variáveis neuropsicológicas dos pacientes e controles na linha de base e resultado do teste de comparação de médias 87 
Tabela 9 - Correlações de Pearson entre as dimensões da DY-BOCS, YBOCS e idade de início dos sintomas obsessivo-compulsivos e o desempenho dos pacientes nos testes neuropsicológicos na linha de base 89

Tabela 10 - Correlações de Pearson entre as principais os Transtornos Depressivo, Transtornos Ansiosos, Transtorno de Déficit de Atenção e Hiperatividade e o desempenho dos pacientes nos testes neuropsicológicos na linha de base 92

Tabela 11 - Associação entre os domínios cognitivos e a melhora clínica dos pacientes considerando a resposta aos diferentes tratamentos de primeira escolha para o TOC

Tabela 12 - Desempenho dos pacientes que foram ou não respondedores nos testes neuropsicológicos na linha de base e após 14 semanas de tratamento 95

Tabela 13 - Dados das variáveis neuropsicológicas da linha de base e após 14 semanas de tratamento e resultado dos testes de comparação de médias 98 


\section{RESUMO}

Souza MM. Avaliação neuropsicológica de crianças e adolescentes com TOC: comparação com controles saudáveis e desfechos pós-tratamento [dissertação]. São Paulo: Faculdade de Medicina, Universidade de São Paulo; 2018.

Até o momento, são escassos os estudos que se propuseram a investigar o funcionamento cognitivo das crianças e adolescentes com Transtorno Obsessivo-Compulsivo (TOC). Os estudos disponíveis apontam que essa população apresenta pior desempenho nos testes neuropsicológicos que avaliam as funções executivas, a memória não-verbal, o funcionamento visuoespacial e a velocidade de processamento, em comparação aos sujeitos saudáveis. Mesmo com esses achados, poucos autores averiguaram a influência dos tratamentos de primeira linha para O TOC [Terapia CognitivoComportamental (TCC) e inibidores de recaptura de serotonina (IRS)] na cognição. Vale ressaltar que tais estudos expressam resultados divergentes, não havendo um consenso sobre a melhora ou manutenção dos déficits no desempenho dos jovens após o tratamento. Diante deste contexto, o presente estudo teve como objetivos: A) Comparar as características sociodemográficas e clínicas e o funcionamento cognitivo de uma amostra pediátrica com TOC e sujeitos saudáveis; B) Verificar as modificações no funcionamento cognitivo do grupo TOC após 14 semanas de tratamento farmacológico ou psicoterápico-. Para isso, foram avaliados 82 crianças e adolescentes com TOC e 82 controles saudáveis, com idades entre 6-17 anos, com questionários para avaliação de sintomas psiquiátricos e uma bateria de testes neuropsicológicos. Todos os participantes do estudo foram submetidos às avaliações na linha de base. Os pacientes, após randomização para TCC em grupo ou fluoxetina (FLX), foram reavaliados findadas 14 semanas de tratamento. A análise dos dados indicou que os pacientes apresentam desempenho cognitivo global pior que os controles, havendo diferenças significativas no QI de execução, nas habilidades visuoconstrutivas, na memória episódica não verbal e na flexibilidade mental. Variáveis clínicas, como idade de início dos sintomas, gravidade dos sintomas do TOC, dimensões dos sintomas obsessivo-compulsivos e comorbidades, não 
correlacionaram com o pior desempenho dos pacientes nos diferentes testes neuropsicológicos. Após 14 semanas de tratamento, embora os pacientes tenham apresentado melhora clínica dos sintomas obsessivo-compulsivos, o mesmo não ocorreu com as diferentes funções neuropsicológicas, mesmo naquelas que estavam prejudicadas na linha de base. De acordo com os resultados do presente estudo, as crianças e adolescentes com TOC apresentam pior desempenho cognitivo global em provas neuropsicológicas quando comparados aos controles saudáveis. O fato da melhora dos sintomas não ser acompanhada da melhora do desempenho neuropsicológico dos pacientes, sugere que as alterações cognitivas observadas no grupo TOC sejam relacionadas à própria neurobiologia do transtorno, independentemente da gravidade dos sintomas. Futuros estudos longitudinais serão necessários para aumentar a compreensão do funcionamento cognitivo dos jovens com TOC e as implicações do tratamento na sua cognição no longo prazo.

Descritores: transtorno obsessivo-compulsivo; psiquiatria infantil; neuropsicologia; testes neuropsicológicos; fluoxetina; psicoterapia; criança; adolescente. 


\begin{abstract}
Souza MM. Neuropsychological evaluation of children and adolescents with OCD: comparison with healthy controls and post-treatment outcomes. [dissertation]. São Paulo: "Faculdade de Medicina, Universidade de São Paulo"; 2018.
\end{abstract}

To date, only a few studies have investigated the cognitive functioning of children and adolescents with Obsessive-Compulsive Disorder (OCD). These studies indicate that youth with OCD present a worse performance in neurocognitive tests that assess the executive functions, nonverbal memory, visuospatial functioning and processing speed. Despite these findings, only a few authors have investigated the influence of Cognitive-Behavioral Therapy (CBT) and selective serotonin reuptake inhibitors (SSRIs) on the cognition of youth with OCD. It is worth noting that these studies express divergent results, and there is no consensus on the improvement or maintenance of the cognitive deficits after treatment. In this context, the present study aimed: A) To compare the sociodemographic/clinical characteristics and the cognitive functioning of youth with OCD and healthy controls; B) To verify the changes in cognitive functioning of children and adolescents with OCD after 14 weeks of randomized pharmacological or cognitive-behavioral treatment. Eighty-two children and adolescents with OCD and 82 healthy controls, aged between 6 and 17 years, were evaluated by means of structured questionnaires and a battery of neuropsychological tests. All participants underwent assessments at baseline. The OCD group, after being randomized to group CBT or Fluoxetine (FLX), was re-evaluated after 14 weeks of treatment. Data analyses indicated that patients presented a worse cognitive performance when compared to the healthy controls, with significant differences in performance IQ, visuoconstructive skills, nonverbal memory, and mental flexibility. Clinical variables, such as age of onset, severity of OCD symptoms, OCD dimensions and comorbidities, did not correlate with poorer performance on neuropsychological tests. Although patients had clinical improvement after 14 weeks of treatment, the same did not occur with the cognitive performance, even in those functions which were impaired at baseline. 
According to the results of the present study, youth with OCD present a worse cognitive performance when compared to controls. The fact that the improvement of the symptoms is not followed by the improvement of the neuropsychological performance suggests that the cognitive deficits observed in the OCD group may be related to the neurobiology of the disorder, regardless of the symptom severity. Future longitudinal studies will be needed to further clarify the cognitive functioning of youth with $\mathrm{OCD}$ and the implications of treatment on their cognition in the long run.

Descriptors: obsessive-compulsive disorder; child psychiatry; neuropsychology; neuropsychological tests; fluoxetine; psychotherapy; child; adolescent. 


\section{INTRODUÇÃO}

O Transtorno Obsessivo-Compulsivo (TOC) é um transtorno neuropsiquiátrico que acomete de 1 a $3 \%$ da população, independentemente do sexo, da etnia e da situação socioeconômica (Ruscio et al., 2010; Andrade et al., 2012; Kessler et al., 2012). Os primeiros sinais e sintomas do TOC ocorrem comumente na infância ou na adolescência, podendo persistir de maneira crônica mesmo após os tratamentos de primeira linha (Rasmussen e Eisen, 1990; Stein et al., 1997; Abramowitz et al., 2009). Estudos na área da Psiquiatria da infância indicam, ainda, que a manifestação precoce do transtorno, isso é, o aparecimento do TOC na infância e na adolescência, está associada a grande prejuízo acadêmico, afetivo e social dessa população (Piacentini et al., 2003), a maior gravidade dos sintomas e ao pior prognóstico da doença (Rosário-Campos et al., 2005; de Mathis et al., 2008; Garcia et al., 2009). Além disso, o TOC na infância possui algumas características específicas, como alta frequência de comorbidades (Rosário-Campos et al., 1999; Geller, 2006; Skoog e Skoog, 1999) e maior presença de sintomas de agressão, de contaminação, de verificação, de simetria, de repetição, de contagem, de ordenação/arranjo; obsessões sexuais; compulsões de lavagem; e, compulsões semelhantes a tiques (Rosário-Campos, 1999). Visando melhor embasar as questões clínicas que permeiam o TOC, sobretudo sua manifestação na população pediátrica, foi realizada a revisão da literatura sobre essa temática, a qual está descrita no item 2.1. Caracterização do Transtorno Obsessivo-Compulsivo deste trabalho.

Se, por um lado, os aspectos clínicos do TOC pediátrico já foram exaustivamente pesquisados, por outro, o funcionamento cognitivo das crianças 
e dos adolescentes acometidos pelo transtorno segue correspondendo a um campo pouco explorado. Indo de encontro ao modelo neurobiológico do transtorno, o qual aponta alterações na circuitaria fronto-estriatal (Abramowitz et al., 2009), os principais estudos neuropsicológicos realizados até o momento evidenciam que a população em questão apresenta pior resultado em testes cognitivos que avaliam funções executivas, memória não-verbal, funcionamento visuoespacial e velocidade de processamento (Geller et al., 2017). Contudo, mesmo com a presença de uma meta-análise sobre a cognição das crianças e adolescentes com TOC (Abramovitch et al., 2015a), são poucas as pesquisas que possuem um grupo controle para comparação dos dados neuropsicológicos, que utilizem mais de um teste cognitivo em suas análises e que contem com uma amostra significativa de crianças e adolescentes portadores do transtorno. Como foco central deste estudo, a revisão da literatura sobre esta temática está retratada no item 2.2. Aspectos Neuropsicológicos do TOC.

A averiguação do funcionamento cognitivo das crianças e dos adolescentes com TOC antes e após a realização de algum dos tratamentos de primeira linha para o transtorno, caso da Terapia Cognitivo-Comportamental (TCC) e dos inibidores de recaptura de serotonina (IRS), também carece de estudos. Até o momento, os estudos que englobaram essa discussão indicaram duas tendências em seus resultados. Em uma delas, os déficits cognitivos observados no momento anterior ao tratamento deixaram de existir após as crianças e os adolescentes receberem uma das intervenções terapêuticas de primeira linha (Andrés et al., 2008; Hybel et al., 2017; van der Straten et al., 2018). Diante desses achados, os autores sugerem que as alterações cognitivas observadas 
nas crianças e nos adolescentes com TOC estariam relacionadas à presença dos sintomas obsessivo-compulsivos (SOC). Já a outra possibilidade seria que, após o tratamento, mesmo com a melhora dos SOC, as crianças e os adolescentes seguiriam com as alterações cognitivas (Lewin et al., 2014; Andrés et al., 2007). Nesse caso, os autores consideram que os déficits cognitivos observados nas testagens estariam relacionados a um traço neurobiológico do transtorno, independentemente da gravidade sintomatológica. Como neste trabalho um dos eixos foi observar se existem mudanças no funcionamento cognitivo das crianças e dos adolescentes com TOC após diferentes modalidades de tratamento, foi realizada a revisão da literatura sobre esse campo, a qual está descrita no item 2.3. Tratamentos do TOC pediátrico e sua relação com a cognição. 


\section{REVISÃO DA LITERATURA}

\subsection{Caracterização do Transtorno Obsessivo-Compulsivo}

O TOC é caracterizado pela presença de obsessões e/ou compulsões, sendo que a forma mais frequente da manifestação do transtorno conta com a presença concomitante de ambos os sintomas (APA, 2013). Entende-se por obsessões pensamentos intrusivos que surgem repetidamente sem que o indivíduo tenha controle sobre os mesmos. Compulsões, por sua vez, consistem em comportamentos repetitivos e intencionais, de natureza motora ou mental, cuja função, em geral, é de aliviar e/ou evitar a angústia gerada pelas obsessões; embora possam ocorrer na ausência dessas. (APA, 2013). Além da presença dos sintomas descritos, faz parte do critério diagnóstico do transtorno o fato dos sintomas acarretarem em consumo significativo de tempo (no mínimo, uma hora diária), trazendo prejuízos funcionais e sofrimento ao indivíduo (APA, 2013).

Cerca de 1 a 3\% da população é acometida pelo TOC ao longo da vida, independente de sexo, etnia ou situação econômica (Ruscio et al., 2010; Andrade et al., 2012). De acordo com Geller (2006), os primeiros sinais e sintomas do transtorno parecem corresponder a um modelo bimodal, uma vez que $50 \%$ dos pacientes apresentam início precoce, isto é, na infância ou na adolescência, e, o restante, no início da vida adulta. Além disso, indicam que os sintomas da doença podem persistir de maneira crônica ao longo da vida, principalmente quando não tratados (Rasmunssem e Eisen, 1990; Stein et al., 1997; Kraemer e Robinson, 2005; Abramowitz et al., 2009).

Os estudos fenomenológicos indicam que os sintomas que compõem o TOC 
são bastante heterogêneos. Diante deste fator, uma das abordagens mais utilizadas para caracterização dos sintomas é a dimensional (Mataix-Cols et al., 1999; Rosário-Campos et al., 2006). Esta, por sua vez, propõe o seguinte agrupamento de sintomas: obsessões sexuais, religiosas, somáticas ou de agressão e compulsões de verificação; obsessões de simetria e compulsões de ordenação/arranjo; obsessões de contaminação e compulsões de limpeza; e, obsessões e compulsões de colecionamento.

Embora as informações anteriormente descritas caracterizem, de modo geral, as formas de manifestação do TOC, algumas particularidades são observadas na população pediátrica. Como neste trabalho os sujeitos-alvo do estudo são crianças e adolescentes, atentar-se-á as configurações do transtorno neste público.

Sobre o perfil do paciente pediátrico com TOC, é possível identificar duas tendências no estudo da prevalência dos sintomas nessa população, as quais são demarcadas pelo período anterior e posterior à puberdade. Estudos indicam que, na infância, há um predomínio de meninos diagnosticados com o referido transtorno, enquanto na adolescência, há preponderância de casos entre as meninas (Rosário-Campos, 1999; Zohar, 1999; Geller e March, 2012).

A literatura também aponta uma especificidade dos sintomas encontrados na população pediátrica. Entre os sintomas frequentes, encontram-se o medo de contaminação; o medo de ferir-se ou de ferir pessoas; obsessões sexuais e de simetria; compulsões de lavagem, verificação, repetição, contagem, ordenação/arranjo; e, compulsões semelhantes a tiques (Rosário-Campos, 
1999). Vale apontar, ainda, que apesar de a maioria das crianças apresentar múltiplas obsessões e compulsões, é comum as compulsões precederem o início das obsessões durante a infância. Além disso, em crianças é muito frequente a existência de compulsões sem a ocorrência de obsessões (March e Leonard, 1996).

Alguns autores apontam ainda que crianças com TOC têm maior risco para o desenvolvimento de outros transtornos psiquiátricos (Skoog e Skoog, 1999). Quanto à presença de comorbidades, os estudos apontam taxa semelhante à encontrada na população adulta, isto é, cerca de 75\% (Kalra e Swedo, 2009). Dentre as comorbidades mais frequentes destacam-se o transtorno de déficit de atenção e hiperatividade (TDAH), transtorno depressivo (TD), transtorno de tiques (TT), transtorno desafiador opositivo (TOD) e outros transtornos de ansiedade (Rosário-Campos, 1999; Geller, 2006).

Além dos dados descritos anteriormente, muitos estudos têm focado ou, ao menos, levado em consideração aspectos neuropsicológicos da população em questão. Dado a extrema importância para este trabalho, esse ponto será amplamente discutido no item a seguir.

\subsection{Aspectos Neuropsicológicos do TOC}

Diante da complexidade descrita na psicopatologia do TOC, os pesquisadores da área têm promovido estudos para melhor compreender os comprometimentos neurobiológicos do transtorno em questão. Enquanto os 
estudos de neuroimagem demonstram a existência de alterações na circuitaria fronto-estriatal, envolvendo regiões como o córtex orbitofrontal e os núcleos da base (núcleo accumbens, núcleo caudado, putâmen e globo pálido) (Abramowitz et al., 2009), os achados neuropsicológicos são divergentes, apontando pior funcionamento cognitivo em domínios variados. Em uma primeira meta-análise abordando o funcionamento cognitivo e TOC na população adulta, em que 115 estudos foram analisados, encontrou-se grande heterogeneidade em relação aos testes empregados nas avaliações cognitivas dos pacientes e nos resultados dos estudos (Abramovitch et al., 2013). No geral, foram encontrados tamanhos de efeito de pequenos a médios para alterações na velocidade de processamento, na memória não verbal e nas funções executivas (Abramovitch et al., 2013; Shin et al., 2014).

Embora haja pesquisas extensivas sobre funcionamento cognitivo dos pacientes adultos com TOC, poucos estudos foram conduzidos com crianças e adolescentes. Mesmo assim, em 2015, foi publicada a primeira meta-análise sobre funcionamento cognitivo na população pediátrica com TOC. Como resultado, apontou-se que a maioria dos domínios cognitivos não se encontrava significativamente alterada nessa população e que apenas o subdomínio planejamento havia apresentado grau moderado de comprometimento (Abramovitch et al., 2015a). Vale ressaltar que tais desfechos foram pautados em um número restrito de estudos (11) e em uma amostra compacta para uma meta-análise (227 pacientes), sendo esses, segundo os autores, os fatores que estariam possivelmente interferindo nos resultados.

Três estudos transversais sobre o funcionamento cognitivo do TOC em 
crianças e adolescentes, os quais foram englobadas pela meta-análise, merecem ser apresentados. Um deles, conduzido por Shin et al. (2008), comparou um grupo de 17 pacientes com TOC com pacientes com TDAH, com TD, com TT e um grupo controle. Como resultado, observaram que os pacientes com TOC apresentaram maior quociente intelectual verbal (QIV), dificuldades em habilidades perceptuais (visuoespaciais) e pior capacidade de flexibilidade mental. Outro estudo, que abordou 14 pacientes com TOC pediátrico e 24 controles saudáveis, descreveu a existência de déficits em atividades que averiguam velocidade de processamento de informações, flexibilidade cognitiva, fluência não verbal, habilidade de planejamento, memória verbal e capacidade de aprendizagem verbal (Ornstein et al., 2010). O terceiro, conduzido por Andrés et al. (2007), analisou 35 pacientes com TOC, com idades entre 7 e 18 anos, sem comorbidades psiquiátricas, e 35 controles; amostras essas que foram pareadas por sexo e por idade. Como resultado, observaram que as crianças com TOC tiveram piores resultados em atividades de memória, tanto verbal como visual, e naquelas que envolviam a avaliação da velocidade de processamento de informações.

Em 2017, Geller et al. buscaram responder em seu estudo algumas lacunas descritas nas pesquisas transversais, tais como: apresentar uma amostra mais representativa da população pediátrica com TOC, compará-la com um grupo de controles saudáveis, e averiguar moderadores potenciais, tais como gravidade do TOC, status da medicação, idade de início dos SOC e comorbidades. Após avaliarem 102 crianças e adolescentes com TOC e 161 controles saudáveis, com idades entre 6 e 17 anos, relataram que os pacientes 
apresentaram pior desempenho nas tarefas neuropsicológicas que envolviam velocidade de processamento. Pior desempenho também foi observado nas variáveis que aferiam tempo em tarefas voltadas à memória de trabalho e ao funcionamento visuoespacial. Os autores descreveram haver, ainda, diferenças no desempenho de pacientes e controles em provas que aferiram funções executivas, memória e organização visuoespacial. Por fim, Geller et al. (2017), na análise de covariáveis, relataram que os déficits cognitivos não estavam associados ao fato do indivíduo estar ou não medicado, às comorbidades clínicas e à idade de início dos sintomas.

McGuire et al. (2014) tentaram observar a relação entre aspectos neuropsicológicos dos pacientes com TOC e as diferentes dimensões dos sintomas. Após avaliarem um total de 93 pacientes, identificaram que crianças e adolescentes com TOC com sintomas de acumulação e de simetria/ordem apresentavam mais déficits cognitivos. Apontaram, ainda, que aqueles que apresentavam sintomas do tipo simetria/ordem demonstraram comprometimentos cognitivos específicos, caso da fluência não-verbal, velocidade de processamento e inibição/mudança de resposta.

Dois estudos longitudinais, do tipo coorte, com a população pediátrica com TOC foram encontrados na literatura. Um deles, conduzido por Grisham et al. (2009), encontrou o que chamou de comprometimentos cognitivos prémórbidos em indivíduos com TOC, ao comparar os resultados neuropsicológicos de crianças e adolescentes acometidos pelo transtorno, os quais foram obtidos em um tempo precoce, com o desempenho de controles saudáveis nos mesmos testes. Dentre esses déficits, houve consistência naqueles aferidos por meio de 
tarefas visuoespaciais, visoconstrutivas e visuomotoras. Já no outro estudo, Bloch et al. (2011) apontaram que o pior desempenho em provas voltadas à avaliação das habilidades motoras finas e visuoespaciais na infância estaria associado a maior persistência dos sintomas do TOC na vida adulta.

Na revisão da literatura, encontrou-se, também, um estudo que relatou não haver diferenças entre o funcionamento cognitivo dos pacientes com TOC e dos controles saudáveis. Ao comparar 21 pacientes pediátricos com TOC, com ausência de sintomas comórbidos e que nunca haviam recebido tratamento medicamentoso, com crianças e adolescentes saudáveis, Beers et al. (1999) não encontraram associações entre os sintomas da doença e os prejuízos nas habilidades cognitivas. Uma hipótese que explicaria esse dado seria a de que os autores averiguaram um pequeno número de crianças e adolescentes, sendo que, caso aumentassem a amostra, poderiam encontrar outros resultados.

Tendo em vista a revisão da literatura sobre o funcionamento cognitivo de crianças e adolescentes portadores de TOC, é possível dizer que os estudos sobre a temática ainda são escassos. Além disso, levando em conta as inconsistências encontradas nos resultados dos estudos e as consequentes sugestões propostas pelos autores para as futuras pesquisas na área, evidenciou-se a necessidade da condução de estudos com amostras mais representativas da população de crianças e de adolescentes com TOC, que apresentassem um grupo controle composto por crianças e adolescentes saudáveis e que realizassem a análise de fatores confundidores clínicos, tais como a gravidade, as diferentes dimensões dos sintomas, a idade de início dos SOC e a presença de comorbidades. 
Por fim, pouco se sabe a influência dos tratamentos de primeira linha para o TOC, como os IRS e a TCC, no funcionamento cognitivo das crianças e adolescentes. Embora seja de extrema importância, são poucos os estudos que se propuseram a estudar a temática. Esses serão apresentados a seguir.

\subsection{Tratamentos do TOC pediátrico e sua relação com a cognição}

Os tratamentos farmacológicos com inibidores de recaptura de serotonina (IRS) e a aplicação de protocolos de TCC, em monoterapia ou combinados, têm sido adotados como métodos terapêuticos efetivos para a redução dos sintomas do TOC (Geller et al., 2003; Watson e Rees, 2008).

Os manuais de tratamento atuais recomendam a TCC como um tratamento de primeira linha para a população pediátrica com TOC com sintomas moderados a graves (Geller e March, 2012). Nesta modalidade psicoterápica, incluem-se a psicoeducação, a exposição com prevenção de respostas (EPR) e técnicas cognitivas. Os ensaios clínicos randomizados (ECRs) existentes na área apontam que a resposta das crianças e dos adolescentes à TCC parece ser superior a outras condições de tratamento, incluindo distintas modalidades de psicoterapia, placebo e tratamentos farmacológicos. Além disso, nos casos em que há maior gravidade dos sintomas, ou para aqueles que não respondem à monoterapia de TCC, é recomendada a associação com um ISRS (Geller e March, 2012).

Os tratamentos farmacológicos, com base nos resultados de diversos 
ensaios clínicos randomizados, também são descritos como eficazes para a redução dos SOC. Embora a clomipramina, ao ser comparada com os ISRS, seja descrita como o medicamento mais eficaz para o tratamento do transtorno, seus efeitos adversos costumam ser mais agressivos e menos tolerados pela população pediátrica. Nesse sentido, os ISRS, caso da fluoxetina, fluvoxamina e sertralina, foram eleitos como tratamentos farmacológicos de primeira escolha para o TOC pediátrico (Geller et al., 2003; Watson e Rees, 2008).

Mesmo com a apresentação de resultados favoráveis à atenuação ou remissão dos sintomas do TOC pelos ECR, estudos sobre os desfechos clínicos dos diferentes tipos de tratamento para o TOC pediátrico revelaram que, em média, um terço das crianças e dos adolescentes não respondem de forma satisfatória a nenhuma intervenção terapêutica (Geller et al., 2003).

Tendo em vista o caráter crônico do TOC, a heterogeneidade dos desfechos dos tratamentos de primeira linha, bem como ao considerar os impactos significativos que o transtorno acarreta para os jovens nos contextos social, familiar e acadêmico (Piacentini et al., 2003), é de extrema importância que outros aspectos relacionados à resposta ao tratamento sejam avaliados, como o funcionamento cognitivo.

A relação entre tratamento farmacológico e o funcionamento cognitivo no TOC pediátrico foi estudada por Lewin et al. (2014) em uma amostra composta por 96 crianças e adolescentes, com idades entre 7 e 17 anos. Dos sujeitos, 49 estavam fazendo uso de qualquer medicação psiquiátrica, 45 estavam medicados com antidepressivos, 11 com antipsicóticos e 6 com estimulantes. 
Como resultado, os autores descreveram a existência de déficits nas funções executivas e na memória não-verbal dos pacientes, principalmente naqueles que faziam uso de neurolépticos atípicos e apresentavam comorbidades clínicas. Além disso, destacaram a hipótese de que a presença e consequente extensão do déficit neuropsicológico não estariam associadas à gravidade do TOC.

Andrés et al. (2007), após avaliarem 35 crianças e adolescentes com TOC e 35 controles saudáveis, com idades entre 7 e 18 anos, observaram não haver diferença no desempenho cognitivo entre os pacientes medicados $(\mathrm{N}=16)$ e não medicados $(\mathrm{N}=19)$. No entanto, ao comparar o grupo acometido pelo transtorno com controles saudáveis, identificaram que os portadores do transtorno, medicados ou não, apresentaram pior desempenho cognitivo em testes de memória e em tarefas que avaliam a velocidade de processamento de informações.

Já Andrés et al. (2008) analisaram os déficits neuropsicológicos do TOC a partir dos efeitos de diferentes tipos de tratamento sobre o funcionamento cognitivo das crianças e dos adolescentes. Para isso, avaliaram 29 pacientes com TOC, com idades entre 7 e 18 anos, e observaram que, embora em um momento inicial pacientes tenham apresentado déficits em relação a amostra composta por sujeitos saudáveis em testes de memória, velocidade e processamento da informação e funções executivas (controle inibitório e flexibilidade mental), após seis meses de tratamento naturalístico (tratamento farmacológico: $90 \%$ ISRS e $10 \%$ dos clomipramina; tratamento farmacológico associado com TCC: $65,5 \%$ ) melhoraram seu desempenho em todas as esferas cognitivas (Andrés et al., 2008). 
No campo da infância e da adolescência, também foram encontrados estudos que buscaram investigar a relação da cognição com métodos não farmacológicos de tratamento, no caso, com a TCC. Van der Straten et al. (2018), em uma amostra que contemplou sujeitos com idades entre 8 e 18 anos, compararam 15 pacientes com TOC com 16 controles saudáveis e mostraram que os pacientes com TOC apresentaram maior tempo de reação nos testes que exigem habilidade de organização e planejamento (Torre de Londres). Relataram ainda que, durante a realização dessas provas, exames de imagem indicaram que os indivíduos com TOC apresentaram maior recrutamento da região frontal do cérebro quando comparados com o grupo controle. Contudo, após as crianças e os adolescentes com TOC serem submetidos à TCC, essas alterações foram "normalizadas", uma vez que os pacientes passaram a apresentar resultados semelhantes aos dos controles saudáveis. Essas mudanças na cognição também foram observadas na reavaliação dos pacientes após dois anos do fim do tratamento (van der Straten et al., 2018).

Um outro grupo de pesquisadores avaliou cognitivamente 100 participantes, com idades entre 7 e 17 anos, sendo 50 indivíduos com TOC e 50 crianças e adolescentes saudáveis (Hybel et al., 2017). Neste estudo, o grupo de crianças e adolescentes com TOC foi avaliado antes e depois de passar por tratamento psicoterápico com TCC. O grupo controle foi avaliado no mesmo período. De acordo com os autores, os pacientes com TOC melhoraram seu desempenho cognitivo após a TCC (Hybel et al., 2017).

A relação entre tratamento e funcionamento cognitivo permite, ainda, pensar na discussão se as alterações cognitivas apresentadas pelas crianças e pelos 
adolescentes com TOC seriam traços ou dependentes do estado do transtorno (Rao et al., 2008). Ao passo que as crianças e os adolescentes, após o tratamento, apresentam melhora tanto dos sintomas de TOC como no desempenho cognitivo, se pode pensar que os déficits cognitivos estariam associados à sintomatologia do transtorno (Andrés et al., 2008; Hybel et al., 2017; van der Straten et al., 2018). Por outro lado, a manutenção dos déficits cognitivos diante da melhora dos sintomas após o tratamento, poderia representar um traço do TOC, ou seja, estariam possivelmente associados à neurobiologia do transtorno (Andrés et al., 2007; Lewin et al., 2014).

Diante da revisão da literatura acerca das implicações dos diferentes tipos de tratamento sobre o funcionamento cognitivo das crianças e adolescentes com TOC, identificou-se que as pesquisas ainda são escassas, sobretudo no que se refere aos estudos longitudinais que comparam o perfil neuropsicológico anterior e posterior ao emprego de diferentes frentes terapêuticas de primeira linha para o tratamento do transtorno. Ao ter como um de seus focos de investigação a relação entre tratamento e o funcionamento neuropsicológico da população pediátrica com TOC, este trabalho pode contribuir com novas perspectivas para a área. 


\section{JUSTIFICATIVA}

No momento em que o presente estudo foi idealizado, notou-se uma carência de publicações acerca da caracterização do funcionamento cognitivo de crianças e adolescentes com TOC, que contassem com uma amostra mais expressiva dessa população e que utilizassem um grupo controle para a comparação de dados. O fato de apenas um estudo preencher esses critérios e a própria meta-análise existente na área ter sublinhado a necessidade de outros estudos com esse perfil, julga-se relevante esta produção cientifica.

Ademais, são poucos os estudos que se propuseram avaliar o funcionamento cognitivo das crianças e dos adolescentes com TOC considerando o momento anterior e posterior ao tratamento. Não há relatos prévios na literatura de estudos longitudinais que comparem os efeitos de ISRS e de TCC, em monoterapia, sobre o desempenho cognitivo de crianças e de adolescentes com TOC em diferentes testes neuropsicológicos. 


\section{OBJETIVOS}

\subsection{Objetivos Gerais}

- Comparar, na linha de base, o desempenho cognitivo de crianças e adolescentes portadores de TOC e controles saudáveis.

- Verificar as possíveis modificações no funcionamento cognitivo das crianças e dos adolescentes portadores de TOC após 14 semanas de tratamento com Fluoxetina (FLX) ou Terapia Cognitivo Comportamental em grupo (TCCG).

\subsection{Objetivos Específicos}

4.2.1. Dados relativos à linha de base (pré-tratamento)

- Comparar as características sociodemográficas e clínicas e o funcionamento cognitivo global das crianças e dos adolescentes portadores de TOC e dos sujeitos saudáveis.

- Investigar uma possível associação entre a gravidade dos sintomas, dimensões dos sintomas, idade de início dos sintomas e/ou comorbidades e o desempenho nos testes neuropsicológicos nos sujeitos portadores do transtorno. 
4.2.2. Dados relativos aos desfechos longitudinais (pós-tratamento)

- Investigar se os pacientes que apresentam melhora clínica dos sintomas do TOC também apresentam melhora no desempenho cognitivo após 14 semanas de tratamento. 


\section{HIPÓTESES}

- Os indivíduos com TOC apresentarão pior desempenho em tarefas que avaliam o quociente intelectual, a capacidade de planejamento, a flexibilidade mental, o controle inibitório e a memória episódica não verbal quando comparados aos indivíduos saudáveis (linha de base).

- As variáveis clínicas estarão associadas ao pior desempenho dos pacientes nos testes neuropsicológicos (linha de base).

- Espera-se, que, após o tratamento, as crianças e os adolescentes portadores de TOC que apresentarem melhora clínica dos sintomas (medida pela redução do escore inicial da escala YBOCS), também apresentem melhor desempenho em diferentes funções cognitivas, sobretudo naquelas relacionados às funções executivas e à memória episódica não-verbal. 


\section{MÉTODO}

O presente estudo se insere em dois subprojetos do Instituto Nacional de Psiquiatria do Desenvolvimento (INPD), conduzidos no Instituto de Psiquiatria (IPq) do Hospital das Clínicas da Faculdade de Medicina da Universidade de São Paulo (HC-FMUSP). A amostra de pacientes derivou do projeto intitulado "Desenvolvendo Estratégias Adaptativas para o Tratamento de Crianças e Adolescentes com TOC" (Fatori et al., 2018). Já a amostra de controles saudáveis, em parte foi obtida pelo projeto intitulado "Ativação cerebral associada à memória episódica verbal no Transtorno Obsessivo-Compulsivo (TOC) por meio de ressonância magnética funcional” (Batistuzzo, 2013) e parte dos controles foi recrutada durante a vigência deste trabalho para garantir o pareamento entre os grupos. Este projeto foi devidamente submetido e aprovado pelo Comitê de Ética e Pesquisa (CEP) do HC-FMUSP (CAAE: 50704015.9.0000.0068).

\subsection{Desenho do Estudo e Seleção da Amostra}

Este projeto constituiu-se em duas etapas. A primeira delas correspondeu a uma avaliação transversal, na qual foram avaliados controles saudáveis e crianças e adolescentes portadores de TOC, no momento anterior ao tratamento (linha de base). A segunda parte do estudo voltou-se ao acompanhamento longitudinal apenas dos afetados pelo transtorno, buscando observar seu desempenho neuropsicológico após terem sido submetidos a uma das duas possibilidades de tratamento do estudo de Fatori et al. (2018): Terapia Cognitiva- 
Comportamental em grupo (TCCG) ou Fluoxetina (FLX).

O recrutamento de crianças e adolescentes ocorreu por meio da divulgação do projeto na mídia, via páginas oficiais do IPq HC-FMUSP, e por meio de mensagem em correio eletrônico para pesquisadores e colegas da área. Aqueles que demonstravam interesse em participar do estudo eram contatados pela equipe para a realização de uma pré-triagem, conduzida por uma psicóloga experiente e treinada para esse fim, de forma a certificar se cumpriam os critérios de inclusão e exclusão da pesquisa. $O$ recrutamento também foi realizado via convocação de colegas dos pacientes ou dos controles para participar da pesquisa, uma vez que, por compartilharem o mesmo ambiente, a estratégia facilitava o pareamento entre as amostras de crianças e adolescentes saudáveis e aqueles que apresentavam sintomas de TOC. Esses, por sua vez, eram submetidos ao mesmo procedimento inicial dos demais participantes.

Diante do assentimento do menor e da permissão dos pais, era agendada a entrevista inicial com os participantes em potencial e seus responsáveis, no IPq HC-FMUSP. A entrevista era conduzida por um psiquiatra e tinha por função avaliar clinicamente a criança e/ou o adolescente. Confirmando-se que o menor atendia os critérios necessários, este ingressava no estudo. Os controles saudáveis não precisavam passar pela triagem presencial.

A etapa seguinte do estudo de tratamento compreendia a avaliação clínica e neuropsicológica das crianças e dos adolescentes portadores de TOC e dos controles saudáveis. As escalas e os questionários clínicos (6.4.1. Instrumentos utilizados para a avaliação clínica) foram aplicados por psicólogos experientes e 
treinados, em consultórios adequados, localizados no IPq HC-FMUSP, em sessão que durava cerca de uma hora e meia. Em seguida, os participantes do estudo eram encaminhados à avaliação neuropsicológica. Esta, por sua vez, era realizada por psicólogos especialistas, previamente treinados para a aplicação da bateria de testes (6.4.2. Instrumentos utilizados para a avaliação neuropsicológica), em um ambiente adequado para essa finalidade (consultório claro, silencioso e com o mínimo de distratores ambientais para o participante da pesquisa).

Enquanto a participação do grupo controle na pesquisa se encerrava na linha de base, as crianças e os adolescentes acometidos pelo transtorno eram randomizados para tratamento com FLX em dose de 20 a 60 mg/dia ou TCCG, na qual estavam incluídas sessões de psicoeducação, técnicas de exposição e prevenção de respostas e duas sessões com a participação dos pais e/ou dos responsáveis. Os encontros do grupo de TCC ocorriam semanalmente no IPq HC-FMUSP, com duração de duas horas cada (Fatori et al., 2018).

Após 14 semanas de tratamento, as crianças e os adolescentes passavam, novamente, por avaliações clínica e neuropsicológica. Vale pontuar que tanto o psiquiatra e o psicólogo que fizeram as entrevistas clínicas como os neuropsicólogos estavam "cegos" para a condição de tratamento dos participantes.

Este estudo avaliou 164 sujeitos, de 6 anos a 17 anos e 11 meses, sendo 82 portadores de TOC e 82 controles saudáveis, os quais foram pareados por sexo, idade, escolaridade e nível socioeconômico. 
6.2. Grupo de pacientes portadores de TOC

6.2.1. Fluxograma da coleta de dados junto às crianças e adolescentes com TOC

Ao longo da condução da pesquisa, foram realizadas 325 ligações telefônicas para candidatos potenciais para o estudo. Dos contatos estabelecidos, 181 crianças e adolescentes foram excluídos do estudo, sendo que o fato do TOC não corresponder ao diagnóstico principal do sujeito consistiu na principal causa para a exclusão $(\mathrm{N}=37)$. As demais motivações encontram-se descritas na Figura 1.

$\mathrm{Na}$ etapa seguinte, caracterizada pela triagem presencial com psiquiatra, foram excluídos mais 52 sujeitos. Dentre as justificativas para esse número, encontram-se a questão diagnóstica e o não comparecimento à triagem (Figura 1).

Diante da confirmação do TOC como entidade nosológica principal, as crianças e os adolescentes eram convocados ao HC para realizar procedimentos clínicos de rotina (exame sorológico e eletrocardiograma). Além disso, os participantes precisavam passar por uma entrevista com o psicólogo clínico da equipe, para preenchimento de escalas e de questionários (6.4.1. Instrumentos utilizados para a avaliação clínica), e por uma avaliação neuropsicológica (6.4.2. Instrumentos utilizados para a avaliação neuropsicológica). Finalizada essa etapa, adotava-se uma decisão randômica computadorizada sobre a forma de tratamento que o paciente seria submetido, TCCG ou FLX. O software para definição randômica, utilizado com base no estudo, levava em consideração informações como idade, gênero e gravidade dos sintomas para definir o 
tratamento a ser oferecido aos participantes (Fossaluza et al., 2009).

Após 14 semanas de tratamento, as crianças e os adolescentes portadores de TOC eram reavaliados por meio de escalas e de questionários clínicos e através da bateria de testes neuropsicológicos. Neste momento, houve a exclusão de mais 16 participantes. Dentre os motivos para isso, se destacaram: o não comparecimento nos agendamentos destinados à avaliação neuropsicológica, a escolha do participante em interromper sua participação no estudo e o fato do TOC não ter se mantido como diagnóstico principal (Figura 1). 
Figura 1 - Fluxograma das ligações e das avaliações realizadas junto aos pacientes na linha de base do estudo e após serem submetidos ao tratamento

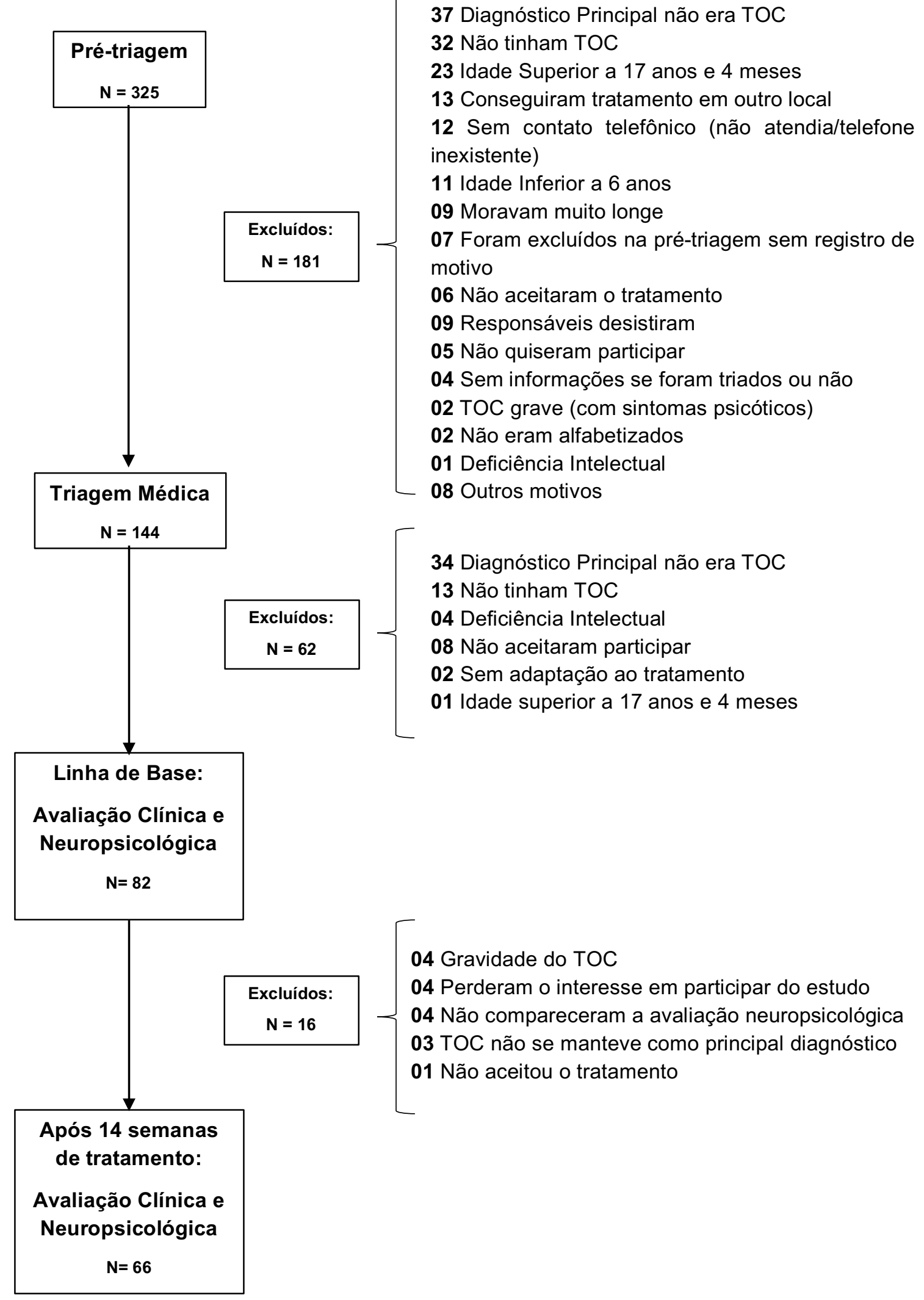


6.2.2. Caracterização da amostra de pacientes portadores de TOC

O recrutamento de pacientes ocorreu mediante o preenchimento dos seguintes critérios de inclusão:

- Idade entre 6 e 17 anos e 11 meses.

- Diagnóstico de TOC, segundo os critérios do Manual Diagnóstico e Estatístico dos Transtornos Mentais - IV versão revisada (DSM-IV-TR) ${ }^{1}$, como principal sintoma.

- Y-BOCS com valor igual ou maior que 16, quando somados as dimensões obsessões e compulsões, ou maior ou igual a 10, quando consideradas, isoladamente, as obsessões e as compulsões.

- Ausência de comprometimentos físicos ou cognitivos que poderiam impedir a participação dos indivíduos do estudo.

- A criança/adolescente estar disposta/o a participar do protocolo clínico, atestando seu aceite ao assinar o TCLE (ANEXO A).

- Permissão dos responsáveis legais pela criança/adolescente, via TCLE, para que o mesmo participasse do estudo (ANEXO A).

Por outro lado, a presença das seguintes características excluiria a pessoa do estudo:

\footnotetext{
${ }^{1}$ A utilização da IV versão revisada do DSM neste trabalho justifica-se pelo fato de, no início do projeto, os diagnósticos de TOC terem sido realizados com base nesta versão do manual e não na lançada em meados de 2013 (DSM V).
} 
- Presença de sintomas psicóticos ou qualquer outro transtorno psiquiátrico de maior importância que o TOC.

- Presença de qualquer condição médica ou neurológica que interferisse na realização dos tratamentos ou avaliações propostas pelo estudo.

- Gravidez.

- Intenção Suicida.

6.3. Grupo de controles saudáveis

6.3.1. Fluxograma da coleta de dados junto aos controles saudáveis

A amostra de controles saudáveis foi construída em dois momentos. Parte das crianças e adolescentes saudáveis $(\mathrm{N}=42)$ foram recrutados e avaliados por outro projeto do INPD ["Ativação cerebral associada à memória episódica verbal no Transtorno Obsessivo-Compulsivo (TOC) por meio de ressonância magnética funcional"]. Visando inteirar a amostra e assim parear controles e pacientes em número amostral $(\mathrm{N}=82)$, sexo, idade, nível socioeconômico e escolaridade, novos recrutamentos, seguido das respectivas avaliações clínicas e neuropsicológicas, foram feitos de 2015 a 2018, no período de execução deste trabalho.

Assim como para os pacientes, num primeiro momento, os responsáveis pelos potenciais candidatos foram contatados via telefone. Na pré-triagem, foram excluídos do estudo 73 crianças e adolescentes, pelo fato de apresentarem 
diagnósticos ou sintomas psiquiátricos, não quererem participar da pesquisa, entre outros (Figura 2).

Sendo elegíveis para o estudo, as crianças e os adolescentes saudáveis eram convocadas ao IPq HC FMUSP para realizar uma entrevista com um psicólogo, na qual eram preenchidas escalas e de questionários (6.4.1. Instrumentos utilizados para a avaliação clínica), e, em seguida, era realizada a bateria de avaliação neuropsicológica (6.4.2. Instrumentos utilizados para a avaliação neuropsicológica).

Figura 2 - Fluxograma das ligações e das avaliações realizadas junto aos controles: o grupo final foi constituído apenas por sujeitos saudáveis que completaram os protocolos clínicos e neuropsicológicos

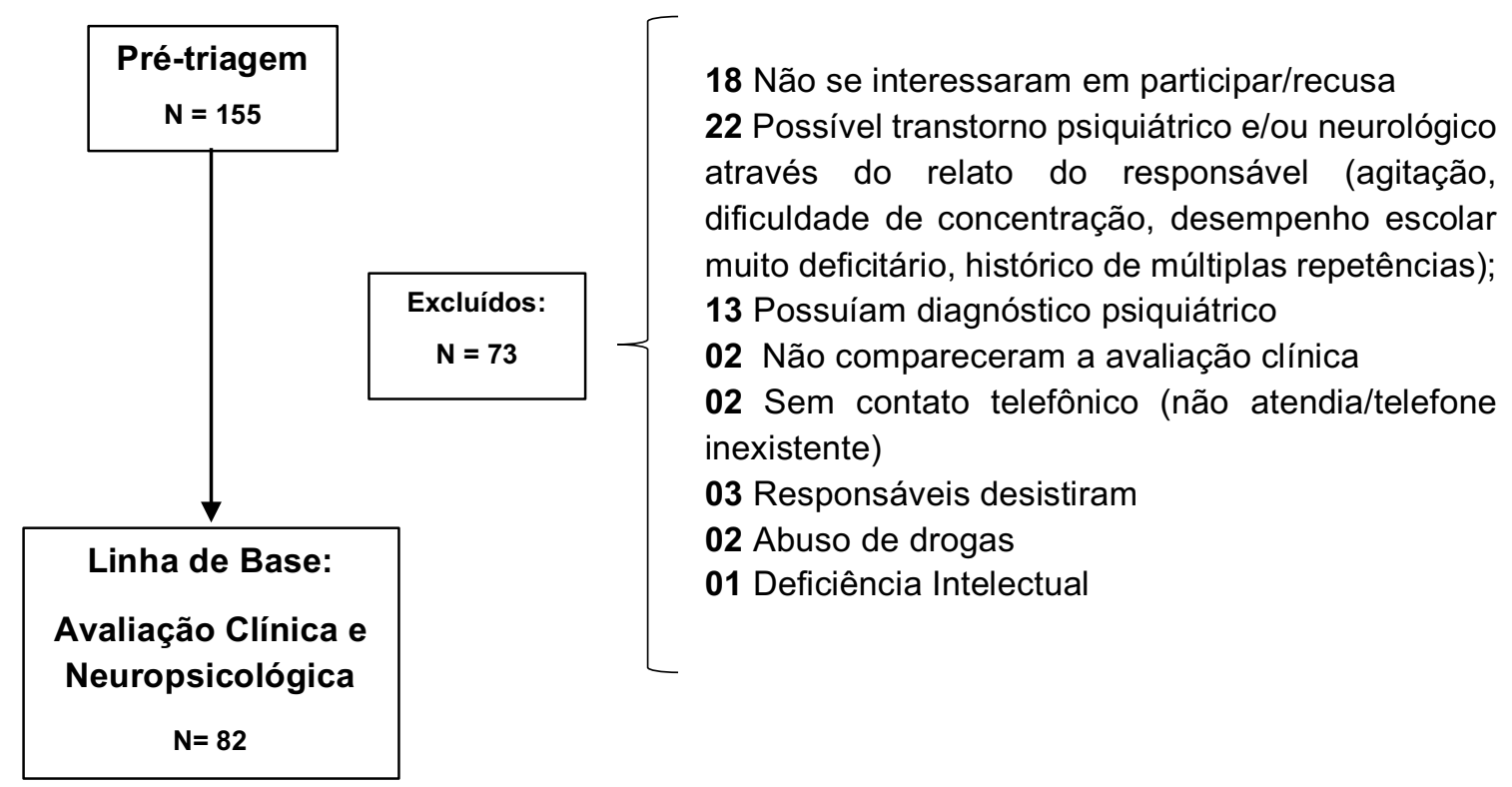


6.3.2. Caracterização da amostra formada por crianças e adolescentes saudáveis

Para participar do estudo, os controles deveriam:

- Parear com os pacientes em idade, gênero, escolaridade e nível socioeconômico.

- Ser saudável e, portanto, não apresentar diagnóstico psiquiátrico do eixo 1 , segundo o DSM-IV-TR, ou qualquer outro comprometimento físico ou cognitivo que pudessem impedir sua participação no estudo.

- Não fazer uso, no momento da pesquisa, de medicação psicotrópica.

- Estar disposto a realizar a testagem neuropsicológica, mediante assinatura do Termo de Assentimento (ANEXO C).

- Ter permissão dos responsáveis legais pela criança/adolescente, via TCLE (ANEXO B).

Os critérios de exclusão da participação do candidato no estudo foram homólogos aos critérios de exclusão dos pacientes com TOC.

6.4. Instrumentos

6.4.1. Instrumentos utilizados para a avaliação clínica

- Escala Yale-Brown de Sintomas Obsessivo-Compulsivos (Yale-Brown Obsessive-Compulsive Scale - Y-BOCS) [Goodman et al., 1989a; 1989b; Scahill et al., 1997): consiste em uma escala que avalia a gravidade dos 
sintomas obsessivos-compulsivos (SOC). Com pontuações variando de 0 a 4, essa escala possui cinco perguntas sobre obsessões e cinco sobre compulsões, com amplitude de 0 a 20 pontos para cada parte, totalizando um máximo de 40 pontos.

- Escala Dimensional Yale-Brown de Sintomas Obsessivo-Compulsivos (Dimensional Yale-Brown Obsessive-Compulsive Scale - DY-BOCS; Rosário-Campos et al., 2006): escala utilizada para avaliar as diferentes dimensões dos SOC (1. Contaminação e limpeza; 2. Ordem, simetria e arranjo; 3. Pensamentos de conteúdo violento, desastres naturais ou agressivos de modo geral; 4. Conteúdo sexual, moral ou religioso; 5 . Colecionismo; 6. Miscelânea). Os escores para cada pergunta variam de 0 a 5 pontos, totalizando 30 pontos.

- Escala para diagnósticos de transtornos psiquiátricos em crianças e adolescentes em idade escolar, versão em língua portuguesa da KiddieSchedule for Affective Disorders and Schizofrenia for School Aged Children Present and Lifetime (K-SADS-PL) [Kaufman et al., 2000; Brasil, 2003]: escala para diagnósticos de transtornos psiquiátricos em crianças e adolescentes em idade escolar que consiste em uma entrevista psiquiátrica semiestruturada para identificar transtornos e sintomas psiquiátricos em crianças e adolescentes.

- Escala de Avaliação de Transtornos Relacionados à Ansiedade Infantil, versão em língua portuguesa da Screen for Child Anxiety Related Emotional 
Disorders (SCARED; Birmaher et al., 1999): consiste em uma escala de 41 itens, autoaplicável, relacionados aos sintomas de ansiedade sentidos nos últimos três meses. Sua pontuação varia de 0 a 82 pontos e o indicativo de transtorno de ansiedade ocorre frente a uma pontuação superior a 25.

- Escala de Avaliação de Depressão para Crianças - Revisada, versão em língua portuguesa da Children's Depression Rating Scale - Revised (CDRSR; Poznanski et al., 1985): é uma escala composta por 17 itens que avaliam sintomas depressivos. Com pontuações variando de 1 a 5 ou de 1 a 7 , a escala pode ter um score total de 113. Pontuações acima de 40 indicam possibilidade de depressão.

- Inventário de Rotina da Infância, versão em língua portuguesa da Childhood Routines Inventory (CRI; Evans et al., 1997). Escala respondida pelos responsáveis da criança, constituída por 19 questões tipo Likert (1 = nunca; $2=$ pouco; 3 = às vezes; $4=$ frequentemente; $5=$ extremo). Com escores variando entre 19 e 95 pontos, a maior a pontuação constitui-se como maior necessidade de rotina por parte da criança.

- Critério de Classificação Econômica Brasil versão 2008 (CCEB 2008; ABEP, 2008) para classificação do nível socioeconômico dos sujeitos. Este instrumento leva em conta pertences materiais da família e o grau de instrução do chefe da família, derivando em classes econômicas (A1, A2, B1, B2, C1, C2, D e E). 


\subsubsection{Instrumentos utilizados para a avaliação neuropsicológica}

Dentre os domínios cognitivos, foram averiguados a eficiência intelectual, memória de trabalho (memória operacional), memória episódica verbal e não verbal, capacidade de aprendizagem verbal, habilidades visuoconstrutivas, planejamento, controle inibitório e flexibilidade mental. Para tanto, foram utilizados os seguintes testes:

- Escala Wechsler Abreviada de Inteligência (WASI) [Wechsler, 1999; Trentini et al., 2014]: Consiste em uma escala para avaliação abreviada do índice do quociente de inteligência (QI), que pode ser ministrada em indivíduos com idades entre 6 e 89 anos. Ela fornece três informações distintas, sendo elas o QI Total (QIT), o QI Verbal (QIV) e o QI de Execução (QIE).

O QIV está relacionado às habilidades verbais do indivíduo e é composto por dois subtestes: a) Vocabulários (VOC), que avalia a capacidade de linguagem, a formação de conceito verbal e conhecimento geral; e, b) Semelhanças (SEM), que avalia a capacidade raciocínio verbal e a formação de conceito. (Wechsler, 1999). Já o QIE é composto pelo subtestes: a)Matrizes (MAT), que avalia o processamento de informação visual e o raciocínio abstrato; e, b) Cubos (CUB), que avalia a capacidade de análise e síntese de estímulos visuais, a percepção e organização visual, a formação de conceitos não-verbais, o processamento de informações simultâneas, a coordenação visual e motora e a habilidade de distinção "figura e fundo". (Wechsler, 1999).

- O subteste Dígitos (DIG), ordens direta e inversa, da Escala Wechsler de 
Inteligência para crianças, em sua terceira versão (Weschler Intelligence Scale for Children, Third edition - WISC III; Wechsler, 1991): Tarefa presente em escala de inteligência voltada para crianças que consiste na avaliação da memória de curto prazo verbal da criança/adolescente, por meio da repetição de sequência numérica em ordem direta, e na avaliação da memória operacional, por meio da repetição de sequência numérica em ordem inversa.

- Blocos de Corsi (COR) da Escala Wechsler de Memória - versão revisada (Wechsler Memory Scale - Revised - WMS-R) [Wechsler, 1987]: Diz respeito a um teste presente em bateria específica de memória que visa avaliar a memória de curto prazo e memória operacional. Nele, a pessoa deve reproduzir a sequência realizada anteriormente pelo aplicador em tábua com blocos, tanto na ordem direta como na ordem inversa.

- Teste de Aprendizagem Auditivo-Verbal de Rey (Rey Auditory Verbal Learning Test - RAVLT) [Rey, 1958; Malloy-Diniz et al., 2000; Magalhães, Malloy-Diniz e Hamdan, 2012; Magalhães e Hamdan, 2010]: É um teste de aprendizagem auditivo verbal no qual o sujeito deve repetir uma lista composta por 15 palavras em cinco momentos. Além da curva de aprendizagem (capacidade de retenção dos estímulos mediante repetição), este teste também avalia a memória episódica de curto e longo prazo, já que a pessoa precisa evocar a lista imediatamente após a apresentação de estímulos distratores (lista com palavras diferentes) e, novamente, 30 minutos depois da última repetição da lista. 
- Teste da Figura Complexa de Rey (Rey-Osterrieth Complex Figure Test RCFT) [Osterrieth, 1944; Rey, 1959; Oliveira, 1999; Oliveira et al., 2004]: Utilizado para avaliar a praxia visoconstrutiva, memória visual e capacidade de planejamento, este teste consiste na cópia de uma figura geométrica complexa, seguida por duas evocações da mesma: a primeira delas três minutos após a cópia do desenho e, a segunda, trinta minutos depois da cópia. A capacidade de planejamento, por sua vez, é pontuada diante da forma que o sujeito dispõe os perceptos ao longo da realização do desenho do material pictórico. O tempo também foi anotado nos três momentos que compõem a atividade.

- Grooved Pegboard Test (GPT) [Trites, 2002; Matthews e Klove,1964]: Neste teste motor o voluntário precisa encaixar pinos em buracos dispostos em uma tábua, no menor tempo possível, sem deixar o pino cair, utilizando, inicialmente, sua mão dominante e, em seguida, sua mão não dominante.

- Sistema Delis-Kaplan de Avaliação do Funcionamento Executivo (DelisKaplan Executive Function System - D-KEFS) [Delis et al., 2001]: Caracteriza-se como uma bateria composta por nove testes neuropsicológicos que avaliam funções executivas. Três provas desta foram utilizadas para este estudo:

a) Teste de Interferência Cor-Palavra (Color-Word Interference Test CWIT), versão traduzida e adaptada, livremente, para a língua portuguesa: avalia a habilidade de inibir uma resposta verbal automática e dominante, dentro do menor tempo possível. É composta por quatro 
momentos, sendo que o último deles, além de verificar o controle inibitório, também é uma medida de flexibilidade cognitiva. Nesta atividade se computam o tempo, os erros e os erros auto-monitorados;

b) Teste de Trilhas (Trail Making Test - TMT): avalia atenção e a capacidade de rastreamento visual, com conjugação de resposta motora. Esta tarefa possui cinco subitens, que devem ser aplicados na seguinte ordem: 1) cancelamento visual, 2) ligar números em ordem crescente, 3) ligar letras em ordem crescente, 4) ligar números e letras, 5) ligar linhas pontilhadas, a serem realizadas no menor tempo possível;

c) Teste de Fluência de Desenho (Design Fluency Test - DFT): mensura a capacidade de resolução de problemas visuais e flexibilidade cognitiva. É uma prova composta por três condições, as quais têm duração de 60 segundos cada. A primeira delas consiste em uma medida de fluência de desenho em que o sujeito deve apenas conectar os pontos pretos. A segunda fornece uma medida de fluência de desenho e de controle inibitório, uma vez que o sujeito deve ligar pontos brancos e negligenciar os pretos. Já a terceira etapa, afere a fluência de desenho e flexibilidade cognitiva, já que os indivíduos devem fazer desenhos alternando os pontos de cores pretas e brancas.

- Teste de Classificação de Cartas de Wisconsin (Wisconsin Card Sorting Test - WCST; Heaton et al.,1981): Consiste em tarefa que visa avaliar raciocínio abstrato e flexibilidade de pensamento, a qual pode ser observada via capacidade do sujeito de mudar de estratégia cognitiva em resposta a 
eventuais mudanças ambientais. O teste foi administrado em sua versão reduzida (64 cartas), em que o sujeito deveria combinar cartas segundo critérios de cor, forma ou número, os quais variavam a cada dez combinações corretas.

- Go/No-Go (Nosek e Banaji, 2001): os testes do estilo Go/No-Go aferem a capacidade de controle inibitório. Tal habilidade, por sua vez, foi avaliada por meio de tarefa programada em computador, na qual o sujeito deveria pressionar a barra de espaços ao ver diversas letras, coloridas com diferentes cores, na tela (Go) e inibir tal comportamento ao se deparar com as letras "O", pintada em azul, e a letra "E", pintada na cor rosa. Assim, a avaliação do controle inibitório é feita por meio da quantidade de omissões (quando a barra de espaços deveria ser apertada, mas o sujeito não o fez), de comissões (pressionar a barra fora de hora), de acertos, bem como a soma do tempo de reação nos acertos e nas comissões.

- Teste de Brixton (Brixton Test - BXT) [Burgess e Shallice, 1997]: consiste em um teste que avalia a capacidade de sequenciamento visuoespacial frente mudanças de regras na sequência de apresentação de estímulos. Para tanto, a prova propõe que um círculo azul percorre nove espaços em branco, sendo que o probando deve "descobrir" onde o círculo estará na prancha seguinte. A pontuação ocorre cada vez que o probando fornece uma resposta coerente com a lógica das apresentações anteriores. 


\subsection{Considerações Éticas}

A participação das crianças e dos adolescentes portadores de TOC neste estudo ocorreu mediante a autorização de seus pais/responsáveis legais, por meio da assinatura do TCLE, conforme constou no protocolo $n^{\circ}$ 0361/09 aprovado pelo CEP. Neste documento, estavam descritas informações como os objetivos, as justificativas, os riscos e os desconfortos desta pesquisa, bem como foi explicitada a garantida da liberdade do sujeito interromper sua participação no estudo quando desejado, sem que isso implicasse em perdas ou em prejuízos no atendimento prestado (ANEXO A).

O mesmo procedimento ocorreu junto aos pais/responsáveis das crianças e adolescentes saudáveis, para os quais foi apresentado o TCLE (ANEXO B) aprovado pelo CEP (CAAE - 50704015.9.0000.0068) $)^{2}$. As crianças e os adolescentes também foram solicitados a assinar um termo de assentimento de sua participação na pesquisa (ANEXO C). Ao assiná-lo, atestavam ter aceito participar do estudo, com ciência das demandas e dos riscos deste, bem como eram assegurados da possibilidade de se retirarem do estudo a qualquer momento.

\footnotetext{
${ }^{2}$ As 42 crianças e adolescentes recrutados pelo projeto "Ativação cerebral associada à memória episódica verbal no Transtorno Obsessivo-Compulsivo (TOC) por meio de ressonância magnética funcional" e seus responsáveis também precisaram assinar os termos presentes no ANEXO B e C, conforme solicitação do CEP para aprovação deste estudo.
} 


\subsection{Análise Estatística}

As análises estatísticas foram realizadas com o auxílio do programa Statistical Package for the Social Sciences (SPSS - versão 23.0).

Todas as variáveis sociodemográficas, clínicas e dos testes neuropsicológicos da amostra foram resumidas segundo uma estatística descritiva (número de sujeitos da amostra e frequência ou média e desvio padrão). Após testar a normalidade dos testes, via teste de Shapiro-Wilk, foram utilizados os teste qui-quadrado $\left(\mathrm{X}^{2}\right)$, para comparação de variáveis categoriais, e testes independentes de comparação de médias (teste $t$-student) ou de medianas (teste $U$ de Mann-Whitney) para comparar os dados clínicos e/ou neuropsicológicos.

Para a comparação do desempenho neuropsicológico dos pacientes e dos controles, foram conduzidas Análises Multivariadas de Variância (MANOVAS) usando os grupos (pacientes e controles) como variável independente e as variáveis neuropsicológicas como variável dependente. Com exceção do QI, que foi analisado de forma individual, por meio do teste t para amostras independentes, as demais variáveis neuropsicológicas foram agrupadas de acordo com os seguintes domínios cognitivos: velocidade de processamento, habilidades visuoconstrutivas, memória episódica não verbal, memória episódica verbal, memória de trabalho, flexibilidade mental e controle inibitório (Tabela 1). A seleção de variáveis para a composição das MANOVAS decorreu de indicações existentes na literatura, como na descrição presente nos manuais dos testes, em Strauss et al. (2006) e em Lezak (1995), e em artigos 
que são referências no campo da Neuropsicologia do TOC na infância e na adolescência (Geller et al., 2017; Abramovitch et al., 2015). Essa abordagem por agrupamento de variáveis neuropsicológicas visou contornar o problema de comparações múltiplas entre os testes que compuseram a bateria de avaliação deste estudo. Por fim, quando determinada MANOVA apresentava resultado positivo, suas variáveis dependentes eram analisadas com o teste $t$ para amostras independentes com o intuito de verificar as diferenças entre grupos.

Buscando encontrar moderadores potenciais para os resultados dos pacientes nos testes neuropsicológicos, foram realizadas análises de correlação (Pearson) entre as variáveis neuropsicológicas, nas quais os pacientes apresentaram pior desempenho, e variáveis clínicas, como idade de início dos sintomas, gravidade dos sintomas, dimensões dos sintomas e comorbidades.

Para os desfechos longitudinais do estudo, isto é, para a comparação do desempenho cognitivo dos pacientes antes e depois de 14 semanas de tratamento, foram conduzidas MANOVAS utilizando os mesmos domínios cognitivos acima citados, com exceção das "habilidades visuoconstrutivas"; uma vez que o subteste Cubos foi aferido apenas na linha de base. Para essas MANOVAS, o grupo de resposta ao tratamento (respondedores e não respondedores) foi selecionado como variável independente e a diferença absoluta entre a pontuação das variáveis neuropsicológicas (diferença entre a pontuação inicial e a pontuação final dos testes) foram utilizados como variável dependente. O índice de resposta ao tratamento foi considerado como a redução de pelo menos 35\% na Y-BOCS na segunda avaliação clínica (pós-tratamento). 
Tabela 1 - Agrupamento das variáveis neuropsicológicas em domínios cognitivos

\begin{tabular}{ccc}
\hline $\begin{array}{c}\text { Domínios Cognitivos } \\
\text { Definição }\end{array}$ & Teste & \\
& Subtestes \\
\hline
\end{tabular}

Velocidade de Processamento

Habilidade de processar a informação de forma rápida e executá-la

CWIT - D-KEFS (Delis et al., 2001)

Condição 1 - nomeação de cores - tempo (CWIT-1)

Condição 2 - leitura - tempo (CWIT-2)

GPT (Matthews e Klove, 1964)

Mão dominante - tempo

Mão não-dominante - tempo

TMT - D-KEFS (Delis et al., 2001)

Condição 5 - tempo

\section{Habilidades Visuoconstrutivas}

Coordenação entre habilidade motora fina e habilidade especial

\section{Memória Episódica Verbal}

Memória para informações verbais

\section{Memória de Trabalho}

Habilidade de reter informações e executar operações mentais com elas
CUB - WASI (Wechsler, 1999; Trentini et al., 2014)

RCFT (Osterrieth, 1944)

Cópia - pontuação total

COR - WMS-R (Wechsler, 1987) sequência direta

RCFT (Osterrieth, 1944) - ver outros

Recuperação Imediata - pontuação total

Recuperação Tardia - pontuação total

DIG - WISC-III (Wechsler, 1991)

Sequência direta

RAVTL (Rey, 1958)

Recuperação imediata

Recuperação tardia

DIG - WISC-III (Wechsler, 1991)

Sequência inversa

COR - WMS-R (Wechsler, 1987)

Sequência inversa 
Tabela 1 - Agrupamento das variáveis neuropsicológicas em domínios cognitivos (Continuação)

\begin{tabular}{lc}
\hline \multicolumn{1}{c}{$\begin{array}{c}\text { Domínios Cognitivos } \\
\text { Definição }\end{array}$} & Teste \\
\hline $\begin{array}{l}\text { Flexibilidade Cognitiva } \\
\text { Habilidade de mudar de } \\
\text { perspectiva e pensar em } \\
\text { novas possibilidades para } \\
\text { resolver problemas. }\end{array}$ & WCST (Heaton et al., 1993) \\
& Erros perseverativos \\
Categorias & \\
& DFT - D-KEFS (Delis et al., 2001) \\
& DFT Condição 3 - \% respostas perseverativas \\
& BXT (Burgess e Shallice, 1997) \\
Total de acertos \\
$\begin{array}{l}\text { Controle Inibitório } \\
\text { Habilidade de resistir a um } \\
\text { impulso para agir de forma } \\
\text { mais conveniente. }\end{array}$ & Condição 4 e 5 - diferença de tempos \\
& Go/NoGo (Nosek e Banaji, 2001) \\
& Erros de comissão \\
& CWIT - D-KEFS (Delis et al., 2001) \\
Condição 3 - erros \\
Condição 4 - erros \\
Condições 3 e 1 - diferença de tempos
\end{tabular}

Legendas: RAVLT: Teste Auditivo-Verbal de Rey; D-KEFS: Sistema Delis-Kaplan de Avaliação do Funcionamento Executivo; TMT- D-KEFS: Teste de Trilhas do D-KEFS; DFT-D-KEFS: Teste de Fluência de Desenhos do D-KEFS; WCST: Teste de Classificação de Cartas do Wisconsin; CWIT - D-KEFS: Teste de Interferência Cor-Palavra do D-KEFS; GPT: Grooved Peagboard Test; CUB -WASI: subteste cubos da Escala Wechsler Abreviada de Inteligência; RCFT Teste da Figura Complexa de Rey; COR - WMS-R: Blocos de Corsi da Escala Wechsler de Memória - versão revisada; DIG -WISC III - subteste dígitos da Escala Wechsler de Inteligência para crianças - terceira versão; BXT - Teste de Brixton.

Ainda em relação aos desfechos longitudinais, para a comparação intragrupo de pacientes, isto é, dos resultados obtidos no momento anterior e posterior ao tratamento, foi utilizado teste t para amostras pareadas tanto para analisar as diferenças dos resultados neuropsicológicos nos diferentes grupos de tratamento (FLX e TCCG), como nos grupos de resposta ao tratamento (respondedores e não respondedores). 
Por fim, vale pontuar que para efetuar a análise das variáveis neuropsicológicas, contou-se com utilização dos dados brutos encontrados em cada teste. Apenas para as análises dos índices de eficiência intelectual (QIT, QIV e QIE) foram utilizados os valores normativos encontrados nas tabelas brasileiras do teste WASI (Trentini et al., 2014).

Este estudo adotou o valor de alpha 0,05. Correção de Bonferroni foi utilizada para corrigir possíveis problemas de comparações múltiplas entre as variáveis. 


\section{RESULTADOS}

\subsection{Característica Geral da Amostra}

As características sociodemográficas da amostra estão apresentadas na Tabela 2. Pacientes $(\mathrm{N}=82)$ e controles $(\mathrm{N}=82)$ não diferiram em relação ao sexo, idade, índice socioeconômico, tipo de sistema educacional utilizado (público ou particular), escolaridade e índice de repetência escolar. Etnia foi a única variável na qual foi encontrada diferença entre grupos ( $p$-valor $=0,001$ ), sendo que 0 grupo controle foi formado por um número maior de não caucasianos $(25,9 \%)$ comparado ao grupo de pacientes $(8,5 \%)$.

A amostra geral foi composta por, principalmente, indivíduos brancos (79,8\%), estudantes de escola particular $(60,4 \%)$ e que cursavam, na época, ou o Ensino Fundamental I ou II (36,9\% para ambos). A média de idade dos participantes da pesquisa foi 12 anos, sendo 85 representantes do sexo masculino e 79 do sexo feminino.

Tendo em vista que o trabalho apresentará dados relativos ao desempenho neuropsicológico, julgou-se necessário incluir na tabela dado relativo à lateralidade manual dos participantes, o qual poderia vir a ser um fator confundidor nos resultados, sobretudo, nos testes que evolvem habilidade motora. Não foi observada diferença significativa entre os grupos, sendo que, em ambas as amostras, houve um maior índice de participantes destros (95,1\%). 
Tabela 2 - Características sociodemográficas e lateralidade manual dos participantes do estudo

\begin{tabular}{|c|c|c|c|c|}
\hline & $\begin{array}{c}\text { TOC } \\
(\mathrm{N}=82)\end{array}$ & $\begin{array}{c}\text { Controles } \\
(\mathrm{N}=82)\end{array}$ & $\begin{array}{c}\text { Total } \\
(\mathrm{N}=164)\end{array}$ & \\
\hline & M (DP) & M (DP) & M (DP) & p-valor ${ }^{1}$ \\
\hline \multirow[t]{2}{*}{ Idade } & $11,80(3,13)$ & $11,85(3,04)$ & $11,83(3,08)$ & 0,103 \\
\hline & $\mathrm{N}(\%)$ & $\mathbf{N}(\%)$ & $\mathrm{N}(\%)$ & p-valor ${ }^{2}$ \\
\hline Sexo & & & & 0,876 \\
\hline Masculino & $43(52,4 \%)$ & $42(51,2 \%)$ & $85(51,8 \%)$ & \\
\hline Etnia & & & & 0,001 \\
\hline Caucasiano & $74(90,2 \%)$ & $56(69,1 \%)$ & $130(79,8 \%)$ & \\
\hline Não caucasiano & $7(8,5 \%)$ & $21(25,9 \%)$ & $28(17,2 \%)$ & \\
\hline Sistema Educacional & & & & 0,874 \\
\hline Particular & $50(61,0 \%)$ & $49(59,8 \%)$ & $99(60,4 \%)$ & \\
\hline Escolaridade & & & & 0,882 \\
\hline Pré-Escola & $2(2,5 \%)$ & & $2(1,3 \%)$ & \\
\hline Fundamental I & $27(33,8 \%)$ & $32(40,0 \%)$ & $59(36,9 \%)$ & \\
\hline Fundamental II & $33(41,3 \%)$ & $26(32,5 \%)$ & $59(36,9 \%)$ & \\
\hline Ensino Médio & $18(22,5 \%)$ & $22(27,5 \%)$ & $40(25,0 \%)$ & \\
\hline $\begin{array}{l}\text { Índice de repetência } \\
\text { escolar }\end{array}$ & $9(11,3 \%)$ & $5(6,3 \%)$ & $14(8,8 \%)$ & 0,265 \\
\hline $\begin{array}{l}\text { Índice } \\
\text { Socioeconômico }\end{array}$ & & & & 0,712 \\
\hline A & $19(24,7 \%)$ & $37(45,7 \%)$ & $56(35,4 \%)$ & \\
\hline B & $42(54,5 \%)$ & $36(44,4 \%)$ & $78(49,4 \%)$ & \\
\hline C & $16(20,8 \%)$ & $7(8,6 \%)$ & $23(14,6 \%)$ & \\
\hline D & & $1(1,2 \%)$ & $1(0,6 \%)$ & \\
\hline Lateralidade & & & & 0,712 \\
\hline Destro & $78(95,1 \%)$ & $78(95,1 \%)$ & $156(95,1 \%)$ & \\
\hline
\end{tabular}

Legenda: ${ }^{1} p$-valor para o teste qui-quadrado; ${ }^{2} p$-valor para o teste de Mann-Whitney. 


\subsection{Características clínicas do grupo de pacientes}

Os dados clínicos relativos ao grupo de pacientes encontram-se descritos na Tabela 3. Em relação aos sintomas do TOC, a média obtida na avaliação YBOCS inicial foi de 26,79 pontos, sendo as dimensões Ordem, simetria, contagem e arranjo $(M=7,71)$, Miscelânea $(M=7,41)$ e Contaminação e Limpeza $(M=7,40)$, as que apresentaram maiores médias de pontuações pelos sujeitos. O início dos sintomas, conforme informado pela família, ocorreu, em média, aos seis anos e meio de idade. No entanto, os dados mostraram que a idade média do diagnóstico do TOC tende a ser mais tardia, aos 11 anos de idade.

A amostra clínica demostrou contar com alto índice de comorbidades, sendo que $92,3 \%$ dos pacientes apresentou pelo menos um diagnóstico psiquiátrico adicional. Dentre as comorbidades, observou-se maior frequência de Transtornos de Ansiedade Generalizada (35,9\%), Agorafobia/Fobias Específicas (35,9\%), Transtorno de Ansiedade de Separação, Transtorno de Ansiedade de Separação (30,8\%), Transtorno de Déficit de Atenção e Hiperatividade (TDAH 22,5\%) e Transtorno Depressivo (20,5\%).

Em relação às escalas de avaliação dos sintomas de ansiedade (SCARED) e dos sintomas de depressão (CDRS-R), foram obtidos valores médios de 28,04 e 29,64, respectivamente. No caso da SCARED, essa pontuação representa que, quando presentes, os sintomas de ansiedade tendiam a ser de moderados à graves. O valor médio apontado pela CDRS-R, por outro lado, indica que a sintomatologia depressiva apresentada pelas crianças e adolescentes, no geral, não estava dentro dos critérios de gravidade 
(acima de 40 pontos). Por fim, o Inventário de Rotina da Infância (CRI), indicou que a população pediátrica com TOC participante deste estudo possui alguma necessidade de rotina, isto é, presença moderada de comportamentos do tipo compulsivo, ao apresentar valor médio de 47,55 pontos.

Com a randomização dos pacientes entre as duas terapêuticas adotadas, isto é, FLX (N=39) e TCCG (N=41), não foram observadas discrepâncias dos dados acima reportados entre os grupos; conforme também apresentado na Tabela 3. Diante desses números, nota-se que houve perda de dois pacientes com TOC, devido à não randomização dos mesmos nesse momento do estudo. 
Tabela 3 - Características clínicas de 80 crianças e adolescentes com TOC que receberam tratamento randomizado com fluoxetina ou terapia cognitivocomportamental em grupo

\begin{tabular}{|c|c|c|c|c|}
\hline & $\begin{array}{c}\text { FLX } \\
(\mathrm{N}=39)\end{array}$ & $\begin{array}{c}\text { TCCG } \\
(\mathrm{N}=41)\end{array}$ & $\begin{array}{c}\text { Total } \\
(\mathrm{N}=80)\end{array}$ & \\
\hline & $M(D P)$ & $M(D P)$ & $M(D P)$ & $\mathrm{p}$-valor ${ }^{1}$ \\
\hline \multicolumn{5}{|l|}{ Y-BOCS } \\
\hline Obsessões & $12,24(4,34)$ & $13,38(2,90)$ & $12,80(3,73)$ & 0,173 \\
\hline Compulsões & $14,07(3,03)$ & $14,03(2,58)$ & $14,05(2,80)$ & 0,940 \\
\hline Total & $26,32(6,83)$ & $27,28(5,01)$ & $26,79(6,00)$ & 0,476 \\
\hline Idade de Início dos SOC & $6,57(2,80)$ & $6,30(2,81)$ & $6,44(2,79)$ & 0,572 \\
\hline Idade diagnóstico do TOC & $11,28(2,85)$ & $10,78(3,04)$ & $11,04(2,94)$ & 0,468 \\
\hline \multicolumn{5}{|l|}{ DY-BOCS } \\
\hline Agressão & $5,52(4,96)$ & $3,95(4,57)$ & $4,477(4,82)$ & 0,152 \\
\hline Colecionismo & $2,02(2,56)$ & $1,55(2,47)$ & $1,79(2,52)$ & 0,411 \\
\hline Contaminação e Limpeza & $7,47(4,67)$ & $7,32(4,72)$ & $7,40(4,67)$ & 0,882 \\
\hline Ordem, Simetria, Contagem e Arranjo & $8,12(4,21)$ & $7,26(4,38)$ & $7,71(4,29)$ & 0,379 \\
\hline Sexual e Religioso & $3,10(4,05)$ & $2,24(3,80)$ & $2,69(3,93)$ & 0,343 \\
\hline Miscelânea & $6,87(4,03)$ & $7,97(3,73)$ & $7,41(3,91)$ & 0,217 \\
\hline Total & $21,30(3,48)$ & $20,24(4,30)$ & $20,78(3,91)$ & 0,232 \\
\hline CDRS-R & $27,00(14,53)$ & $29,02(14,40)$ & $28,04(14,41)$ & 0,538 \\
\hline SCARED & $32,18(13,13)$ & $26,97(13,66)$ & $29,64(13,56)$ & 0,090 \\
\hline \multirow[t]{2}{*}{ CRI } & $46,14(13,31)$ & $48,82(19,19)$ & $47,55(16,62)$ & 0,701 \\
\hline & $N(\%)$ & $N(\%)$ & $\mathrm{N}(\%)$ & $p$-valor ${ }^{2}$ \\
\hline Presença de pelo menos uma comorbidade & $38(95,0 \%)$ & $34(89,5 \%)$ & $72(92,3 \%)$ & 0,363 \\
\hline \multicolumn{5}{|l|}{ Comorbidades ( $\geq 5 \%$ da amostra total) } \\
\hline Transtorno Opositivo-Desafiador & $8(20,0 \%)$ & $5(13,2 \%)$ & $13(16,7 \%)$ & 0,421 \\
\hline Transtorno de Déficit de Atenção e Hiperatividade & $7(17,5 \%)$ & $11(28,9 \%)$ & $18(23,1 \%)$ & 0,233 \\
\hline Transtorno de Pânico & $3(7,5 \%)$ & $1(2,6 \%)$ & $4(5,1 \%)$ & 0,333 \\
\hline Transtorno de Ansiedade de Separação & $11(27,5 \%)$ & $13(34,2 \%)$ & $24(30,8 \%)$ & 0,524 \\
\hline Transtorno de Evitação/Fobia Social & $11(27,5 \%)$ & $9(23,7 \%)$ & $28(35,9 \%)$ & 0,702 \\
\hline Agorafobia e Fobias Específicas & $15(37,5 \%)$ & $13(34,2 \%)$ & $28(35,9 \%)$ & 0,764 \\
\hline Transtorno de Ansiedade Generalidada & $18(43,9 \%)$ & $10(25,6 \%)$ & $28(35,9 \%)$ & 0,088 \\
\hline Transtorno Depressivo & $11(27,5 \%)$ & $5(13,2 \%)$ & $16(20,5 \%)$ & 0,119 \\
\hline Tricotilomania & $1(2,6 \%)$ & $3(7,9 \%)$ & $4(5,2 \%)$ & 0,295 \\
\hline Transtorno de Escoriação & $5(12,8 \%)$ & $5(13,2 \%)$ & $10(13,0 \%)$ & 0,750 \\
\hline Transtorno de Tique Transitório & $4(10,0 \%)$ & $2(5,3 \%)$ & $6(7,7 \%)$ & 0,276 \\
\hline Síndrome de Tourette & $4(10,0 \%)$ & $2(5,3 \%)$ & $6(7,7 \%)$ & 0,276 \\
\hline Transtorno de Tique Motor ou Vocal Crônico & $4(10,0 \%)$ & $7(18,4 \%)$ & $11(14,1 \%)$ & 0,438 \\
\hline
\end{tabular}

Legenda: Y-BOCS: Escala Yale-Brown de Sintomas Obsessivos-Compulsivos; DY-BOCS: Y-BOCS Dimensional; SOC: Sintomas Obsessivo-Compulsivos; TOC: Transtorno Obsessivo-Compulsivo; CDRS-R: Escala de Avaliação de Depressão para Crianças - Revisada; SCARED: Escala de avaliação de transtornos relacionados à ansiedade infantil; CRI: Inventário de Rotinas da Infância; ${ }^{1} p$-valor do teste de Mann-Whitney para amostras independentes; ${ }^{2} p$-valor teste qui-quadrado. 
Sobre a caracterização do grupo de pacientes, vale reportar, ainda, que após as 14 semanas de tratamento, $48,8 \%$ daqueles que fizeram uso de FLX foram respondedores ao tratamento proposto, e 53,8\% dos indivíduos foram respondedores a TCCG. A média da melhora da YBOCS foi de 10,66 pontos para aqueles que realizaram tratamento medicamentoso e 11,66 pontos para os que foram submetidos à terapia. Os dados descritos estão apresentados na Tabela 4.

Tabela 4 - Taxa de Resposta a TCCG e a FLX após 14 semanas de tratamento

\begin{tabular}{lcccc}
\hline & $\begin{array}{c}\text { FLX } \\
(\mathbf{N = 4 1 )}\end{array}$ & $\begin{array}{c}\text { TCCG } \\
(\mathbf{N}=39)\end{array}$ & $\begin{array}{c}\text { Total (N=80) } \\
(\mathbf{N}=\mathbf{8 0})\end{array}$ & \\
\hline delta YBOCS & $\mathbf{M}(\mathbf{D P})$ & $\mathbf{M}(\mathbf{D P})$ & $\mathbf{M}(\mathbf{D P})$ & $\mathbf{p}$-valor \\
\hline & $10,65(9,85)$ & $11,65(8,67)$ & $11,15(9,22)$ & $0,949^{1}$ \\
\hline & $\mathbf{N}(\%)$ & $\mathbf{N}(\%)$ & $\mathbf{N}(\%)$ & $\mathbf{p}$-valor \\
Respondedor & & & & $0,810^{2}$ \\
Não Respondedor & $20(57,1 \%)$ & $21(60,0 \%)$ & $41(58,6 \%)$ & \\
\hline
\end{tabular}

Legenda: Y-BOCS: Escala Yale-Brown de sintomas obsessivos-compulsivos; delta YBOCS: razão entre a diferença dos valores da YBOCS Final e Inicial e o escore inicial; Respondedor: pacientes que apresentaram melhora de $35 \%$ na YBOCS na segunda avaliação clínica; Não Respondedor: indivíduos que não apresentaram $35 \%$ de melhora na Y-BOCS.

1 p-valor do teste qui-quadrado; ${ }^{2}$ p-valor do teste de Mann-Whitney para amostras independentes

7.3. Resultados relativos à linha de base

7.3.1. Comparação entre grupos: pacientes versus controles

7.3.1.1. Comparação do Quociente de Inteligência entre grupos

Não foram encontradas diferenças significativas ente os grupos no que se refere ao QIT ( $p$-valor = 0,477) e ao QIV ( $p$-valor = 0,317). Por outro lado, os pacientes apresentaram piores escores no QIE (p-valor $=0,017)$. Visando 
investigar as diferenças existentes entre os QIV e QIE, criou-se uma nova variável de análise caracterizada pela diferença dos valores dessas variáveis. Como resultado, observou-se maior discrepância no grupo de pacientes quando comparado ao grupo controle $(p$-valor $=0.002)$ [ Tabela 5].

A análise dos subtestes do WASI indicou que os pacientes com TOC apresentam pontuações significativamente mais baixas que o grupo controle no subtestes CUB ( $p$-valor $=0.006)$. Porém, não foram encontradas diferenças entre os grupos nos demais subtestes (VOC: $p$-valor $=0.799$; SEM: $p$-valor $=0.378$; MAT: $p$-valor $=0.523$ ), conforme apresentado na Tabela 5 (para t do teste t para amostras independentes, consultar ANEXO D, Tabela 8).

Tabela 5 - Desempenho dos pacientes e controles no teste de QI e nos subtestes do teste WASI

\begin{tabular}{lcccc}
\hline & $\begin{array}{c}\text { TOC } \\
\text { (N= 82) }\end{array}$ & $\begin{array}{c}\text { Controles } \\
\text { (N= 82) }\end{array}$ & $\begin{array}{c}\text { Total } \\
\text { (N= 164) }\end{array}$ & (D) \\
\hline WASI & M (DP) & M (DP) & M (DP) & p-valor $^{\mathbf{1}}$ \\
$\quad$ QI Total & & & & \\
QI Verbal & $105,085(15,261)$ & $106,841(16,249)$ & $105,963(15,739)$ & 0,447 \\
QI Execução & $112,557(15,426)$ & $110,036(16,411)$ & $111,273(15,936)$ & 0,317 \\
$\quad$ Diferença QI Verbal - Qi Execução & $96,481(15,173)$ & $102,195(14,993)$ & $99,391(15,305)$ & $\mathbf{0 , 0 1 7}$ \\
Subtestes & $14,829(14,927)$ & $7,841(13,337)$ & $11,335(14,540)$ & $\mathbf{0 , 0 0 2}$ \\
$\quad$ Vocabulário & & & & \\
Semelhanças & $45,940(11,748)$ & $45,50(10,184)$ & $45,72(10,962)$ & 0,799 \\
Cubos & $30,510(8,155)$ & $29,35(8,367)$ & $29,92(8,258)$ & 0,378 \\
$\quad$ Matrizes & $25,560(17,149)$ & $32,63(15,470)$ & $29,10(16,663)$ & $\mathbf{0 , 0 0 6}$ \\
\hline
\end{tabular}

Legenda: WASI: Escala Wechsler Abreviada de Inteligência; QI: Quociente de Inteligência; ${ }^{1} \mathrm{p}$-valor resultante do teste t para amostras independentes. 
7.3.1.2. Comparação do funcionamento neuropsicológico de pacientes e controles em diferentes domínios cognitivos

Considerando o desempenho dos pacientes nos diversos testes neuropsicológicos é possível observar um pior funcionamento global dos pacientes quando comparados com controles saudáveis. Após a correção de Bonferroni, se mantiveram significativos os resultados encontrados para as seguintes funções neuropsicológicas: Habilidades Visuoconstrutivas ( $F=4,341$; p-valor= 0,015); Memória Episódica Não Verbal $(F=10,527 ; p$-valor $=<0,001)$ e Flexibilidade Mental ( $F=3,559 ; p$-valor=0,005).

Ainda sobre esses resultados, foi possível notar nas análises post-hoc, com uso do teste $t$-student, que as diferenças nos desempenhos entre pacientes e controles foram mantidas para todas as variáveis neuropsicológicas que compuseram as MANOVAS apenas nos domínios relativos às Habilidades Visuoconstrutivas e à Memória Episódica Não Verbal. Esses resultados estão demonstrados na Tabela 6 (os valores $t$ dos testes $t$ para amostras independentes encontram-se na Tabela 8, ANEXO D). 
Tabela 6 - Comparação do Desempenho Cognitivo de Pacientes e Controles

\begin{tabular}{|c|c|c|c|c|c|}
\hline Função Neuropsicológica & $\begin{array}{c}\text { TOC } \\
\text { M (DP) }\end{array}$ & $\begin{array}{l}\text { Controles } \\
\text { M (DP) }\end{array}$ & $\mathbf{F}$ & gl & p-valor \\
\hline Velocidade Motora e de Processamento & & & 2,642 & 5 & $0,025^{1}$ \\
\hline CWIT 1 tempo & $42,201(11,660)$ & $38,363(11,091)$ & & & $0,032^{2}$ \\
\hline CWIT 2 tempo & $31,368(13,099)$ & $30,512(9,799)$ & & & $0,636^{2}$ \\
\hline TMT 5 tempo & $42,747(21,014)$ & $43,377(25,322)$ & & & $0,863^{2}$ \\
\hline GPT mão dominante tempo & $82,663(29,286)$ & $75,752(16,508)$ & & & $0,069^{2}$ \\
\hline GPT mão não dominante tempo & $95,903(33,019)$ & $84,946(17,922)$ & & & $0,010^{2}$ \\
\hline Habilidades Visuoconstrutivas & & & 4,341 & 2 & $0,015^{1}$ \\
\hline RCFT pontuação cópia & $29,640(7,128)$ & $31,902(4,463)$ & & & $0,016^{2}$ \\
\hline Cubos & $25,56(17,149)$ & $32,630(15,470)$ & & & $0,006^{2}$ \\
\hline Memória Não-Verbal & & & 10,527 & 3 & $<0,0011$ \\
\hline COR direto & $6,72(1,886)$ & $8,160(2,153)$ & & & $<0,001^{2}$ \\
\hline RCFT recuperação imediata & $18,018(7,645)$ & $22,945(6,862)$ & & & $<0,001^{2}$ \\
\hline RCFT recuperação tardia & $17,652(8,104)$ & $22,561(7,520)$ & & & $<0,001^{2}$ \\
\hline Memória Verbal & & & 1,502 & 3 & $0,216^{1}$ \\
\hline DIG direto & $8,000(2,085)$ & $7,930(2,130)$ & & & \\
\hline RAVLT recuperação imediata & $10,620(2,551)$ & $11,180(2,460)$ & & & \\
\hline RAVLT recuperação tardia & $10,340(2,616)$ & $11,110(2,655)$ & & & \\
\hline Memória de Trabalho & & & 3,262 & 2 & $0,041^{1}$ \\
\hline COR inverso & $6,200(2,034)$ & $6,960(1,792)$ & & & $0,012^{2}$ \\
\hline DIG inverso & $5,170(2,403)$ & $5,730(2,272)$ & & & $0,126^{2}$ \\
\hline Flexibilidade Mental & & & 3,559 & 5 & $0,005^{1}$ \\
\hline WCST erros perseverativos & $10,350(4,501)$ & $9,15(3,621)$ & & & $0,960^{2}$ \\
\hline WCST categorias & $2,610(1,229)$ & $2,930(1,235)$ & & & $0,113^{2}$ \\
\hline FDT $3 \%$ erros perseverativos & $0,283(0,261)$ & $0,179(0,188)$ & & & $0,004^{2}$ \\
\hline TMT 4-5 tempo & $95,655(81,491)$ & $67,054(62,235)$ & & & $0,013^{2}$ \\
\hline Brixton & $38,330(7,999)$ & $41,270(5,591)$ & & & $0,009^{2}$ \\
\hline Controle Inibitório & & & 1,435 & 4 & $0,225^{1}$ \\
\hline Go-NoGo erros de comissão & $7,830(3,823)$ & $6,910(3,739)$ & & & \\
\hline CWIT 3 erros & $78,434(32,950)$ & $71,206(27,401)$ & & & \\
\hline CWIT 4 erros & $84,275(28,891)$ & $78,617(26,575)$ & & & \\
\hline CWIT 3 -1 tempo & $36,233(26,264)$ & $32,842(23,147)$ & & & \\
\hline
\end{tabular}

Legenda: RAVLT: Teste Auditivo-Verbal de Rey; TMT: Teste de Trilhas; DFT: Teste de Fluência de Desenhos; WCST: Teste de Classificação de Cartas do Wisconsin; CWIT: Teste de Interferência Cor-Palavra; GPT: Grooved Peagboard Test; RCFT - Teste da Figura Complexa de Rey; COR: Blocos de Corsi; DIG: Dígitos; ${ }^{1}$ p-valor da MANOVA; ${ }^{2}$ p-valor do teste $t$ de amostras independentes 
7.3.1.3. Associação das variáveis clínicas com o desempenho cognitivo dos pacientes

Buscando encontrar possíveis variáveis clínicas moderadoras para o pior desempenho dos pacientes nas variáveis dos testes neuropsicológicos conforme apresentado na Tabela 6 (CUB; COR - sequência direta, GPT - mão não dominante; DFT - soma da porcentagem de erros nas condições 1 e 2; DFT _ porcentagem de erros perseverativos da condição 3; RCFT - pontuação da cópia, RCFT - pontuação da recuperação imediata; RCFT - pontuação da recuperação tardia; TMT - diferença dos tempos das condições 4 e 5; e, BXT), foram realizadas correlações com idade de início dos sintomas, gravidade dos sintomas (Y-BOCS), dimensões dos sintomas (diferentes dimensões da DYBOCS), bem como com as seguintes comorbidades: Transtorno Depressivo, Transtorno Ansioso e Transtorno de Déficit de Atenção e Hiperatividade. Não foram encontradas correlações estatisticamente significativas entre as variáveis (os valores estão disponíveis na Tabela 9, ANEXO E, e Tabela 10, ANEXO F). 
7.4. Desfechos longitudinais

7.4.1. Comparação do desempenho cognitivo das crianças e adolescentes com TOC antes e depois do tratamento nos diferentes domínios cognitivos.

Ao comparar o desempenho dos pacientes nos diferentes domínios cognitivos antes e depois de receberam tratamento (FLX ou TCCG) para o TOC, não foram observadas diferenças entre aqueles que apresentaram ou não melhora dos sintomas, isto é, redução de $35 \%$ na Y-BOCS, conforme resultados apresentados na Tabela 7.

Ao incluir o tipo de tratamento para a referida análise, isto é, analisar se os respondedores dentro dos grupos específicos de tratamento (FLX ou TCCG) apresentavam mudanças em seu desempenho cognitivo após 14 semanas de tratamento, também não foram observados resultados significativos (Tabela 11, ANEXO G). 
Tabela 7 - Associação entre os domínios cognitivos e melhora clínica dos sintomas do TOC

\begin{tabular}{|c|c|c|c|}
\hline Função Neuropsicológica & $\mathbf{F}$ & gl & p-valor \\
\hline $\begin{array}{l}\text { Velocidade Motora e de } \\
\text { Processamento }\end{array}$ & 1,594 & 5 & 0,177 \\
\hline \multicolumn{4}{|l|}{ CWIT 1 tempo } \\
\hline \multicolumn{4}{|l|}{ CWIT 2 tempo } \\
\hline \multicolumn{4}{|l|}{ TMT 5 tempo } \\
\hline \multicolumn{4}{|l|}{ GPT mão dominante tempo } \\
\hline \multicolumn{4}{|l|}{ GPT mão não dominante tempo } \\
\hline Memória Não-Verbal & 0,468 & 3 & 0,706 \\
\hline \multicolumn{4}{|l|}{ COR direto } \\
\hline \multicolumn{4}{|l|}{ RCFT recuperação imediata } \\
\hline \multicolumn{4}{|l|}{ RCFT recuperação tardia } \\
\hline Memória Verbal & 0,213 & 3 & 0,887 \\
\hline \multicolumn{4}{|l|}{ DIG direto } \\
\hline \multicolumn{4}{|l|}{ RAVLT recuperação imediata } \\
\hline \multicolumn{4}{|l|}{ RAVLT recuperação tardia } \\
\hline Memória de Trabalho & 0,255 & 2 & 0,776 \\
\hline \multicolumn{4}{|l|}{ COR inverso } \\
\hline \multicolumn{4}{|l|}{ DIG inverso } \\
\hline \multicolumn{4}{|l|}{ WCST erros perseverativos } \\
\hline \multicolumn{4}{|l|}{ WCST categorias } \\
\hline \multicolumn{4}{|l|}{ FDT $3 \%$ erros perseverativos } \\
\hline \multicolumn{4}{|l|}{ TMT 4-5 tempo } \\
\hline \multicolumn{4}{|l|}{ Brixton } \\
\hline Controle Inibitório & 0,753 & 4 & 0,562 \\
\hline \multicolumn{4}{|l|}{ Go-NoGo erros de comissão } \\
\hline \multicolumn{4}{|l|}{ CWIT 3 erros } \\
\hline \multicolumn{4}{|l|}{ CWIT 4 erros } \\
\hline CWIT 3 -1 tempo & & & \\
\hline
\end{tabular}

Legenda: RAVLT: Teste Auditivo-Verbal de Rey; TMT: Teste de Trilhas; DFT: Teste de Fluência de Desenhos; WCST: Teste de Classificação de Cartas do Wisconsin; CWIT: Teste de Interferência Cor-Palavra; GPT: Grooved Peagboard Test; RCFT - Teste da Figura Complexa de Rey; COR: Blocos de Corsi; DIG: Dígitos; p-valor da MANOVA 
7.4.2. Comparação do desempenho cognitivo das crianças e adolescentes com TOC antes e depois do tratamento nos diferentes testes neuropsicológicos

Ao realizar a análise intragrupo dos resultados pré e pós tratamento, foi possível observar a existência de melhor desempenho em algumas variáveis dos testes neuropsicológicos, tanto para os pacientes que foram respondedores $(\mathrm{N}=39)$ como para os pacientes que não foram respondedores ao tratamento ( $\mathrm{N}=27$ ) [Tabela 12, ANEXO H].

Os pacientes que foram respondedores aos tratamentos, demonstraram melhora em seu desempenho nas seguintes variáveis neuropsicológicas: WCST- número de respostas $(p=0,044)$ e erros perseverativos ( $p$-valor $=0,048)$; GPT - tempo ( $p$-valor=0,014) e o número de erros ( $p$-valor: 0,049), ambos na condição mão não-dominante; RAVLT - pontuação da lista B ( $p$-valor=0,002); RCFT: escore de planejamento durante a cópia $(p$-valor $=0,004)$, tempo para a realização da cópia da figura ( $p$-valor: $<0,001$ ), recuperação imediata ( $p$ valor $<0,001)$ e tardia ( $p$-valor $<0,001)$ da figura; DFT- pontuação total das condições 2 e 3 (p-valores= 0,032 e 0,031, respectivamente); TMT - tempo de execução das condições 2 e 3 ( $p$-valores= 0,050 e 0,024); CWIT - erros não corrigidos na condição 2 ( $p$-valor: 0,011) e condição 4 tempo $(0,047)$; BXT - total de acertos ( $p$-valor $=0,011)$ [Tabela12, ANEXO H]. Contudo, diante da diversidade dos testes e suas consequentes variáveis, ao adotar-se um valor de alpha mais rigoroso $(p<0,001)$, apenas os resultados do tempo da cópia da RCFT, da recuperação imediata e da recuperação tardia da figura foram mantidos. 
Mesmo para aqueles que não foram respondedores aos tratamentos, foi observada melhora na pontuação de algumas variáveis neuropsicológicas, conforme apresentado na Tabela 12 (ANEXO H). Dentre elas, pode-se citar: RAVLT - pontuação lista B ( $p$-valor = 0,021), RCFT - pontuação da cópia da figura (p-valor=0,002) e TMT - Condição 5 (p-valor = 0,001). Diferentemente do que aconteceu nos respondedores, nenhum desses resultados sobreviveram à correção.

Um segundo modo de olhar os resultados longitudinais das variáveis neuropsicológicas, seria considerar o desempenho dos pacientes dentro dos grupos de tratamento, isto é, FLX e TCCG, independentemente da melhora dos sintomas do TOC (Tabela 13, ANEXO I).

Nesse modo de analisar os dados, os pacientes submetidos a FLX melhoraram os escores de variáveis associadas à RCFT e no TMT. O grupo randomizado para FLX, após 14 semanas de tratamento, apresentou melhora significativa no escore de planejamento da RCFT ( $p$-valor $=<0,001$ ), no tempo da cópia da RCFT ( $p$-valor $=<0,001$ ) e na pontuação referente recuperação tardia da RCFT ( $p$-valor $=<0,001)$.

O grupo randomizado para TCCG apresentou desempenho levemente melhor na avaliação realizada após o tratamento. Porém os valores não se mantiveram após as correções [Tabela 13, ANEXO I].

Por fim, comparar o desempenho dos pacientes nos momentos anterior e posterior ao tratamento, é possível identificar que os mesmos apresentam melhora significativa no planejamento da cópia e no tempo da cópia da RCFT 
( $p$-valor<0,001, para ambos), bem como na capacidade de evocação imediata e tardia da RCFT ( $p=<0,001$ e $p=0,001$, respectivamente) [Tabela 13, ANEXO I]. 


\section{DISCUSSÃO}

Este estudo consistiu na investigação do desempenho cognitivo de crianças e adolescentes com TOC, considerando dois momentos de avaliação: antes (linha de base) e depois do tratamento. Até o momento, este parece ser o estudo com a maior amostra de indivíduos com TOC, não medicados, que teve seu funcionamento neuropsicológico comparado ao de controles saudáveis. Além disso, nenhum outro estudo na literatura do TOC pediátrico reportou a análise longitudinal das diferentes funções cognitivas após os pacientes terem recebido diferentes tratamentos de primeira linha para os sintomas do transtorno, no caso FLX e TCCG. Visando facilitar a apresentação e discussão dos dados, esta seção se dividirá em duas partes. A primeira parte será dedicada aos dados da linha de base, enquanto a segunda, será dedicada à discussão dos resultados longitudinais.

\subsection{Discussão dos dados de linha de base}

Os resultados referentes à linha de base sugerem que crianças e adolescentes com TOC possuem pior funcionamento cognitivo global quando comparado ao desempenho de controles saudáveis. Diferenças significativas foram observadas no QI de execução, na discrepância entre os QI verbal e de execução, nas habilidades visuoconstrutivas, na memória episódica não verbal e na flexibilidade mental.

Embora não tenha sido encontrada diferença entre os QIT do grupo TOC e dos controles saudáveis, conforme a hipótese inicial deste estudo, outros 
dados relevantes sobre o QI foram observados. Dentre eles, destaca-se o fato dos pacientes apresentaram um QIE significativamente menor que o dos controles saudáveis e uma maior discrepância entre a diferença de pontuação dos QIV e QIE (QIV-QIE). Esses resultados são compatíveis com variáveis reportadas em estudos cognitivos realizados com a população infantil (Kodaira et al., 2012; Shin et al., 2008; Taner et al., 2011; Hybel et al., 2017), bem como com uma recente meta-análise específica sobre QI na população adulta com TOC (Abramovitch et al., 2018).

Diante da análise pormenorizada dos subtestes que compunham os valores dos QIT, QIE e QIV, foi possível observar que os pacientes com TOC apresentam pontuação significativamente mais baixa no subteste Cubos, o que poderia estar influenciando no pior QIE. Uma das explicações possíveis para o pior resultado dos pacientes no subteste Cubos seria o fato do mesmo envolver vários domínios não verbais, tais como velocidade de processamento, habilidades visuoconstrutivas e funções executivas; os quais a literatura relata estar comprometidos nas crianças e nos adolescentes com TOC (Geller et al., 2017). Neste estudo, essa hipótese é endossada pelo pior desempenho dos pacientes nas habilidades Visuoconstrutivas, na memória episódica não verbal e na flexibilidade mental.

Conforme anteriormente mencionado, ao comparar o desempenho neuropsicológico dos pacientes em diferentes domínios cognitivos, observou-se valores significativamente piores nas seguintes funções: habilidades visuoespaciais, memória episódica não-verbal e flexibilidade mental. Déficits nessas áreas já foram citados por estudos anteriores realizados com a 
população pediátrica com TOC. Shin et al. (2008), Grisham et al. (2009), Bloch et al. (2011) e Geller et al. (2017), descreveram em seus estudos que a população pediátrica com TOC apresentou mais dificuldade em tarefas que envolviam habilidades visuoespaciais. Falhas na memória não verbal, por sua vez, foram apontadas por Andrés et al. (2007) e Geller et al. (2017), e pior desempenho em tarefas que aferem flexibilidade mental foram reportados por Shin et al. (2008) e Ornstein et al. (2010).

Com o intuito de se verificar as implicações das variáveis clinicas no funcionamento cognitivo das crianças e adolescentes com TOC, foram conduzidas análises de correlação entre a idade de início dos SOC, gravidade do TOC, dimensões dos sintomas e comorbidades, e o desempenho dos pacientes nos diferentes testes neuropsicológicos. Tal como previamente reportado na literatura (Geller et al, 2017), não foram observadas correlações significativas entre as variáveis analisadas. McGuire et al. (2014), contudo, reportaram um estudo indicando que diferentes dimensões dos sintomas estariam relacionadas a um pior funcionamento cognitivo em domínios específicos. Para os autores, pacientes com TOC com sintomas de acumulação e de simetria/ordem apresentam mais déficits cognitivos que os pacientes com sintomas que compreendem aos demais domínios cognitivos. Já aqueles que apresentam sintomas do tipo simetria/ordem, demonstram comprometimentos cognitivos específicos, caso da fluência não-verbal, velocidade de processamento e inibição/mudança de resposta. Esses resultados dispares sugerem que futuros estudos precisam ser conduzidos junto à população pediátrica como forma de melhor compreender a relação entre dimensão dos 
sintomas e desempenho cognitivo.

\subsection{Discussão dos dados longitudinais}

Os resultados referentes à comparação do desempenho dos pacientes na linha de base e 14 semanas após terem recebido um dos tratamentos de primeira linha para o TOC, isto é, FLX ou TCCG, indicaram que a melhora dos sintomas clínicos do TOC não foi acompanhada pela melhora do funcionamento cognitivo dos pacientes.

Até o momento, a literatura existente sobre os aspectos cognitivos do TOC pediátrico antes e após diferentes modalidades de tratamento é bem controversa, não havendo uma decisão homogênea sobre a questão. Os desfechos longitudinais deste estudo, por sua vez, são suportados por algumas pesquisas que demonstraram que as disfunções cognitivas persistiriam após a melhora clínica. Nielen and den Boer (2003), descreveram que mesmo após 12 semanas de tratamento com FLX, as crianças e adolescentes com TOC persistiram com os déficits cognitivos encontrados na avaliação inicial. Resultado semelhante foi observado por Kim et al. (2002) com a população adulta depois de 4 meses de tratamento e por Roth et al. (2005) após um ano de seguimento clínico com adultos.

De acordo com esses autores, os déficits neuropsicológicos encontrados na população com TOC seriam estáveis ao longo do tempo, refletindo uma disfunção crônica na região estriatal dorso-lateral (Nielen e den Boer, 2003). Tal 
consideração está alinhada com os déficits encontrados nos pacientes deste estudo em um momento inicial, relacionados às habilidades visuoespaciais e memória não verbal. Outros autores dizem, ainda, que a estabilidade dos déficits seriam um marcador cognitivo de um subtipo específico de TOC que manteria as disfunções cognitivas após tratamento adequado (Chamberlain et al., 2005).

Em contraste, Andrés et al. (2008) observaram paralelismo entre a melhora clínica e a melhora cognitiva de crianças e adolescentes com TOC após seis meses de tratamento naturalístico. Esses autores argumentam que o tempo de evolução do TOC mais curto nos jovens possa ter contribuído para uma evolução mais favorável, clínica e cognitiva. Alternativamente, consideram a existência de um subgrupo de pacientes com déficits cognitivos estáveis, que seria um grupo com pior evolução clínica, com persistência do transtorno na vida adulta. Nesse caso, os déficits cognitivos seriam um marcador endofenotípico para um subgrupo especifico de pacientes, que manteriam essas disfunções mesmo depois do tratamento.

Dentre as características clínicas da população do presente estudo, chamou a atenção o fato de as famílias demorarem cerca de três anos e meio para buscar tratamento clínico. Esse intervalo de tempo entre o surgimento dos sintomas e início do tratamento poderia exercer um papel decisivo para a evolução e manutenção das alterações cognitivas. Essa variável é de grande interesse clínico e de saúde pública, uma vez que abre espaço para se pensar na importância da detecção e tratamento precoce dos sintomas obsessivocompulsivos, evitando maiores comprometimentos para esses indivíduos em longo prazo. A necessidade dessas medidas pode ser extrapolada a partir do 
estudo conduzido por Perez-Vigil et al., (2018), que retrataram recentemente que pacientes com TOC, principalmente os de início precoce, possuem pior aproveitamento escolar e têm mais comprometimentos na vida funcional.

Concluindo, os poucos estudos disponíveis que avaliaram a melhora cognitiva após o tratamento do TOC/SOC apresentam resultados conflitantes. O presente estudo avaliou a influência de dois tratamentos de primeira linha para o TOC administrados de forma randomizada por um período de 14 semanas, e não foi observado paralelismo entre a melhora clínica do TOC e dos diferentes domínios cognitivos avaliados. No entanto, a observação de melhora em algumas variáveis dos testes da bateria neuropsicológica sugere que seria importante acompanhar a evolução desses indivíduos por um prazo mais longo, possibilitando detectar possíveis mudanças ou a manutenção da estabilidade das funções cognitivas. 


\section{LIMITAÇÕES E PERSPECTIVAS FUTURAS}

Algumas limitações acerca deste estudo merecem ser apontadas. Uma delas diz respeito à falta de um grupo de pacientes com TOC mais "puro", isto é, que não apresentasse tantas comorbidades como na amostra deste estudo. Embora a presença de comorbidade seja mais a regra do que exceção nos pacientes portadores do transtorno, um grupo sem outras sintomatologias psiquiátricas auxiliaria na obtenção de uma medida neuropsicológica "mais limpa", com menor possibilidade de interferências.

Uma segunda limitação corresponde à falta de um acompanhamento longitudinal do grupo de crianças e adolescentes saudáveis, como forma de melhor controlar os possíveis efeitos de aprendizagem entre uma testagem e outra (14 semanas). Além disso, a comparação longitudinal entre pacientes e controles poderia ser mais sensível à detecção de possíveis mudanças no funcionamento cognitivo dos pacientes após o tratamento, uma vez que esses resultados poderiam ser contrastados com os do grupo controle.

A falta um acompanhamento longitudinal maior que 14 semanas também pode ter acarretado em implicações para os resultados deste estudo. Isso porque, diferentemente da melhora clínica dos sintomas, a melhora do desempenho cognitivo pode ser mais gradual, já que depende da interação do sujeito com o ambiente. Nesse sentido, a realização de uma nova avaliação dos pacientes seria interessante para ver se a melhora do desempenho cognitivo das crianças e adolescentes com TOC depende de mais tempo do que a melhora clínica dos sintomas para se manifestar. 
Embora se tenha feito uma primeira exploração de dados clínicos, correlacionando-os com o desempenho cognitivo dos pacientes, no futuro, essas variáveis poderiam ser incluídas outros modelos para análises longitudinais dos dados, caso dos modelos de predição e moderação. 


\section{CONCLUSÃO}

De acordo com os resultados do presente estudo, as crianças e adolescentes com TOC apresentam pior desempenho cognitivo global em provas neuropsicológicas quando comparados aos controles saudáveis. Comparando o seu desempenho antes e após o tratamento, o fato de a melhora dos sintomas não ter sido acompanhada da melhora do desempenho neuropsicológico dos pacientes em diferentes domínios cognitivos, sugere que as alterações cognitivas observadas no grupo TOC sejam relacionadas à própria neurobiologia do transtorno, independentemente da gravidade dos sintomas. Futuros estudos longitudinais serão necessários para aumentar a compreensão do funcionamento cognitivo dos jovens com TOC e as implicações do tratamento na sua cognição no longo prazo. 


\section{ANEXOS}

\subsection{ANEXO A}

HOSPITAL DAS CLÍNICAS DA FACULDADE DE MEDICINA DA UNIVERSIDADE DE SÃO PAULO-HCFMUSP

\section{TERMO DE CONSENTIMENTO LIVRE E ESCLARECIDO}

(OBRIGATÓRIO PARA PESQUISAS CIENTÍFICAS EM SERES HUMANOS RESOLUÇÃO № 196 - CNS)

DADOS DE IDENTIFICAÇÃO DO SUJEITO DA PESQUISA OU RESPONSÁVEL LEGAL NOME:

DOCUMENTO DE IDENTIDADE N ${ }^{\circ}$ : SEXO:.$M \square F \square$ DATA NASCIMENTO: ........................

ENDEREÇO

CIDADE

CEP:

TELEFONE: ( ..)

2.RESPONSÁVEL LEGAL

NATUREZA (grau de parentesco, tutor, curador etc.)

DOCUMENTO DE IDENTIDADE: SEXO: $M \square F \square$ DATA NASCIMENTO.: .................... ENDEREÇO: BAIRRO: CIDADE: CEP: TELEFONE: ...). 


\section{DADOS SOBRE A PESQUISA}

1. TítULO DO PROTOCOLO DE PESQUISA: "Desenvolvendo estratégias adaptativas de tratamento de crianças e adolescentes com transtornos psiquiátricos no contexto da saúde pública: a "medicina em prática". Aprovado em 07/05/2009 sob o número 361/09 no Comitê de Ética em Pesquisa do Hospital das Clínicas da Faculdade de Medicina da Universidade de São Paulo.

2. PESQUISADOR RESPONSÁVEL: EURÍPEDES CONSTANTINO MIGUEL FILHO.

CARGO/FUNÇÃO: PROFESSOR ASSOCIADO

INSCRIÇÃO CONSELHO REGIONAL: Nº 45280

UNIDADE DO HCFMUSP: Departamento de Psiquiatria

Investigadores executantes:

Roseli Gedanke Shavitt

Aluna de pós doutorado do Departamento de Psiquiatria da FMUSP.

Inscrição no Conselho Regional no. 59483

3. AVALIAÇÃO DO RISCO DA PESQUISA:

RISCO MÍNIMO $\square$ RISCO MÉDIO X

RISCO BAIXO RISCO MAIOR

4.DURAÇÃO DA PESQUISA: A duração total deste projeto é prevista em 5 anos. 
Você está sendo convidado(a) a participar deste projeto por ter transtorno obsessivo-compulsivo (TOC).

\section{Proposta da pesquisa}

Este grupo de Pesquisa oferece tratamento para aqueles pacientes que tem transtorno obsessivo-compulsivo (TOC), que não tem outras doenças que possam piorar com o tratamento para o TOC e que aceitem participar dos projetos de pesquisa em andamento.

Ao aceitar participar deste estudo você será passará inicialmente por uma avaliação psiquiátrica bastante completa, que inclui uma série de entrevistas e questionários sobre sua pessoa, sobre sua família, educação, saúde, e sobre os sintomas de sua doença (TOC), além de outras possíveis doenças psiquiátricas que você possua, como depressão e ansiedade. Após essa avaliação inicial, você entrará na fase de tratamento, mas para tal, passará por um sorteio inicial (sorteio 1), quando você poderá ser escolhido para fazer um tipo específico de psicoterapia, chamada de Psicoterapia Cognitivo-Comportamental em Grupo (TCC-G) (onde você aprenderá a desafiar as manias compulsivas e a corrigir os pensamento obsessivos distorcidos que o fazem sofrer num sistema computadorizado), $\underline{\mathrm{OU}}$ a tomar uma medicação específica, chamada cloridrato de fluoxetina, em doses que variam de 10 a $80 \mathrm{mg}$ por dia. Durante os tratamentos, você seguirá em acompanhamento e sendo avaliado. Após 14 semanas de tratamento efetivo com um ou outro método, você será avaliado quanto aos sintomas do TOC. Se eles tiverem reduzido significativamente (mais de 50\%), você será considerado como respondedor e será mantido em "fase de monitoramento de resposta". Se você obtiver menos de $50 \%$ de resposta você 
será sorteado ( $\underline{\text { sorteio 2) }}$ para um segundo tratamento, quando você poderá: A) se você estava no grupo da TCC-G, será sorteado para manter a TCCG e acrescentar o cloridrato de fluoxetina; ou encerrar a TCC-G e passar a fazer apenas o tratamento medicamentoso com o cloridrato de fluoxetina; ou B) se você estava no grupo do cloridrato de fluoxetina, será sorteado para acrescentar a TCC-G ao tratamento medicamentoso, ou suspender o medicamento e fazer a TCC-G por 14 semanas. Cada uma dessas fases subsequentes terá 14 semanas.

\section{O tratamento será oferecido com as seguintes condições:}

A todos que aceitarem participar e puderem entrar, segundo nossos critérios, no ensaio clínico.

Ao ingressar no projeto você poderá ser acompanhado por um período de dois anos (28 semanas do projeto mais seguimento), durante o qual receberão tratamento com medicações e consultas semanais, mensais ou bimestrais com psiquiatra residente, médico assistente, psicólogo ou outros profissionais da área da saúde especializados no tratamento do TOC. A continuação do tratamento após dois anos dependerá de suas condições e da disponibilidade do serviço.

Se durante as primeiras 32 semanas, você for retirado da pesquisa devido ao surgimento de algum risco para a sua saúde, ainda assim poderá ser acompanhado pelo período de 2 anos conforme o previsto.

Durante os dois anos de seguimento, os pacientes que optarem por abandonar o tratamento neste serviço serão encaminhados para serviços regionalizados com carta de orientação sobre o tratamento já realizado. 
Aqueles que quiserem continuar o tratamento, mas que não aceitarem as condições do protocolo de pesquisa após já terem iniciado a participação no ensaio clínico serão acompanhados pelo período de 6 meses. A continuação do tratamento após esse período dependerá das suas condições e da disponibilidade do serviço. Na ausência de disponibilidade para o tratamento neste serviço, esses pacientes serão re-encaminhados para a rede pública com carta de orientação.

Obs.: Aqueles que estiverem em projetos que envolvem tratamento clínico não poderão estar em tratamento psicológico e/ou psiquiátrico de qualquer natureza (incluindo terapias alternativas) fora do serviço pelo período inicial do projeto (primeiras 12 a 24 semanas). Os pacientes que optarem por tratamento adjuvante fora do serviço serão acompanhados por 6 meses após a desistência e encaminhados para serviços públicos regionalizados.

\section{Procedimentos}

Caso você aceite participar deste estudo, terá que responder a uma série de entrevistas semi-estruturadas e escalas de avaliação psiquiátricas que podem durar de 4 a 6 horas para seu total preenchimento. Essas entrevistas poderão acontecer em mais de um encontro. Além disso, você receberá tratamento com medicações conhecidamente eficazes para o TOC ou terapia em grupo. Novas formas de tratamento não comprovadamente eficazes só poderão ser indicadas perante consentimento esclarecido para cada procedimento. Todas as drogas utilizadas neste protocolo de pesquisa são aprovadas para o tratamento de pacientes com transtornos psiquiátricos. 
Durante a pesquisa, amostras suas de sangue (4 tubos de $5 \mathrm{ml}$ - que correspondem a quatro colheres de chá) serão colhidas. Esses exames poderão ser utilizados para avaliação científica, pesquisa e ensino ou mesmo para o desenvolvimento de novos produtos para a saúde. Caso você concorde com o uso desse material para pesquisa, será convocado para assinar um novo termo nos autorizando a utilizá-los.

\section{Riscos e Inconveniências}

As tarefas a serem realizadas para a conclusão deste projeto possuem alguns riscos e inconveniências para o paciente.

Coleta de amostra de sangue. Neste procedimento pode ocorrer o aparecimento de manchas arroxeadas no local de onde o sangue foi tirado. Todos os pacientes serão previamente orientados com relação a este risco e sobre os cuidados necessários caso ocorra. Além disso, raramente o local de onde foi retirada amostra de sangue pode inflamar e necessitar de cuidados locais (limpeza e pomadas) por alguns dias. Exames de sangue são necessários para dois objetivos :1. garantir que você não terá prejuízo para a sua saúde com as medicações utilizadas e fazem parte do tratamento clínico habitual; 2. Duas das amostras de sangue coletadas serão utilizadas para verificarmos qual a dose da medicação em circulação no sangue. Para o objetivo 2 os exames não fazem parte do tratamento clínico habitual e são procedimentos relacionados somente a esta pesquisa. 
Eletrocardiograma. O eletrocardiograma é um exame realizado para verificar a condução elétrica do coração e tem por objetivo garantir a segurança para a sua saúde com as medicações do estudo. Este exame faz parte d o tratamento clínico habitual.

Tratamento ambulatorial medicamentoso: o tratamento oferecido possui os riscos habituais de qualquer tratamento (reações imprevisíveis e efeitos colaterias das medicações utilizadas). Na possibilidade da medicação prevista no protocolo representar risco para você devido a outras doenças clínicas ou psiquiátricas, ou devido à piora da doença de base (TOC), você poderá ser retirado do protocolo e tratado no Serviço Médico em que está sendo atendido para resolver esse risco.

Em qualquer momento do estudo você poderá solicitar sua retirada do protocolo de pesquisa sem que isso apresente qualquer consequência para o seu tratamento. Para tanto, cada caso deverá ser discutido com o corpo clínico do Grupo de Pesquisa (Instituto Nacional de Psiquiatria do Desenvolvimento). Se necessário (persistência de dúvida quanto a manutenção ou não do paciente no protocolo) será solicitado parecer da Comissão de Ética do Serviço Médico onde você está sendo atendido.

\section{Benefícios}

Não há outro benefício direto para os pacientes que participarem deste estudo além de receber tratamento gratuito para o TOC descrito acima. O potencial 
benefício para a sociedade é que este estudo pode aumentar o conhecimento sobre o tratamento do TOC.

\section{Alternativas para participação}

Sua participação é voluntária e caso você decida não participar da pesquisa você receberá atendimento neste mesmo serviço ou na rede de saúde da comunidade. Caso você tenha interesse em receber uma avaliação psiquiátrica, ainda que não tenha sido escolhido para participar do estudo, você poderá solicitar esta avaliação no próprio serviço de Psiquiatria.

A seguir, as considerações usuais envolvidas com estudos de pesquisa envolvendo seres humanos, que devem constar de todos os consentimentos:

\section{Uso de material}

Durante a pesquisa, amostras suas de sangue serão colhidas e poderão ser utilizadas para avaliação científica, pesquisa e ensino ou mesmo para o desenvolvimento de novos produtos para a saúde. Caso você concorde, poderá ser convocado para assinar novo termo de consentimento autorizando o uso dessas amostras para os objetivos já propostos.

\section{Sigilo e privacidade}

As informações produzidas nesta tarefa serão mantidas em lugar seguro, codificadas e a identificação só poderá ser realizada pelo pessoal envolvido diretamente com o projeto.

Caso o material venha a ser utilizado para publicação científica ou atividades didáticas, não serão utilizados nomes que possam vir a identificá-lo. Vídeos, 
fotos e outros materiais audiovisuais serão utilizados para fins didáticos ou científicos, e só serão utilizados após minha permissão por escrito, sendo que você poderá ver este material antes de assinar o consentimento. Caso ocorra qualquer problema relacionado ao procedimento realizado, o nosso serviço se responsabiliza e acarretará os custos de atendimento relativos aos riscos envolvidos. Estudos com drogas ainda não liberadas pelos órgãos oficiais constarão de outro consentimento, porém você aceita participar de estudos clínicos com drogas já liberadas.

\section{Demais informações}

Em qualquer momento do estudo você poderá obter mais informações com a Dra. Roseli Gedanke Shavitt ou um médico da equipe, pelo telefone 3069-6972, que estão aptos a solucionar suas dúvidas. Você poderá solicitar informações de qualquer conhecimento significativo descoberto durante este projeto. Se você tiver alguma consideração ou dúvida sobre a ética da pesquisa, entre em contato com o Comitê de Ética em Pesquisa (CEP) - Rua Ovídio Pires de Campos, 225 - $5^{\circ}$ andar - tel: (11) 2661- 6442 ramais 16, 17, 18, ou (11) 2661-7585; e-mail: cappesq.adm@hc.fm.usp.br

\section{Despesas e compensações}

Não há despesas pessoais para o participante em qualquer fase do estudo, incluindo exames e consultas. Também não há compensação financeira relacionada à sua participação. Se existir qualquer despesa adicional, ela será absorvida pelo orçamento da pesquisa. Em caso de dano pessoal, diretamente causado pelos procedimentos ou tratamentos propostos neste estudo (nexo 
causal comprovado), o participante tem direito a tratamento médico na Instituição, bem como às indenizações legalmente estabelecidas. Eu compreendo que poderei solicitar meu desligamento do presente projeto a qualquer momento. Acredito ter sido suficientemente informado a respeito das informações que li ou que foram lidas para mim, descrevendo o estudo:

"Desenvolvendo estratégias adaptativas de tratamento de crianças e adolescentes com transtornos psiquiátricos no contexto da saúde pública: a "medicina em prática".

Eu discuti com a sobre a minha decisão em participar nesse estudo. Ficaram claros para mim quais são os propósitos do estudo, os procedimentos a serem realizados, seus desconfortos e riscos, as garantias de confidencialidade e de esclarecimentos permanentes. Ficou claro também que minha participação é isenta de despesas e que tenho garantia do acesso a tratamento hospitalar quando necessário. Concordo voluntariamente em participar deste estudo e poderei retirar o meu consentimento a qualquer momento, antes ou durante o mesmo, sem penalidades ou prejuízo ou perda de qualquer benefício que eu possa ter adquirido, ou no meu atendimento neste Serviço.

Assinatura do paciente/representante legal

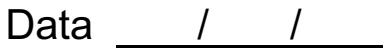


Assinatura da testemunha

Data 11

para casos de pacientes menores de 18 anos, analfabetos, semi-analfabetos ou portadores de deficiência auditiva ou visual.

(Somente para o responsável do projeto)

Declaro que obtive de forma apropriada e voluntária o Consentimento Livre e Esclarecido deste paciente ou representante legal para a participação neste estudo.

Assinatura do responsável pelo estudo Data 11 
11.2. ANEXO B

\author{
HOSPITAL DAS CLÍNICAS DA FACULDADE DE MEDICINA DA \\ UNIVERSIDADE DE SÃO PAULO-HCFMUSP
}

\title{
TERMO DE CONSENTIMENTO LIVRE E ESCLARECIDO
}

(OBRIGATÓRIO PARA PESQUISAS CIENTÍFICAS EM SERES HUMANOS RESOLUÇÃO № 196 - CNS)

DADOS DE IDENTIFICAÇÃO DO SUJEITO DA PESQUISA OU RESPONSÁVEL LEGAL

1NOME:

DOCUMENTO DE IDENTIDADE N ${ }^{\circ}$ : SEXO : .M $\square \mathrm{F} \square$ DATA NASCIMENTO: .......................

ENDEREÇO

CIDADE

CEP:

TELEFONE:

2.RESPONSÁVEL LEGAL

NATUREZA (grau de parentesco, tutor, curador etc.)

DOCUMENTO DE IDENTIDADE: SEXO: $M \square F \square$ DATA NASCIMENTO.: .....................

ENDEREÇO: 
BAIRRO:

CIDADE:

CEP:

TELEFONE:

..).

\section{DADOS SOBRE A PESQUISA}

1. TíTULO DO PROTOCOLO DE PESQUISA: "Avaliação neuropsicológica de crianças e adolescentes com TOC: comparação com controles saudáveis e impacto do tratamento"

2. PESQUISADOR RESPONSÁVEL: ROSELI GEDANKE SHAVITT.

CARGO/FUNÇÃO: Orientadora da Pós Graduação

INSCRIÇÃO CONSELHO REGIONAL: Nº 59483

UNIDADE DO HCFMUSP: Departamento de Psiquiatria

Investigadores executantes:

Marina de Marco e Souza

Aluna de mestrado do Departamento de Psiquiatria da FMUSP. Inscrição no Conselho Regional de Psicologia: 06/98118

3. AVALIAÇÃO DO RISCO DA PESQUISA:

RISCO MÍNIMO X

RISCO MÉDIO

RISCO BAIXO

RISCO MAIOR

4.DURAÇÃO DA PESQUISA: A duração total deste projeto é prevista para dois anos. 
Você está sendo convidado (a) a participar deste projeto por não ser portador de

transtorno neuropsiquiátrico e, assim, poder fornecer dados que ajudem a melhor entender os possíveis déficits neuropsicológicos existentes nas crianças e adolescentes que apresentam Transtorno Obsessivo Compulsivo (TOC).

\section{Proposta da pesquisa e procedimentos}

Ao aceitar participar deste estudo você será passará inicialmente por uma avaliação psiquiátrica bastante completa, que inclui uma série de entrevistas e questionários sobre sua pessoa, sobre sua família, educação, saúde e sobre a presença de possíveis sintomas psiquiátricos. Tendo descartado a existência de quadro neuropsiquiátrico, será realizada uma avaliação neuropsicológica, isto é, você será submetido a diferentes testes os quais são destinados à averiguação de funções cognitivas como inteligência, atenção, controle inibitório, fluência, memória, capacidade de aprendizagem e funções executivas. Tais dados serão comparados com aqueles encontrados em pacientes pediátricos com TOC, com o intuito de melhor entender as peculiaridades do funcionamento cognitivo desses pacientes, caso de fato essas existirem.

\section{Riscos e Inconveniências}

Não há riscos ou inconveniências para a criança e adolescente, bem como para suas famílias, ao participar deste projeto.

\section{Benefícios}


Não há outro benefício direto para os pacientes que participarem deste estudo além de receber tratamento gratuito para o TOC descrito acima. O potencial benefício para a sociedade é que este estudo pode aumentar o conhecimento sobre o tratamento do TOC.

\section{Alternativas para participação}

Sua participação é voluntária e caso você decida não participar da pesquisa você poderá se retirar da mesma em qualquer momento.

\section{Sigilo e privacidade}

As informações produzidas nesta tarefa serão mantidas em lugar seguro, codificadas e a identificação só poderá ser realizada pelo pessoal envolvido diretamente com o projeto.

Caso o material venha a ser utilizado para publicação científica ou atividades didáticas, não serão utilizados nomes que possam vir a identificá-lo.

\section{Demais informações}

Em qualquer momento do estudo você poderá obter mais informações com a psicóloga Marina de Marco e Souza, pelo telefone 2661-6972, que estão aptos a solucionar suas dúvidas. Você poderá solicitar informações de qualquer conhecimento significativo descoberto durante este projeto. Se você tiver alguma consideração ou dúvida sobre a ética da pesquisa, entre em contato com o Comitê de Ética em Pesquisa (CEP) - Rua Ovídio Pires de Campos, 225 - $5^{\circ}$ andar - tel: (11) 2661- 6442 ramais 16, 17, 18, ou (11) 2661-7585; e-mail: cappesq.adm@hc.fm.usp.br 


\section{Despesas e compensações}

Não há despesas pessoais para o participante em qualquer fase do estudo. Também não há compensação financeira relacionada à sua participação. Se existir qualquer despesa adicional, ela será absorvida pelo orçamento da pesquisa. Eu compreendo que poderei solicitar meu desligamento do presente projeto a qualquer momento. Acredito ter sido suficientemente informado a respeito das informações que li ou que foram lidas para mim, descrevendo o estudo: "Avaliação neuropsicológica de crianças e adolescentes com TOC: comparação com controles saudáveis e impacto do tratamento"

Eu discuti com a sobre a minha decisão em participar nesse estudo. Ficaram claros para mim quais são os propósitos do estudo, os procedimentos a serem realizados, as garantias de confidencialidade e de esclarecimentos permanentes. Ficou claro também que minha participação é isenta de despesas. Concordo voluntariamente em participar deste estudo e poderei retirar o meu consentimento a qualquer momento, antes ou durante o mesmo, sem penalidades ou prejuízo

Assinatura do paciente/representante legal

Data:

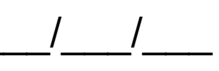

Assinatura da testemunha

Data:

para casos de pacientes menores de 18 anos, analfabetos, semi-analfabetos ou portadores de deficiência auditiva ou visual.

(Somente para o responsável do projeto) 
Declaro que obtive de forma apropriada e voluntária o Consentimento Livre e Esclarecido deste paciente ou representante legal para a participação neste estudo.

Assinatura do responsável pelo estudo

Data 1 


\subsection{ANEXO C}

\section{TERMO DE ASSENTIMENTO}

Você está sendo convidado(a) como voluntário(a) a participar da pesquisa "Avaliação neuropsicológica de crianças e adolescentes com TOC: comparação com controles saudáveis e impacto do tratamento". O presente estudo tem como objetivo comparar características neuropsicológicas de crianças e adolescentes com TOC, com idades entre 6 e 17 anos, e controles saudáveis, buscando verificar as possíveis alterações do funcionamento cognitivo no TOC pediátrico, e as associações entre as medidas neuropsicológicas e a resposta aos tratamentos medicamentoso e psicoterápico.

\section{Proposta da pesquisa e procedimentos}

Ao aceitar participar deste estudo você será passará inicialmente por uma avaliação psiquiátrica bastante completa, que inclui uma série de entrevistas e questionários sobre sua pessoa, sobre sua família, educação, saúde e sobre a presença de possíveis sintomas psiquiátricos. Tendo descartado a existência de quadro neuropsiquiátrico, será realizada uma avaliação neuropsicológica, isto é, você será submetido a diferentes testes os quais são destinados à averiguação de funções cognitivas como inteligência, atenção, controle inibitório, fluência, memória, capacidade de aprendizagem e funções executivas. Tais dados serão comparados com aqueles encontrados em pacientes pediátricos com TOC, com 
o intuito de melhor entender as peculiaridades do funcionamento cognitivo desses pacientes, caso de fato essas existirem.

\section{Riscos e Inconveniências}

Não há riscos ou inconveniências para a criança e adolescente, bem como para suas famílias, ao participar deste projeto.

\section{Benefícios}

Não há outro benefício direto para os pacientes que participarem deste estudo além de receber tratamento gratuito para o TOC descrito acima. O potencial benefício para a sociedade é que este estudo pode aumentar o conhecimento sobre o tratamento do TOC.

\section{Alternativas para participação}

Sua participação é voluntária e caso você decida não participar da pesquisa você poderá se retirar da mesma em qualquer momento.

\section{Sigilo e privacidade}

As informações produzidas nesta tarefa serão mantidas em lugar seguro, codificadas e a identificação só poderá ser realizada pelo pessoal envolvido diretamente com o projeto.

Caso o material venha a ser utilizado para publicação científica ou atividades didáticas, não serão utilizados nomes que possam vir a identificá-lo.

Demais informações 
Em qualquer momento do estudo você poderá obter mais informações com a psicóloga Marina de Marco e Souza, pelo telefone 2661-6972, que estão aptos a solucionar suas dúvidas. Você poderá solicitar informações de qualquer conhecimento significativo descoberto durante este projeto. Se você tiver alguma consideração ou dúvida sobre a ética da pesquisa, entre em contato com o Comitê de Ética em Pesquisa (CEP) - Rua Ovídio Pires de Campos, 225 - 5º andar - tel: (11) 2661- 6442 ramais 16, 17, 18, ou (11) 2661-7585; e-mail: cappesq.adm@hc.fm.usp.br

$E u$, portador(a) do documento de Identidade (se já tiver documento), fui informado(a) dos objetivos do presente estudo de maneira clara e detalhada e esclareci minhas dúvidas. Sei que a qualquer momento poderei solicitar novas informações, e o meu responsável poderá modificar a decisão de participar se assim o desejar. Tendo o consentimento do meu responsável já assinado, declaro que concordo em participar desse estudo. Recebi uma cópia deste termo assentimento e me foi dada a oportunidade de ler e esclarecer as minhas dúvidas.

São Paulo, de de 20

Assinatura do(a) menor Assinatura do(a) pesquisador(a) 
11.4. ANEXO D

Tabela 8 - Dados das variáveis neuropsicológicas dos pacientes e controles na linha de base e resultado do teste de comparação de médias

\begin{tabular}{|c|c|c|c|c|}
\hline & $\begin{array}{c}\text { TOC } \\
(\mathrm{N}=82)\end{array}$ & $\begin{array}{c}\text { Controles } \\
(\mathrm{N}=82)\end{array}$ & $\begin{array}{c}\text { Total } \\
(\mathrm{N}=164)\end{array}$ & \\
\hline & $M(D P)$ & $M(D P)$ & $\mathrm{M}(\mathrm{DP})$ & $\mathrm{p}$-valor ${ }^{1}$ \\
\hline \multicolumn{5}{|l|}{ WASI } \\
\hline QI Total & $105,085(15,261)$ & $106,841(16,249)$ & $105,963(15,739)$ & 0,447 \\
\hline QI Verbal & $112,557(15,426)$ & $110,036(16,411)$ & $111,273(15,936)$ & 0,317 \\
\hline QI Execução & $96,481(15,173)$ & $102,195(14,993)$ & $99,391(15,305)$ & 0,017 \\
\hline Vocabulário & $45,940(11,748)$ & $45,50(10,184)$ & $45,72(10,962)$ & 0,799 \\
\hline Semelhanças & $30,510(8,155)$ & $29,35(8,367)$ & $29,92(8,258)$ & 0,378 \\
\hline Cubos & $25,560(17,149)$ & $32,63(15,470)$ & $29,10(16,663)$ & 0,006 \\
\hline Matrizes & $23,180(6,082)$ & $23,74(5,137)$ & $23,47(5,610)$ & 0,523 \\
\hline Diferença QI Verbal - Qi Execução & $14,829(14,927)$ & $7,841(13,337)$ & $11,335(14,540)$ & 0,002 \\
\hline \multicolumn{5}{|l|}{ Dígitos } \\
\hline Direto & $8,00(2,085)$ & $7,93(2,130)$ & $7,96(2,101)$ & 0,824 \\
\hline Inverso & $5,17(2,403)$ & $5,73(2,272)$ & $5,45(2,348)$ & 0,126 \\
\hline \multicolumn{5}{|l|}{ Cubos de Corsi } \\
\hline Direto & $6,72(1,886)$ & $8,16(2,153)$ & $7,44(2,144)$ & 0,000 \\
\hline Inverso & $6,20(2,034)$ & $6,96(1,792)$ & $6,58(1,949)$ & 0,012 \\
\hline \multicolumn{5}{|l|}{ WCST } \\
\hline Erros & $19,99(10,034)$ & $17,66(7,028)$ & $18,77(8,647)$ & 0,092 \\
\hline Respostas Perseverativas & $11,24(5,309)$ & $10,06(4,668)$ & $10,62(5,003)$ & 0,141 \\
\hline Erros Não Pererseverativos & $9,77(7,403)$ & $8,37(4,523)$ & $9,04(6,092)$ & 0,149 \\
\hline Erros Perseverativos & $10,25(4,644)$ & $9,15(3,621)$ & $9,68(4,165)$ & 0,96 \\
\hline Categorias & $2,61(1,229)$ & $2,93(1,235)$ & $2,78(1,238)$ & 0,113 \\
\hline Perdas de Set & $0,91(0,939)$ & $0,87(0,872)$ & $0,88(0,901)$ & 0,785 \\
\hline Tentativas Primeira Categoria & $17,88(10,264)$ & $14,18(6,433)$ & $15,92(8,628)$ & 0,007 \\
\hline \multicolumn{5}{|l|}{ Go/NoGO } \\
\hline Acertos & $68,87(3,749)$ & $68,29(6,726)$ & $68,57(5,501)$ & 0,517 \\
\hline Acertos - Tempo & $531,925(87,355)$ & $508,325(73,814)$ & $519,338(81,007)$ & 0,075 \\
\hline Omissões & $3,01(3,600)$ & $2,63(2,991)$ & $2,81(3,295)$ & 0,465 \\
\hline Comissões & $7,83(3,823)$ & $6,91(3,739)$ & $7,36(3,796)$ & 0,130 \\
\hline Comissões - Tempo & $168,618(93,494)$ & $146,631(81,873)$ & $157,038(87,960)$ & 0,127 \\
\hline \multicolumn{5}{|l|}{ Grooved } \\
\hline Mão Dominante - Tempo & $82,663(29,286)$ & $75,752(16,508)$ & $79,251(24,026)$ & 0,069 \\
\hline Mão Dominante - Erros & $0,52(0,808)$ & $0,33(0,655)$ & $0,43(0,740)$ & 0,105 \\
\hline Mão Não Dominante - Tempo & $95,903(33,019)$ & $84,946(17,922)$ & $90,493(27,135)$ & 0,010 \\
\hline Mão Não Dominante - Erros & $0,680(1,105)$ & $0,57(0,901)$ & $0,62(1,008)$ & 0,494 \\
\hline \multicolumn{5}{|l|}{ RAVLT } \\
\hline Pontuação total & $49,50(9,192)$ & $51,87(8,891)$ & $50,68(9,093)$ & 0,096 \\
\hline Intrusões & $1,27(1,778)$ & $0,67(1,918)$ & $0,97(1,868)$ & 0,040 \\
\hline Perseverações & $4,02(3,186)$ & $2,57(2,424)$ & $3,30(2,914)$ & 0,001 \\
\hline Evocação Imediata & $10,62(2,551)$ & $11,18(2,460)$ & $10,90(2,514)$ & 0,154 \\
\hline Evocação Imediata - Intrusões & $0,12(0,365)$ & $0,07(0,262)$ & $0,10(0,318)$ & 0,327 \\
\hline Evocação Imediata - Perseverções & $0,65(0,948)$ & $0,40(0,751)$ & $0,52(0,861)$ & 0,07 \\
\hline Evocação Tardia & $10,34(2,616)$ & $11,11(2,655)$ & $10,73(2,656)$ & 0,067 \\
\hline Evocação Tardia - Intrusões & $0,28(0,530)$ & $0,19(0,527)$ & $0,23(0,529)$ & 0,266 \\
\hline Evocação Tardia - Perseverações & $0,49(1,061)$ & $0,22(0,612)$ & $0,36(0,871)$ & 0,048 \\
\hline Lista A 1 - Evocação Imediata & $6,49(1,642)$ & $6,56(1,880)$ & $6,52(1,760)$ & 0,791 \\
\hline Lista A 5 - Evocação Imediata & $12,17(2,428)$ & $12,75(1,994)$ & $12,45(2,242)$ & 0,105 \\
\hline Lista B - Evocação Imediata & $5,74(1,727)$ & $5,78(1,678)$ & $5,76(1,698)$ & 0,891 \\
\hline
\end{tabular}


Tabela 8: Dados das variáveis neuropsicológicas dos pacientes e controles na linha de base e resultado do teste de comparação de médias (continuação)

\begin{tabular}{|c|c|c|c|c|}
\hline & $\begin{array}{c}\text { TOC } \\
(\mathrm{N}=82)\end{array}$ & $\begin{array}{c}\text { Controles } \\
(\mathrm{N}=82)\end{array}$ & $\begin{array}{c}\text { Total } \\
(\mathrm{N}=164)\end{array}$ & \\
\hline & $\mathrm{M}(\mathrm{DP})$ & $\mathrm{M}(\mathrm{DP})$ & $\mathrm{M}(\mathrm{DP})$ & $\mathrm{p}$-valor ${ }^{1}$ \\
\hline \multicolumn{5}{|l|}{ RCFT } \\
\hline Cópia - Escore Planejamento (Savage) & $2,05(1,571)$ & $2,96(1,802)$ & $2,51(1,746)$ & 0,001 \\
\hline Cópia - Classificação Total & $29,640(7,128)$ & $31,902(4,463)$ & $30,77(6,036)$ & 0,016 \\
\hline Cópia - Tempo & $286,74(131,15)$ & $264,980(124,370)$ & $274,737(127,472)$ & 0,308 \\
\hline Evocação Imediata - Classificação total & $18,018(7,645)$ & $22,945(6,862)$ & $20,481(7,651)$ & 0,000 \\
\hline Evocação Imediata - Tempo & $172,970(91,958)$ & $177,349(65,760)$ & $175,505(77,575)$ & 0,762 \\
\hline Evocação Tardia - Classificação Total & $17,652(8,104)$ & $22,561(7,520)$ & $20,106(8,173)$ & 0,000 \\
\hline Evocação Tardia - Tempo & $122,487(73,361)$ & $130,702(56,766)$ & $127,23(64,14)$ & 0,476 \\
\hline \multicolumn{5}{|l|}{ FDT } \\
\hline Condição 1 - Pontuação Total & $7,790(3,276)$ & $9,990(3,211)$ & $8,89(3,416)$ & 0,000 \\
\hline Condição 1 - Perda de Set & $0,630(0,962)$ & $0,270(0,589)$ & $0,45(0,816)$ & 0,004 \\
\hline Condição 1 - Desenho Repetido & $0,880(1,190)$ & $1,040(1,300)$ & $0,96(1,245)$ & 0,417 \\
\hline Condição 1 - Porcentagem de erros & $0,167(0,151)$ & $0,111(0,118)$ & $0,139(0,138)$ & 0,01 \\
\hline Condição 2 - Pontuação Total & $8,85(3,120)$ & $9,990(2,895)$ & $9,42(3,054)$ & 0,017 \\
\hline Condição 2 - Perda de Set & $0,49(0,820)$ & $0,150(0,419)$ & $0,32(0,672)$ & 0,001 \\
\hline Condição 2 - Desenho Repetido & $2,12(2,682)$ & $1,480(1,701)$ & $1,80(2,262)$ & 0,067 \\
\hline Condição 2 - Porcentagem de erros & $0,209(0,175)$ & $0,132(0,138)$ & $0,171(0,162)$ & 0,002 \\
\hline Porcentagem de erros FTD 1 + 2 & $0,192(0,137)$ & $0,126(0,104)$ & $0,159(0,126)$ & 0,001 \\
\hline Condição 3 - Pontuação Total & $5,350(3,040)$ & $7,300(2,792)$ & $6,33(3,070)$ & 0,000 \\
\hline Condição 3 - Perda de Set & $2,070(1,930)$ & $1,700(2,198)$ & $1,88(2,071)$ & 0,244 \\
\hline Condição 3 - Desenhos Repetidos & $0,73(1,432)$ & $0,450(0,669)$ & $0,59(1,123)$ & 0,111 \\
\hline Condição 3 - porcentagem de erros (totais) & $0,352(0,250)$ & $0,224(0,189)$ & $0,288(0,230)$ & 0,000 \\
\hline Condição 3 - porcentagem erros perseverativos & $0,283(0,261)$ & $0,179(0,188)$ & $0,231(0,233)$ & 0,004 \\
\hline \multicolumn{5}{|l|}{ TMT } \\
\hline Condição 1 - Tempo & $34,758(16,091)$ & $33,000(11,223)$ & $33,879(13,858)$ & 0,418 \\
\hline Condição 1 - Comissões & $0,00(0,00)$ & $0,01(0,110)$ & $0,01(0,078)$ & 0,320 \\
\hline Condição 1 - Omissões & $0,29(0,555)$ & $0,12(0,365)$ & $0,21(0,476)$ & 0,021 \\
\hline Condição 2 - Tempo & $53,703(28,526)$ & $44,858(18,673)$ & $49,307(24,469)$ & 0,021 \\
\hline Condição 2 - Erros de Sequência & $0,06(0,287)$ & $0,010(0,111)$ & $0,04(0,219)$ & 0,156 \\
\hline Condição 2 - Perda de Set & $0,00(0,00)$ & $0,010(0,111)$ & $0,01(0,079)$ & 0,320 \\
\hline Condição 3 - Tempo & $61,933(38,374)$ & $52,367(25,938)$ & $57,150(33,002)$ & 0,064 \\
\hline Condição 3 - Erros de Sequência & $0,10(0,337)$ & $0,07(0,262)$ & $0,09(0,301)$ & 0,606 \\
\hline Condição 3 - Perda de Set & $0,00(0,00)$ & $0,02(0,155)$ & $0,01(0,110)$ & 0,159 \\
\hline Condição 4 - Tempo & $138,402(88,663)$ & $110,431(59,040)$ & $124,416(76,390)$ & 0,019 \\
\hline Condição 4 - Erros de Sequência & $0,43(0,875)$ & $0,330(0,649)$ & $0,38(0,770)$ & 0,419 \\
\hline Condição 4 - Perda de Set & $0,27(0,568)$ & $0,390(0,698)$ & $0,33(0,637)$ & 0,222 \\
\hline Condição 5 - Tempo & $42,747(21,014)$ & $43,377(25,322)$ & $43,062(23,199)$ & 0,863 \\
\hline Diferença Tempo - Condição 4 - 5 & $95,655(81,491)$ & $67,054(62,235)$ & $81,354(73,692)$ & 0,013 \\
\hline \multicolumn{5}{|l|}{ CWIT } \\
\hline Condição 1 - Tempo & $42,201(11,660)$ & $38,363(11,091)$ & $40,282(11,506)$ & 0,032 \\
\hline Condição 1 - Erros Auto-corrigidos & $0,79(1,184)$ & $0,410(0,719)$ & $0,600(0,995)$ & 0,015 \\
\hline Condição 1 - Erros Não Corrigidos & $0,20(0,456)$ & $0,160(0,598)$ & $0,180(0,530)$ & 0,660 \\
\hline Condição 2 - Tempo & $31,368(13,099)$ & $30,512(9,799)$ & $30,940(11,540)$ & 0,636 \\
\hline Condição 2 - Erros Auto-corrigidos & $0,18(0,611)$ & $0,220(0,545)$ & $0,20(0,577)$ & 0,686 \\
\hline Condição 2 - Erros Não Corrigidos & $0,28(0,821)$ & $0,060(0,241)$ & $0,17(0,613)$ & 0,021 \\
\hline Condição 3 - Tempo & $78,434(32,950)$ & $71,206(27,401)$ & $74,820(30,426)$ & 0,129 \\
\hline Condição 3 - Erros Auto-corrigidos & $2,28(2,588)$ & $1,960(2,128)$ & $2,12(2,367)$ & 0,393 \\
\hline Condição 3 - Erros Não-Corrigidos & $0,80(1,452)$ & $1,270(2,299)$ & $1,04(1,931)$ & 0,125 \\
\hline Condição 4 - Tempo & $84,275(28,891)$ & $78,617(26,575)$ & $81,446(27,817)$ & 0,194 \\
\hline Condição 4 - Erros Auto-Corrigidos & $2,57(2,368)$ & $1,610(1,986)$ & $2,090(2,231)$ & 0,005 \\
\hline Condição 4 - Erros Não Corrigidos & $1,61(1,923)$ & $1,720(2,851)$ & $1,660(2,425)$ & 0,773 \\
\hline Diferença Tempo - Condição 3 - 1 & $36,233(26,264)$ & $32,842(23,147)$ & $34,538(24,737)$ & 0,382 \\
\hline \multicolumn{5}{|l|}{ Brixton } \\
\hline Total de Acertos & $38,33(7,999)$ & $41,270(5,591)$ & $39,93(6,931)$ & 0,009 \\
\hline
\end{tabular}

${ }^{1} \mathrm{p}$-valor do teste $\mathrm{t}$ para amostras independentes 


\subsection{ANEXO E}

Tabela 9 - Correlações de Pearson entre as dimensões da DY-BOCS, Y-BOCS e idade de início dos sintomas obsessivo-compulsivos e o desempenho dos pacientes nos testes neuropsicológicos na linha de base

\begin{tabular}{|c|c|c|c|c|c|}
\hline 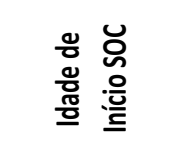 & 总 & 总 㞻 & 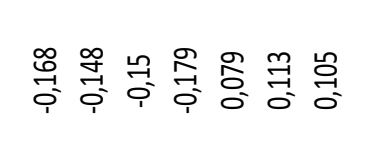 & 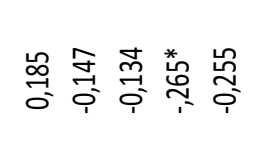 & 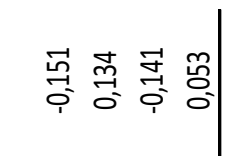 \\
\hline 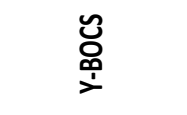 & ○ 劲 & mo & 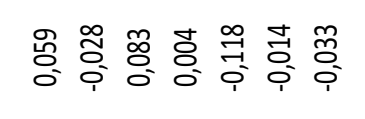 & 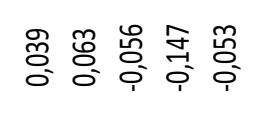 & 总営总吉吉 \\
\hline 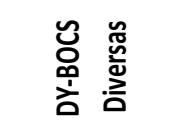 & $\stackrel{*}{\stackrel{*}{\beth}} \stackrel{\overrightarrow{0}}{0}$ & 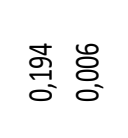 & 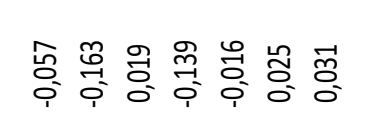 & 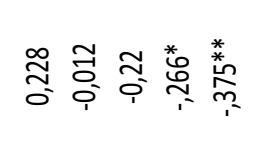 & 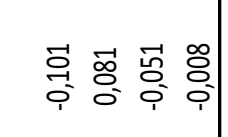 \\
\hline 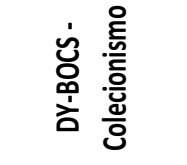 & 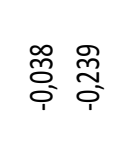 & 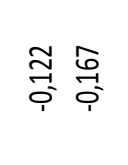 & 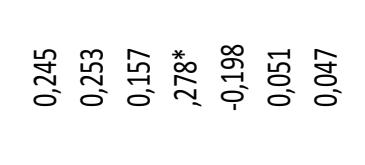 & 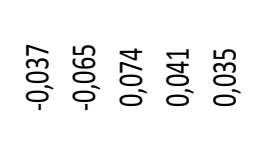 & 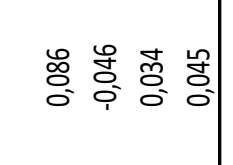 \\
\hline 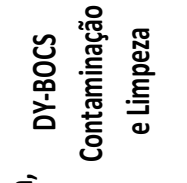 & 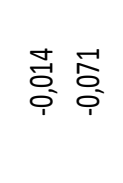 & 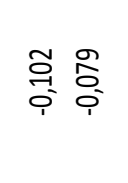 & 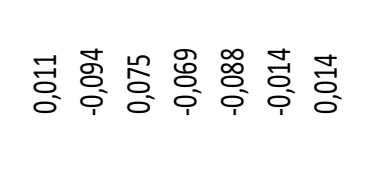 & 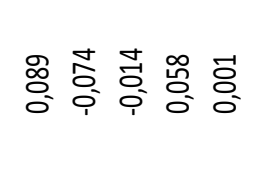 & 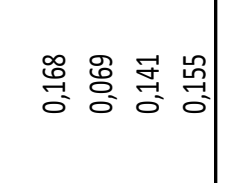 \\
\hline 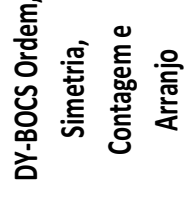 & 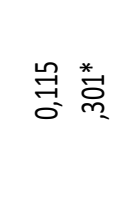 & 总 总 & 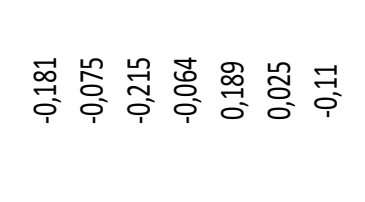 & 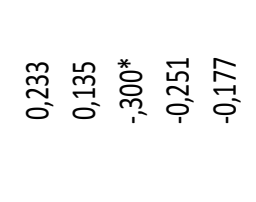 & 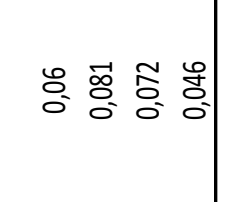 \\
\hline 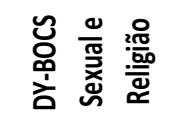 & 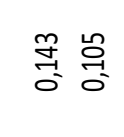 & 产亜 & 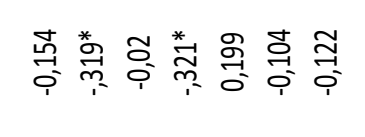 & 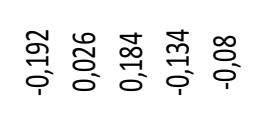 & 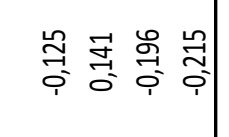 \\
\hline 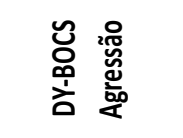 & $\underset{\sim}{\stackrel{a}{0}} \overrightarrow{0}$ & 兽 & 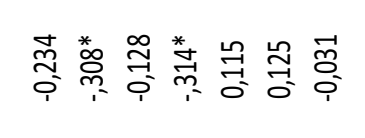 & 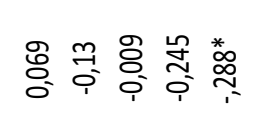 & 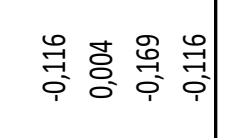 \\
\hline & & & 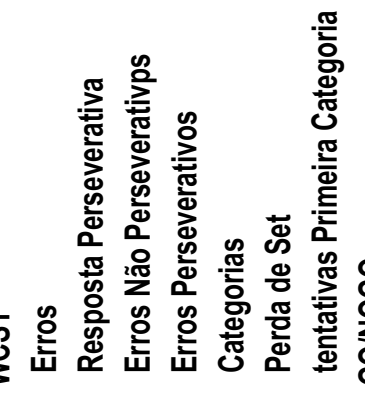 & 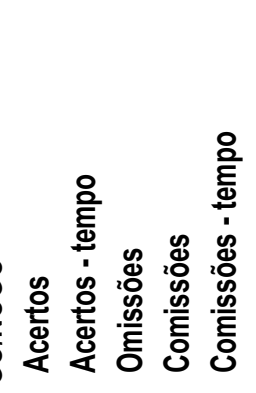 & 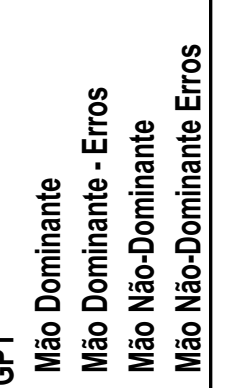 \\
\hline
\end{tabular}




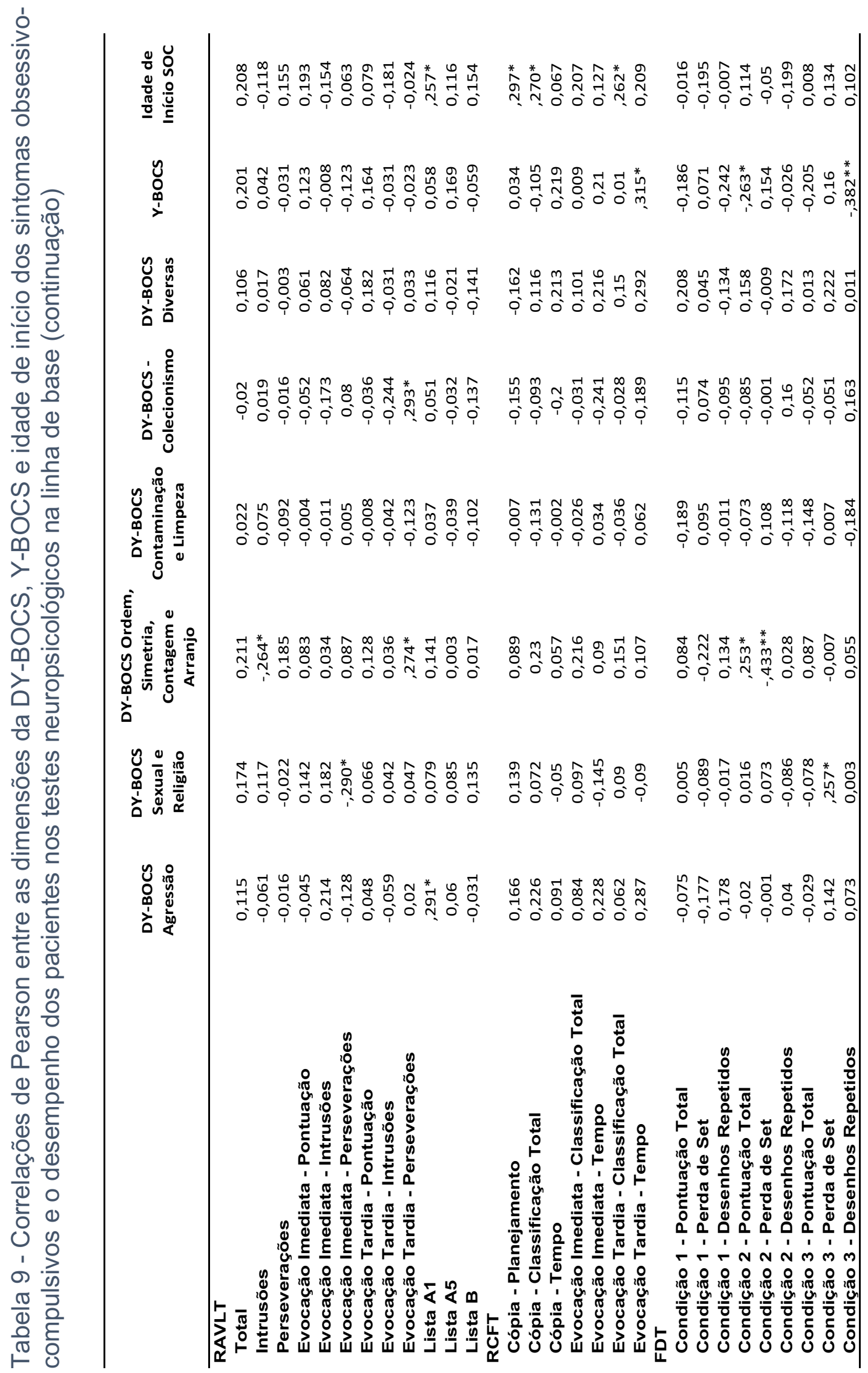




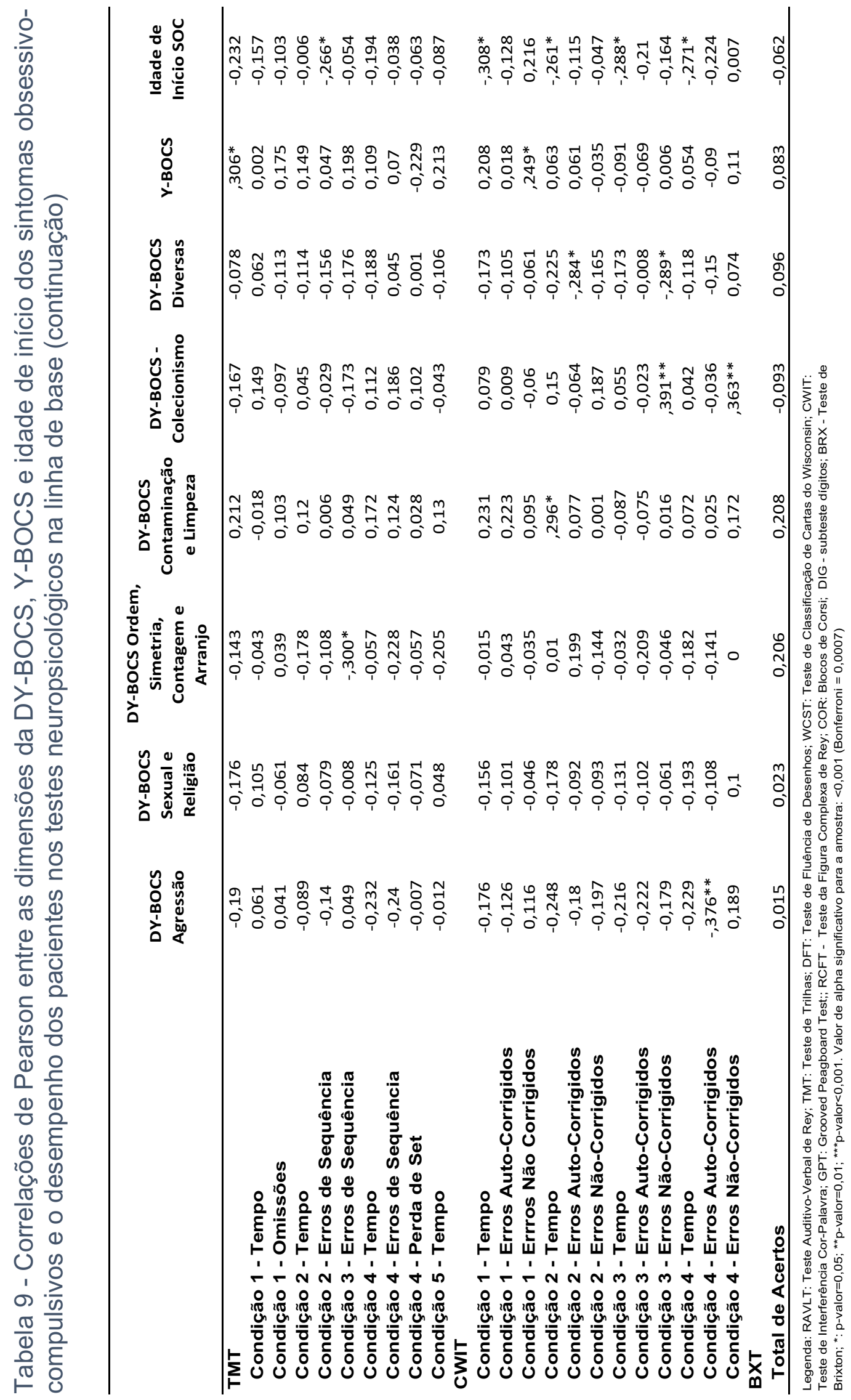




\subsection{ANEXO F}

Tabela 10 - Correlações de Pearson entre as principais os Transtornos Depressivo, Transtornos Ansiosos, Transtorno de Déficit de Atenção e Hiperatividade e o desempenho dos pacientes nos testes neuropsicológicos na linha de base

\begin{tabular}{|c|c|c|c|}
\hline & TD & TA & TDAH \\
\hline \multicolumn{4}{|l|}{ DIG } \\
\hline Direto & $-0,096$ & $-0,062$ & 0,091 \\
\hline Inverso & $-0,012$ & $-0,121$ & 0,286 \\
\hline \multicolumn{4}{|l|}{ COR } \\
\hline Direto & $-0,13$ & $-0,083$ & 0,157 \\
\hline Inverso & 0,024 & $-0,078$ & 0,041 \\
\hline \multicolumn{4}{|l|}{ WCST } \\
\hline Erros & 0,031 & 0,026 & $-0,196$ \\
\hline Resposta Perseverativa & 0,137 & $-0,027$ & $-0,172$ \\
\hline Erros Não Perseverativos & $-0,037$ & 0,077 & $-0,152$ \\
\hline Erros Perseverativos & 0,14 & $-0,023$ & $-0,184$ \\
\hline Categorias & 0,04 & $-0,047$ & 0,188 \\
\hline Perda de Set & 0,034 & $-0,008$ & $-0,098$ \\
\hline Tentativas Primeira Categoria & 0,049 & 0,109 & 0,000 \\
\hline \multicolumn{4}{|l|}{ GO/NOGO } \\
\hline Acertos & 0,066 & $-0,008$ & 0,007 \\
\hline Acertos - tempo & 0,081 & $-0,001$ &,$- 289^{*}$ \\
\hline Omissões & $-0,077$ & $-0,019$ & 0,082 \\
\hline Comissões & 0,14 & 0,081 & 0,185 \\
\hline Comissões - tempo & 0,134 & 0,057 & 0,034 \\
\hline \multicolumn{4}{|l|}{ GPT } \\
\hline Mão Dominante & 0,049 & $-0,031$ &,$- 343^{* *}$ \\
\hline Mão Dominante - Erros & 0,136 & $-0,04$ & 0,088 \\
\hline Mão Não-Dominante & 0,031 & 0,001 &,$- 387^{* *}$ \\
\hline Mão Não-Dominante Erros & $-0,077$ & $-0,023$ & $-0,097$ \\
\hline \multicolumn{4}{|l|}{ RAVLT } \\
\hline Total & $-0,169$ & 0,043 & 0,228 \\
\hline Intrusões & 0,193 & $-0,083$ & $-0,219$ \\
\hline Perseverações & 0,115 & $-0,145$ & $-0,028$ \\
\hline Evocação Imediata - Pontuação & $-0,091$ & $-0,098$ & 0,117 \\
\hline Evocação Imediata - Intrusões & 0,157 & 0,141 & 0,069 \\
\hline Evocação Imediata - Perseverações & $-0,099$ & $-0,041$ & $-0,039$ \\
\hline Evocação Tardia - Pontuação & $-0,111$ & 0,044 & 0,191 \\
\hline Evocação Tardia - Intrusões & 0,24 & 0,132 & 0,021 \\
\hline Evocação Tardia - Perseverações & 0,053 & $-0,188$ & 0,012 \\
\hline Lista A1 & $-0,169$ & $-0,075$ &, $249^{*}$ \\
\hline Lista A5 & $-0,069$ & $-0,008$ & 0,128 \\
\hline Lista B & 0,105 &,$- 283^{*}$ & 0,138 \\
\hline \multicolumn{4}{|l|}{ RCFT } \\
\hline Cópia - Planejamento & $-0,102$ & 0,018 &, $278^{*}$ \\
\hline Cópia - Classificação Total & $-0,071$ & 0,016 & 0,210 \\
\hline Cópia - Tempo & $-0,069$ & 0,082 & $-0,048$ \\
\hline Evocação Imediata - Classificação Total & $-0,07$ & 0,117 &, $303^{*}$ \\
\hline Evocação Imediata - Tempo & $-0,166$ & 0,019 & $-0,198$ \\
\hline Evocação Tardia - Classificação Total & $-0,082$ & 0,057 & 0,235 \\
\hline Evocação Tardia - Tempo & $-0,181$ & 0,085 & $-0,167$ \\
\hline
\end{tabular}


Tabela 10 - Correlações de Pearson entre as principais os Transtornos Depressivo, Transtornos Ansiosos, Transtorno de Déficit de Atenção e Hiperatividade e o desempenho dos pacientes nos testes neuropsicológicos na linha de base (Continuação)

\begin{tabular}{|c|c|c|c|}
\hline & TD & TA & TDAH \\
\hline \multicolumn{4}{|l|}{ FDT } \\
\hline Condição 1 - Pontuação Total & $-0,032$ & 0,076 &, $288^{*}$ \\
\hline Condição 1 - Perda de Set & 0,121 & $-0,032$ &,$- 367^{* *}$ \\
\hline Condição 1 - Desenhos Repetidos & 0,026 & 0,107 &, $310^{*}$ \\
\hline Condição 2 - Pontuação Total & $-0,093$ & $-0,009$ &, $272^{*}$ \\
\hline Condição 2 - Perda de Set & 0,028 & $-0,066$ &,$- 256^{*}$ \\
\hline Condição 2 - Desenhos Repetidos & 0,085 & 0,151 & 0,141 \\
\hline Condição 3 - Pontuação Total & 0,047 & $-0,02$ & ,291* \\
\hline Condição 3 - Perda de Set & $-0,139$ & $-0,081$ & 0,027 \\
\hline Condição 3 - Desenhos Repetidos & 0,104 & 0,03 & 0,172 \\
\hline \multicolumn{4}{|l|}{ TMT } \\
\hline Condição 1 - Tempo & $-0,042$ & 0,112 & $-0,184$ \\
\hline Condição 1 - Omissões & 0,062 & $-0,049$ & $-0,159$ \\
\hline Condição 2 - Tempo & 0,074 & 0,143 & $-0,112$ \\
\hline Condição 2 - Erros de Sequência & $-0,023$ & $-0,18$ &,$- 253^{*}$ \\
\hline Condição 3 - Tempo & 0,163 & 0,153 & $-0,142$ \\
\hline Condição 3 - Erros de Sequência & $-0,06$ & 0,026 & 0,069 \\
\hline Condição 4 - Tempo & 0,032 & 0,018 & $-0,176$ \\
\hline Condição 4 - Erros de Sequência & $-0,043$ & $-0,133$ &,$- 287^{*}$ \\
\hline Condição 4 - Perda de Set & 0,231 & 0,068 & 0,003 \\
\hline Condição 5 - Tempo & $-0,005$ & 0,061 & $-0,223$ \\
\hline \multicolumn{4}{|l|}{ CWIT } \\
\hline Condição 1 - Tempo & 0,03 & 0,085 &,$- 332^{* *}$ \\
\hline Condição 1 - Erros Auto-Corrigidos & $-0,057$ & 0,179 & $-0,034$ \\
\hline Condição 1 - Erros Não Corrigidos & $-0,009$ & 0,038 & $-0,051$ \\
\hline Condição 2 - Tempo & 0,007 & $-0,02$ & $-0,180$ \\
\hline Condição 2 - Erros Auto-Corrigidos & 0,146 & 0,006 & 0,048 \\
\hline Condição 2 - Erros Não-Corrigidos & 0,075 & 0,138 & $-0,144$ \\
\hline Condição 3 - Tempo & 0,237 & 0,117 &,$- 318^{*}$ \\
\hline Condição 3 - Erros Auto-Corrigidos & 0,156 & 0,018 &,$- 396^{\star *}$ \\
\hline Condição 3 - Erros Não-Corrigidos & 0,244 & $-0,127$ & $-0,126$ \\
\hline Condição 4 - Tempo & 0,022 & 0,051 & $-0,209$ \\
\hline Condição 4 - Erros Auto-Corrigidos & 0,057 & 0,001 &,$- 389^{* *}$ \\
\hline Condição 4 - Erros Não-Corrigidos &,$- 279^{*}$ & 0,069 & $-0,005$ \\
\hline \multicolumn{4}{|l|}{ BXT } \\
\hline Total de Acertos & $-0,022$ & $-0,092$ & 0,016 \\
\hline
\end{tabular}

Legenda: TD: Transtorno Depressivo; TA: Transtorno Ansioso; TDAH: Transtorno de Déficit de Atenção e Hiperatividade; RAVLT: Teste Auditivo-Verbal de Rey; TMT: Teste de Trilhas; DFT: Teste de Fluência de Desenhos; WCST: Teste de Classificação de Cartas do Wisconsin; CWIT: Teste de Interferência Cor-Palavra; GPT: Grooved Peagboard Test;; RCFT - Teste da Figura Complexa de Rey; COR: Blocos de Corsi; DIG - subteste dígitos; BRX - Teste de Brixton; *: pvalor $=0,05 ;{ }^{* \star} p$-valor $=0,01 ;{ }^{* \star *} p$-valor $<0,001$. Valor de alpha significativo para a amostra: $<0,001$ (Bonferroni $=0,0007$ ) 


\subsection{ANEXO G}

Tabela 11 - Associação entre os domínios cognitivos e a melhora clínica dos pacientes considerando a resposta aos diferentes tratamentos de primeira escolha para o TOC

\begin{tabular}{llll}
\hline \multicolumn{1}{c}{ Função Neuropsicológica } & F & gl & p-valor \\
\hline $\begin{array}{l}\text { Velocidade Motora e de Processamento } \\
\text { CWIT } 1 \text { tempo }\end{array}$ & 0,698 & 5 & 0,627 \\
CWIT 2 tempo & & \\
TMT 5 tempo & & \\
GPT mão dominante tempo & & \\
GPT mão não dominante tempo & & \\
Memória Não-Verbal & 2,179 & \\
COR direto & & \\
RCFT recuperação imediata & & \\
RCFT recuperação tardia & & \\
Memória Verbal & & \\
DIG direto & 1,736 & \\
RAVLT recuperação imediata & & \\
RAVLT recuperação tardia & & \\
Memória de Trabalho & & \\
COR inverso \\
DIG inverso
\end{tabular}

Legenda: RAVLT: Teste Auditivo-Verbal de Rey; TMT: Teste de Trilhas; DFT: Teste de Fluência de Desenhos; WCST: Teste de Classificação de Cartas do Wisconsin; CWIT: Teste de Interferência Cor-Palavra; GPT: Grooved Peagboard Test; RCFT - Teste da Figura Complexa de Rey; COR: Blocos de Corsi; DIG: Dígitos; p-valor da MANOVA 


\subsection{ANEXO H}

Tabela 12 - Desempenho dos pacientes que foram ou não respondedores nos testes neuropsicológicos na linha de base e após 14 semanas de tratamento

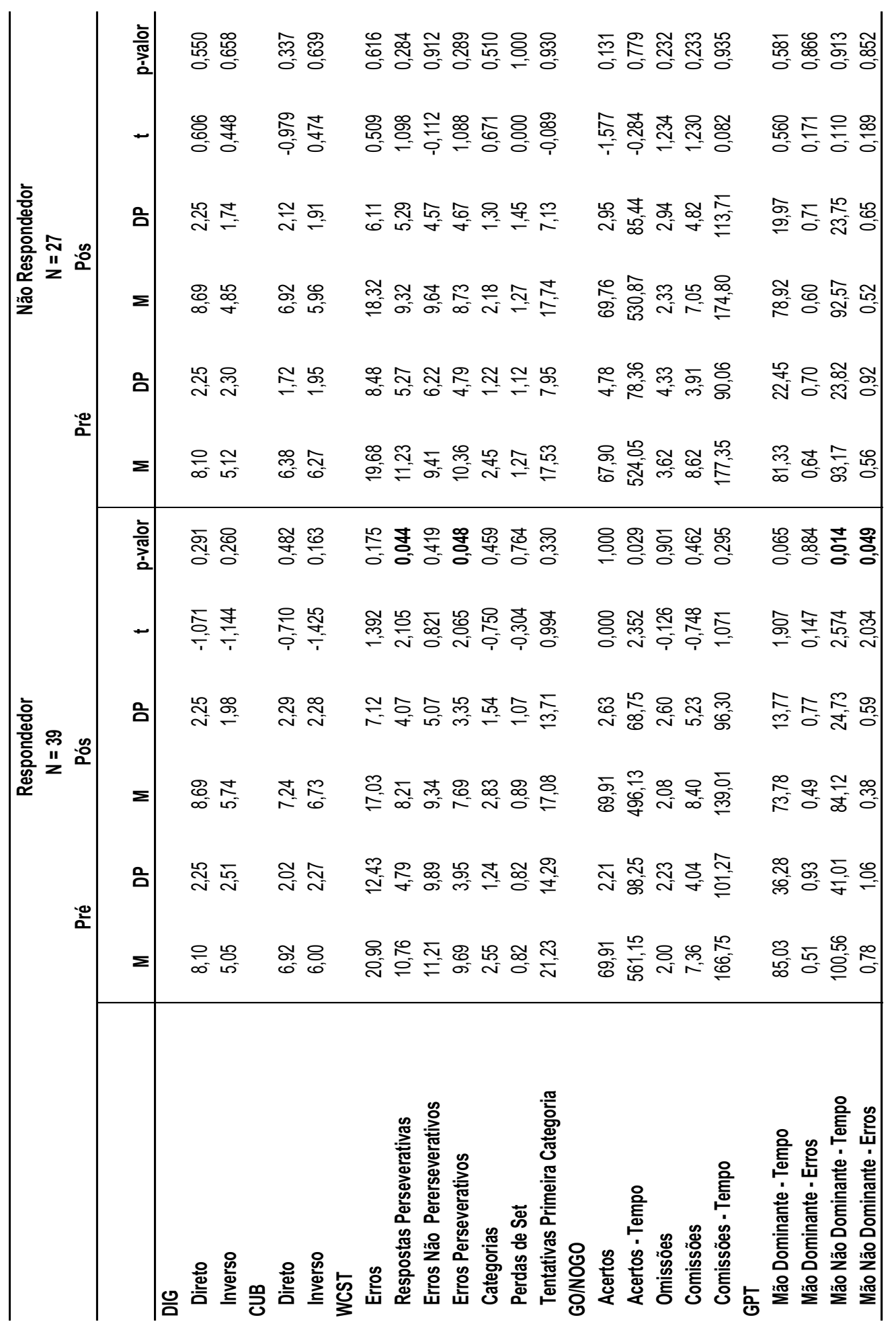




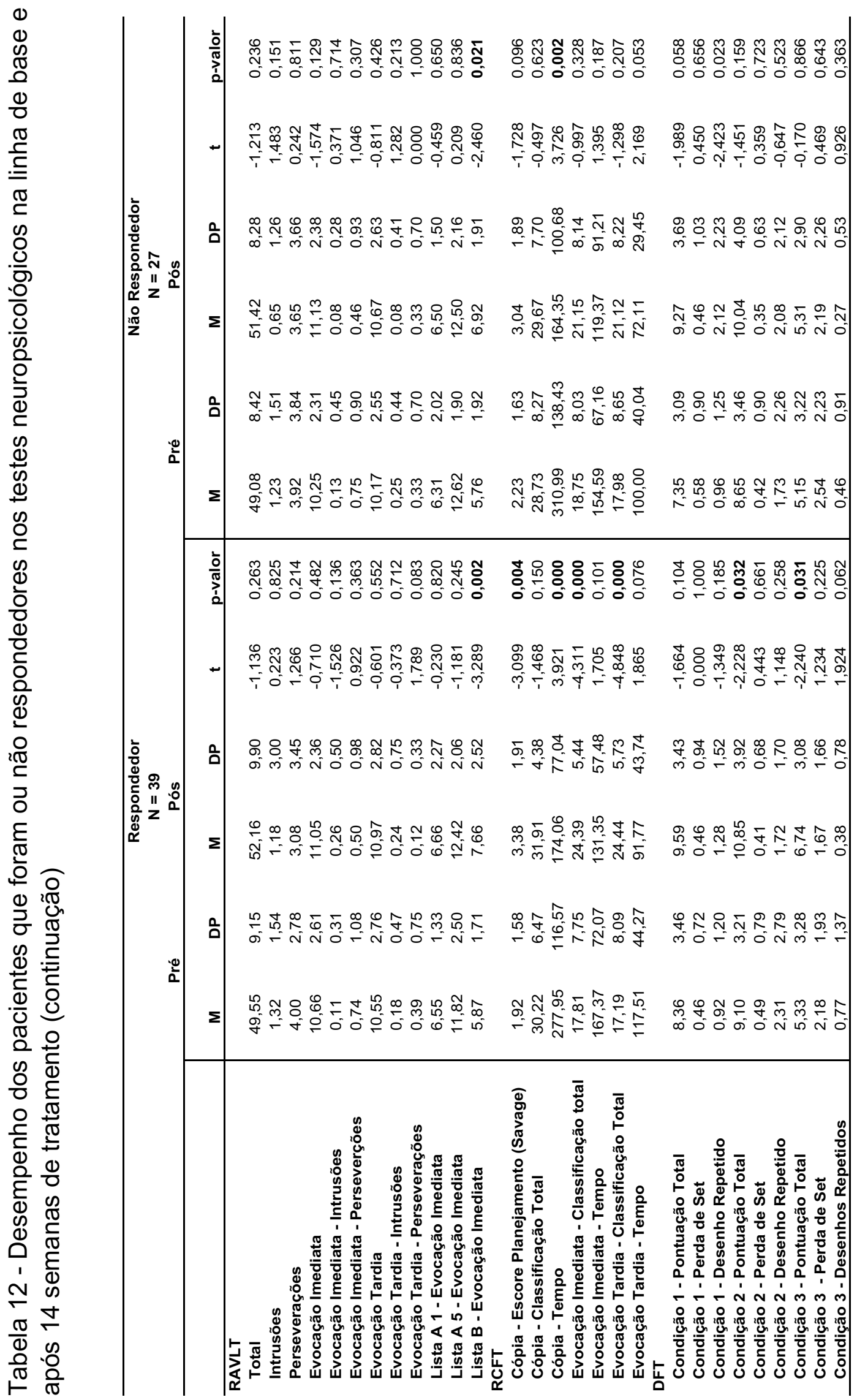




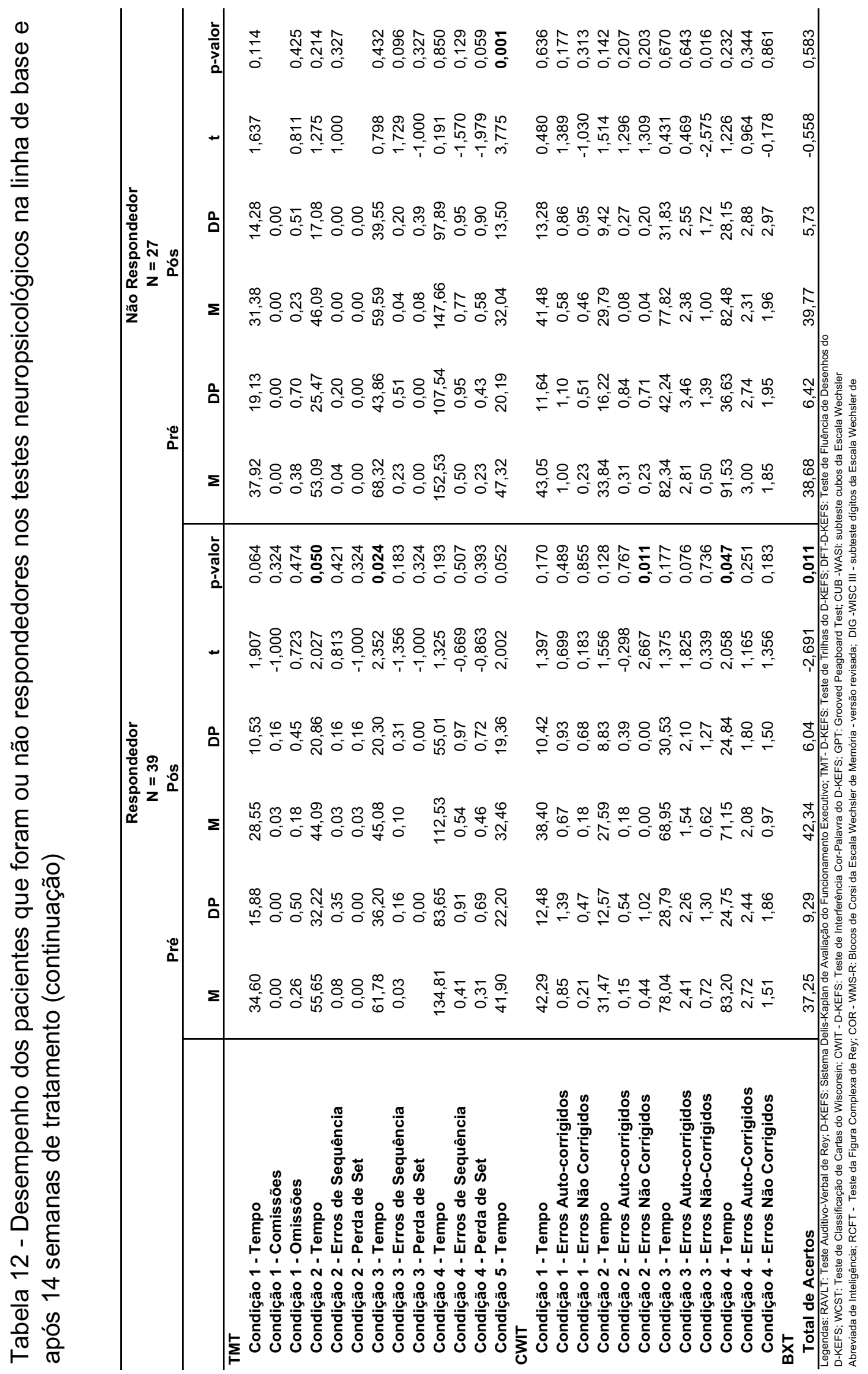




\subsection{ANEXO I}

Tabela 13 - Dados das variáveis neuropsicológicas da linha de base e após 14 semanas de tratamento e resultado dos testes de comparação de médias

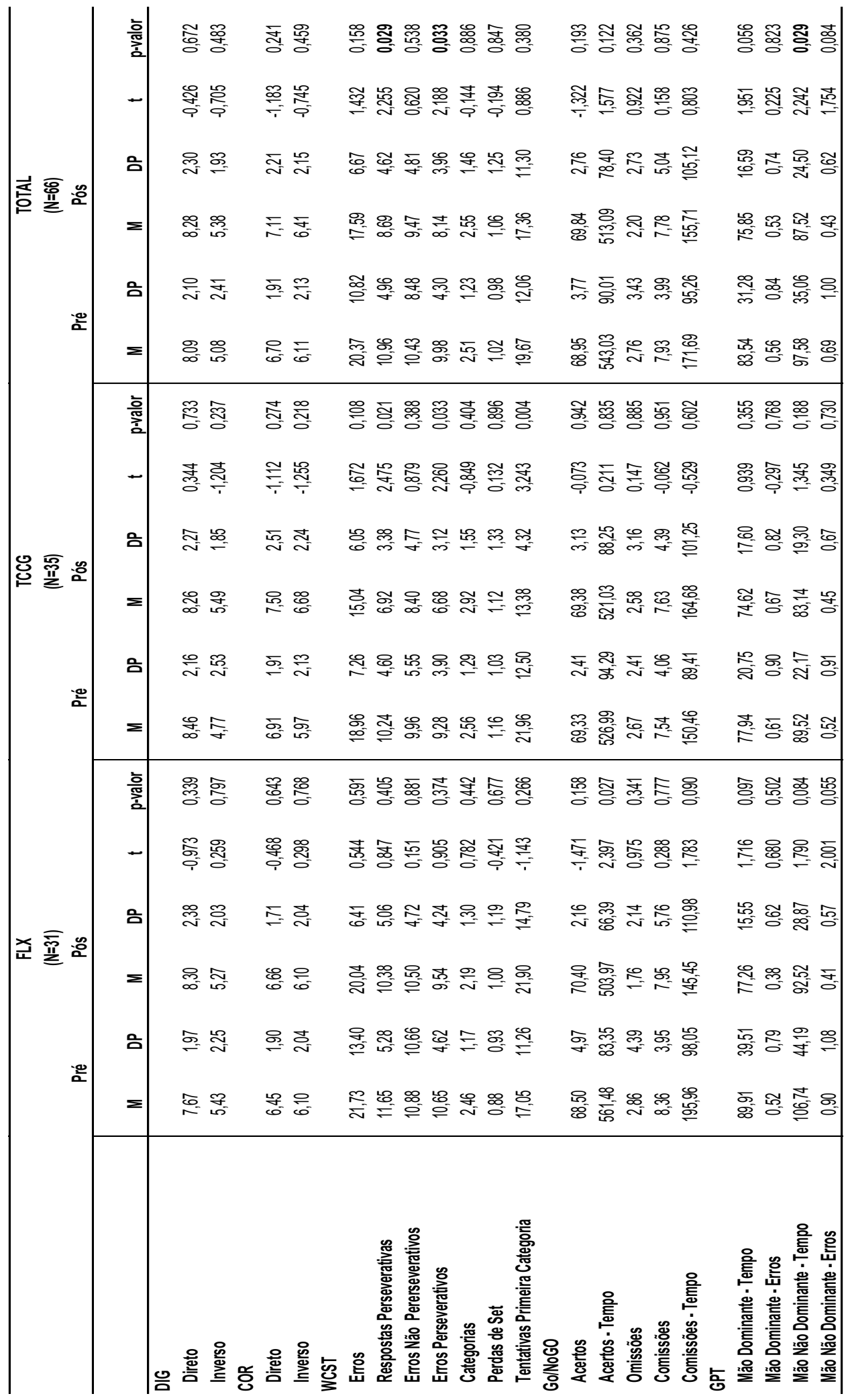




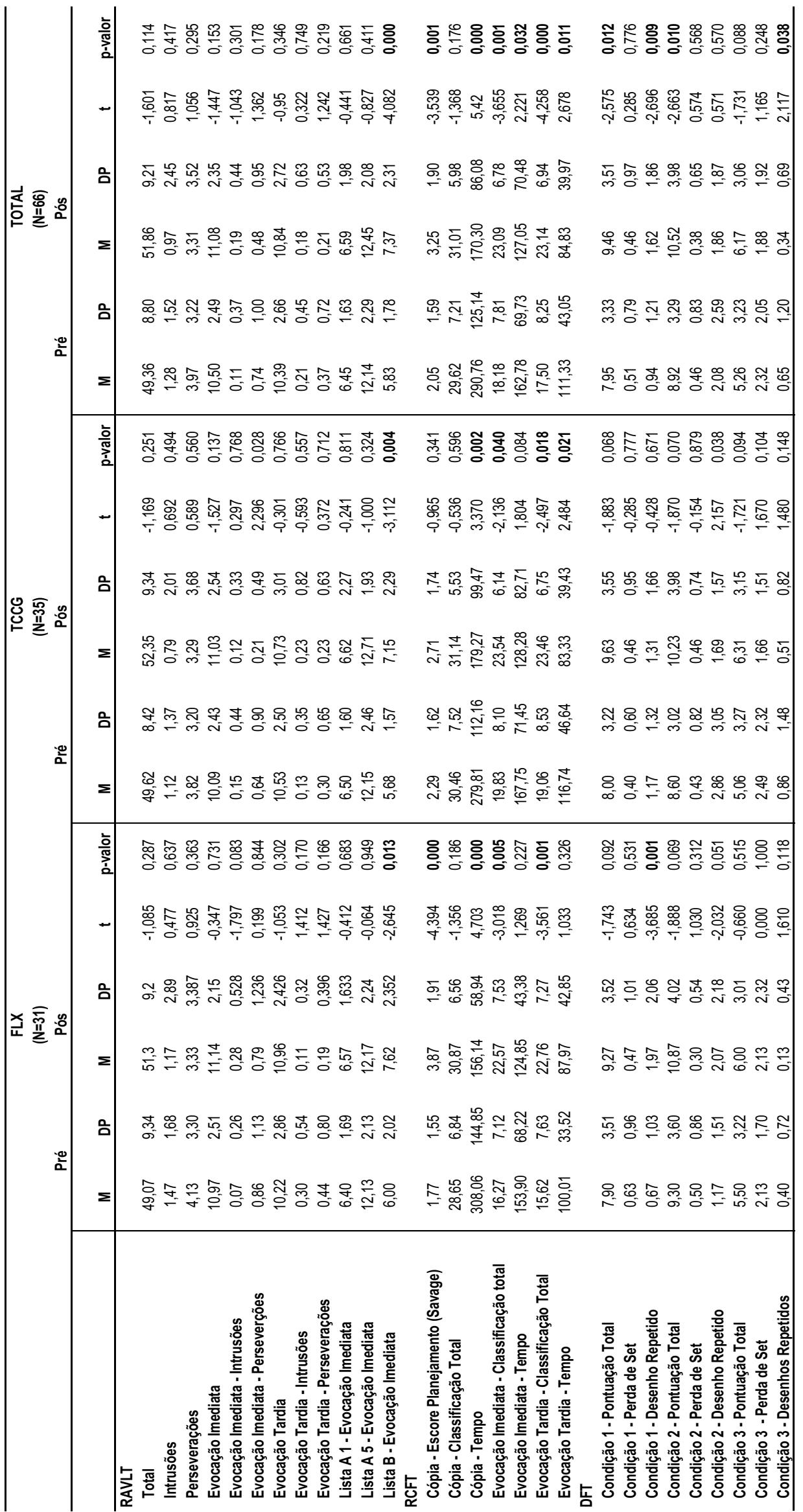




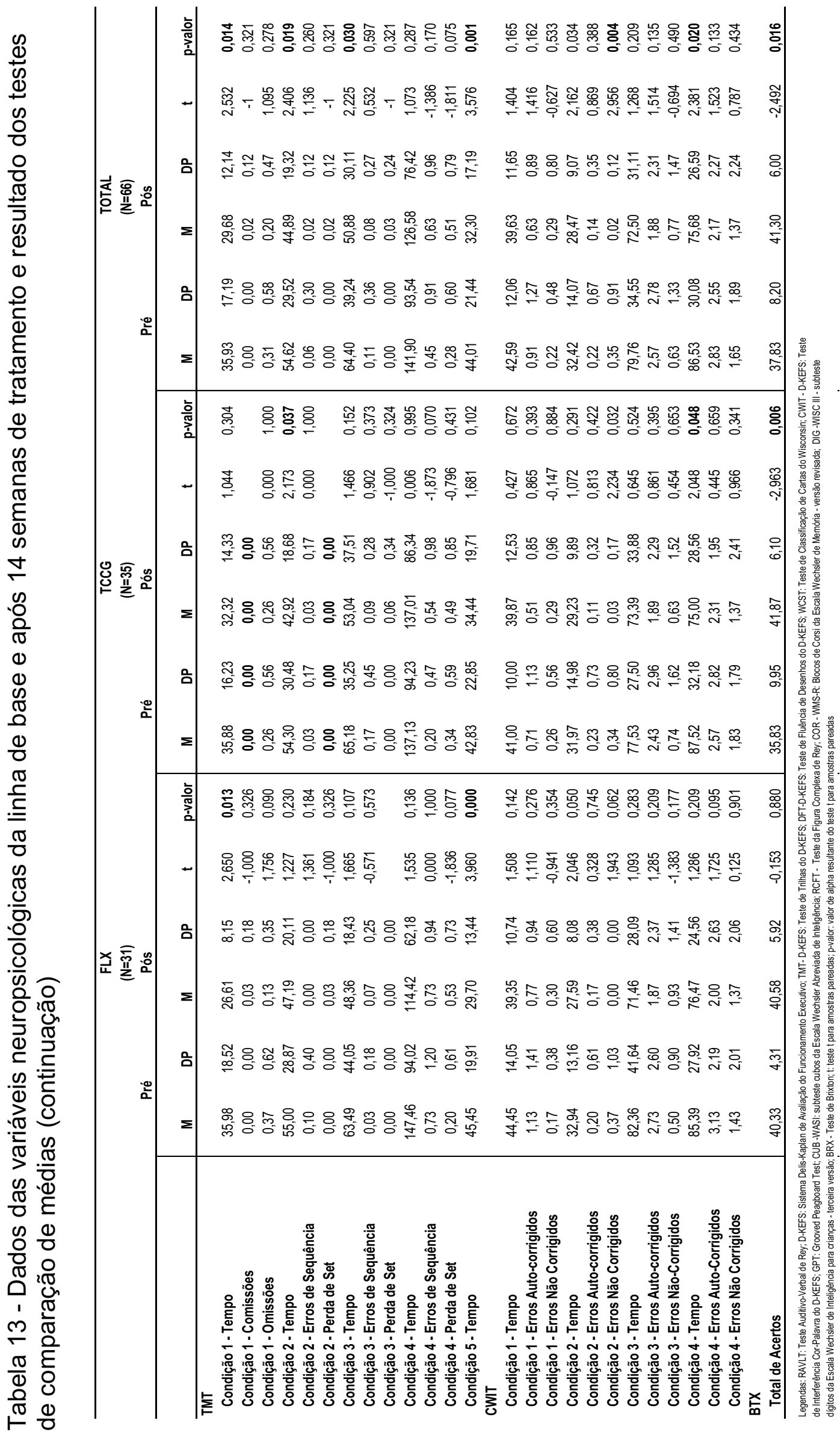




\section{REFERÊNCIAS}

Associação Brasileira de Empresas de Pesquisa. Critério de Classificação Econômica Brasil (CCEB) versão 2008. Disponível para download em http://www.abep.org/criterio-brasil.

Abramowitz JS, Taylor S, McKay D. Obsessive-compulsive disorder. Lancet. 2009 Aug 8; 374 (9688): 491-9.

Abramovitch A, Mittelman A, Henin A, Geller DA. Neuroimaging and neuropsychological findings in pediatric obsessive-compulsive disorder: a review and developmental considerations. Neuropsych. 2012; 2 (4): 313-329.

Abramovitch A, Abramowitz JS, Mittelman A. The neuropsychology of adult obsessive-compulsive disorder: a meta-analysis. Clin Psychol Rev. 2013; 33: 1163-1171.

Abramovitch A, Abramowitz JS, Mittelman A, Stark A, Ramsey K, Geller DA. 2015. Research review: neuropsychological test performance in pediatric obsessive-compulsive disorder: a meta-analysis. J Child Psychol Psychiatr. 2015a; 56: 837-847.

Abramovitch A, Mittelman A, Tankersley AP, Abramowitz JS, Shweiger A. Neuropsychological investigations in obsessive-compulsive disorder: A systematic review of methodological challenges. Psychiatry Res. 2015b; 228: $112-120$. 
American Psychiatric Association. Diagnostic and Statistical Manual of Mental Disorders: DSM-IV-TR. Washington DC: American Psychiatric Press Inc.; 1994.

American Psychiatric Association. Diagnostic and Statistical Manual of Mental Disorders: DSM V. Airlington, VA: American Psychiatric Association; 2013.

Andrade LH, Wang Y-P, Andreoni S, Silveira CM, Alexandrino-Silva C, Siu ER, et al. Mental Disorders in Megacities: Findings from the São Paulo Megacity Mental Health Survey, Brazil. PLoS ONE 2012; 7(2): e31879.

Andrés S, Boget T, Lazaro L, Penades R, Morer A, Salamero M, Castro-Fornieles J. Neuropsychological performance in children and adolescents with obsessivecompulsive disorder and influence of clinical variables. Biol Psychiatry. 2007; 61: 946-951.

Andrés S, Lázaro L, Salameto M, Boget T, Penadés, Castro-Fornieles J. Changes in cognitive dysfunction in children and adolescents with obsessivecompulsive disorder after treatment. J Psychiatr Res 2008; 42(6), 507-514.

Batistuzzo MC. Ativação cerebral associada à memória episódica verbal no transtorno obsessive-compulsivo por meio de ressonância magnética functional [tese]. São Paulo: Faculdade de Medicina, Universidade de São Paulo; 2013.

Beers SR, Rosenberg DR, Dick EL, Williams T, O’Hearn KM, Birmaher B, Ryan CM. Neuropsychological study of frontal lobe function in psychotropic-naïve children with obsessive-compulsive disorder. Am J Psychiatry. 1999, 156(5): 777779. 
Birmaher B, Brent DA, Chiappetta L, Jeffrey Bridge BS, Suneeta Monga BS, Buagher M. Psychometric properties of the Screen for Child Anxiety Related Emotional Disorders (SCARED): a replication study. J Am Acad Child Adolesc Psychiatry. 1999; 38(10): 1230-6.

Bloch MH, Sukhodolsky DG, Dombrowski PA, Panza KE, Craiglow BG, Landeros-Weisenberg A, Schultz RT Poor fine-motor and visuospatial skills predict persistence of pediatric-onset obsessive-compulsive disorder into adulthood. J Child Psychol Psychiatry. 2011 Sep; 52 (9): 974-83.

Brasil HHA. Desenvolvimento da versäo brasileira da K-SADS-PL (Schudule for Affective Disorders and Schizophrenia for Scholl Aged Children Present and Lifetime Version) e estudo de suas propriedades psicométricas [tese]. São Paulo: Escola Paulista de Medicina, Universidade Federal de São Paulo; 2003.

Burgess P, Shallice T. The Hayling and Brixton Tests - Test manual. Bury St Edmunds, UK: Thames Valley Test Company; 1997.

Chamberlain SR, Blackwell AD, Fineberg NA, Robbins TW, Sahakian BJ. The neuropsychology of obsessive compulsive disorder: the importance of failures in cognitive and behavioural inhibition as candidate endophenotypic markers. Neurosci Biobehav Rev. 2005 May; 29 (3): 399-419.

de Mathis MA, do Rosario MC, Diniz JB, Torres AR, Shavitt RG, Ferrão YA, Fossaluza V, de Bragança Pereira CA, Miguel EC. Obsessive-compulsive disorder: influence of age at onset on comorbidity patterns. Eur Psychiatry. 2008; 23 (3): 187-94. 
Delis DC, Kaplan E, Kramer J H. Delis-Kaplan Executive Function System (DKEFS). San Antonio, TX: The Psychological Corporation; 2001.

Evans DW, Leckman JF, Carter A, Reznick JS, Henshaw D, King RA, Pauls D. Ritual, Habit, and Perfectionism: The Prevalence and Development of Compulsive-like Behavior in Normal Young Children. Child Development. 1997; 68: 58-68.

Fatori D, Pereira CAB, Asbahr FR, Requena G, Alvarenga PG, de Mathis, MA, Rohde LA, Leckman JF, Mach JS, Polanczyk GV, Miguel EC, Shavitt RG. Adaptative treatment strategies for children and adolescents with obsessivecompulsive disorder: A sequencial multiple assignment randomized trial. $J$ Anxiety Disord. 2018; 58: 42-50.

Flessner CA, Allgair A, Garcia A, Freeman J, Sapyta J, Franklin ME, Foa E, March $\mathrm{J}$ The impact of neuropsychological functioning on treatment outcome in pediatric obsessive-compulsive disorder. Depress Anxiety. 2010; 27 (4): 365-71.

Fossaluza V, Diniz JB, Pereira BB, Miguel EC, Pereira, CAB. Sequential allocation to balance prognostic factors in a psychiatric clinical trial. Clinics. 2009; $64(6), 511-518$.

Garcia AM, Sapyta JJ, Moore PS, Freeman JB, Franklin ME, March JS, FOA EB. Predictors and moderators of treatment outcome in pediatric obsessive compulsive treatment study (POTS I). J Am Acad Child Adolesc Psychiatry. 2009; 49 (10): 1024-1033. 
Geller DA. Obsessive-compulsive and spectrum disorders in children and adolescents. Psychiatr Clin North Am. 2006, 29: 353-370.

Geller DA, Biederman J, Jones J, Shapiro S, Schwartz S, Park KS. Obsessivecompulsive disorder in children and adolescents: a review. Harv Rev Psychiatry.1998; 5: 260-73.

Geller DA, Biederman J, Stewart ES, et al. Which SSRI? A meta-analysis of pharmacotherapy trials in pediatric obsessive compulsive disorder. Am $J$ Psychiatry. 2003; 160: 1919-1928.

Geller DA, March J. Practice parameter for the assessment and treatment of children and adolescents with obsessive-compulsive disorder. J Am Acad Child Adolesc Psychiatry. 2012; 51 (1), 98-113.

Geller DA, Abramovitch A, Mittelman A, Stark A, Ramsey K, Cooperman A, Baer L, Stewart. Neurocognitive function in pediatric obsessive-compulsive disorder. World J Biol Psychiatry. 2017; 19 (2): 142-151.

Goodman W K, Price, L. H., Rasmussen, S. A., Mazure, C., Delgado, P., Heninger, G. R., \& Charney, D. S. The YaleBrown Obsessive Compulsive Scale. II. Validity. Arch Gen Psychiatry. 1989a; 46 (11): 1012-1016.

Goodman W K, Price L H, Rasmussen SA, Mazure C, Fleischmann RL, Hill CL, Heninger GR, et al. The Yale-Brown Obsessive Compulsive Scale. I. Development, use, and reliability. Arch Gen Psychiatry. 1989b; 46 (11): 10061011. 
Grisham JR, Anderson TM, Poulton R, Moffitt TE, Andrews G. Childhood neuropsychological deficits associated with adult obsessive-compulsive disorder. Br J Psychiatry. 2009; 195(2): 138-41.

Heaton RK, Chelune GJ, Talley JL, Kay GG, Curtiss G. Wisconsin Card Sorting Test Manual-Revised and Expanded. Odessa, FL: Psychological Assessment Resources Inc; 1993.

Hybel KA, Mortensen EL, Lambek R, Højgaard DRMA, Thomsen PH. (2017). Executive function predicts cognitive-behavioral therapy response in childhood obsessive-compulsive disorder. Behav Res Ther. 2017; 99: 11-18.

Kalra SK, Swedo SE. Children with obsessive-compulsive disorder: are they just little adults? J Clin Invest. 2009; 119(4): 737-46.

Kaufman J, Birmaher B, Brent DA, Ryan ND, Rao U. K-SADS-PL. J Am Acad Child Adolesc Psychiatry. 2000 Oct; 39 (10): 1208.

Kessler RC, Avenevoli S, Costello EJ, Georgiades K, Green JG, Gruber MJ, He JP, Koretz D, McLaughlin KA, Petukhova M, Sampson NA, Zaslavsky AM, Merikangas KR. Prevalence, persistence, and sociodemographic correlates of DSM-IV disorders in the National Comorbidity Survey Replication Adolescent Supplement. Arch Gen Psychiatry 2012 Apr; 69 (4): 372-80.

Kim MS, Park SJ, Shin MS, Kwon JS. Neuropsychological profile in patients with obsessive-compulsive disorder over a period of 4-month treatment. J Psychiatr Res. 2002 Jul-Aug; 36 (4): 257-65. 
Kraemer HC, Robinson TN. Are certain multicenter randomized clinical trial structures misleading clinical and policy decisions? Contemp Clin Trials. 2005 Oct; 26(5): 518-29.

Lewin AB, Larson MJ, Park JM, McGuire JF, Murphy TK, Storch EA. Neuropsychological functioning in youth with obsessive-compulsive disorder: An examination of executive function and memory impairment. Psychiatry Res. $2014 ; 216(1): 108-115$.

Lezak M, Howieson D, Loring D. Neuropsychological Assessment (4 ${ }^{\text {th }}$ Edition). New York, NY: Oford University Press; 2004.

Magalhães SS, Hamdan AC. The Rey Auditory Verbal Learning Test: Normative data for Brazilian Population and analysis of the influence of demographic variables. Psychol \& Neurosci. 2010; 3 (1): 85-91.

Magalhães SS, Malloy-Diniz LF, Hamdan AC. Validity convergent and reliability test-retest of the Rey Auditory Verbal Learning Test. Clinical Neuropsychiatry. 2012, 9 (3): 129-137.

Malloy-Diniz LF, da Cruz MF, Torres V, Cosenza R. O teste de Aprendizagem Auditivo-Verbal de Rey: normas para uma população brasileira. Rev Bras Neurol. 2000; 36(3): 79-83. 
March JS, Leonard HL. Obsessive-Compulsive Disorder in Children and Adolescents: A Review of the Past 10 Years. J Am Acad Child Adolesc Psychiatry. 1996; 35(10): 1265-1273.

Mataix-Cols D, Rauch SL, Manzo PA, Jenike MA, Baer L. Use of factor-analyzed symptom dimensions to predict outcome with serotonin reuptake inhibitors and placebo in the treatment of obsessive-compulsive disorder. The Am J Psychiatry. 1999; 156(9), 1409-1416.

Matthews C, Klove H. Instruction manual for Adult Neuropsychology Test Battery. Madison, WI: University of Wisconsin Medical School; 1964.

McGuire JF, Crawford EA, Park JM, Storch EA, Murphy TK, Larson MJ, Lewin AB. Neuropsychological Performance Across Symptom Dimensions In Pediatric Obsessive Compulsive Disorder. Depress Anxiety. 2014; 31: 988-996.

Nielen MM, Den Boer JA. Neuropsychological performance of OCD patients before and after treatment with fluoxetine: evidence for persistent cognitive deficits. Psychol Med. 2003 Jul; 33 (5): 917-25.

Nosek BA, Banaji MR. The go/no-go association task. Social Cognition. 2001; 19(6): 161-176.

Oliveira M. Manual: Figuras Complexas de Rey - Teste de Cópia e de Reprodução de Memória de Figuras Geométricas Complexas. São Paulo, SP: Casa do Psicólogo; 1999. 
Oliveira M, Rigoni M, Andretta I, Moraes JL. Validação do teste figuras complexas de Rey na população Brasileira. Avaliação Psicológica. 2004; 3(1): 33-38.

Ornstein T, Arnold P, Manassis K, Mendlowitz S,Schachar R. Neuropsychological performance in childhood OCD: a preliminary stydy. Depress Anxiety. 2010; 27(4): 372-380.

Osterrieth P. Le test de copie d'une figure complexe. Arch Psychol. 1944; 30: 206-356.

Pérez-Vigil A, Fernàndez de la Cruz L, Bender G et al. Association of ObsessiveCompulsive Disorder With Objective Indicators of Educational Attainment - A Nationwide Registrer Based Sibling Control Study. JAMA Psychiatry. 2018; 75 (1): 47-55.

Piacentini J, Bergman RL, Keller M, McCracken J. Functional impairment in children and adolescents with obsessive-compulsive disorder. J Child Adolesc Psychopharmacol. 2003; 13(Suppl. 1): 61-69.

Poznanski E, Mokros HB, Grossman J, Freeman LN. Diagnostic criteria in childhood depression. Am J Psychiatry. 1985; 142 (10):1168-1173.

Rao NP, Reddy YC, Kumar KJ, Kandavel T, Chandrasheakar CR. Are neuropsychological déficits trait markers in OCD? Prog Neuropsychopharmacol Bio Psychiatry. 2008 Aug 1; 32 (6): 1574-9.

Rasmunssen SA, Eisen JL. Epidemiology of obsessive compulsive disorder. $J$ Clin Psychiatry. 1990 Feb; 51 (Suppl): 10-3. 
Rey A. L'Examen Clinique en Psychologie. Paris: Press Universitaire de France; 1958.

Rey A. Manuel: Test de Copie d'une Figure Complexe. Paris, EU: Centre de Psychologie Appliqueé; 1959.

Rosário-Campos MC. Transtorno obsessivo-compulsivo em crianças e adolescentes. Pediatria moderna. 1999; 35 (4): 211-216.

Rosário-Campos MC, Leckman JF, Curi M, Quatrano S, Katsovitch L, Miguel EC, \& Pauls, D. L. (2005). A family study of early-onset obsessive-compulsive disorder. Am J of Med Genet B Neuropsychiatr Gent. 2005 Jul 5; 136B (1), 9297.

Rosário-Campos MC, Miguel EC, Quatrano S, Chacon P, Ferrao Y, Findley D, et al. The Dimensional Yale-Brown Obsessive-Compulsive Scale (DY-BOCS): an instrument for assessing obsessive-compulsive symptom dimensions. $J \mathrm{Mol}$ Psychiatry. 2006; 11(5): 495-504.

Ruscio AM, Stein DJ, Chiu WT, Kessler RC. The epidemiology of obsessivecompulsive disorder in the National Comorbidity Survey Replication. $J$ Mol Psychiatry. 2010 Jan; 15(1): 53-63.

Scahill L, Riddle MA, McSwiggin-Hardin M, Ort SI, King RA, Goodman WK, Cicchetti D, Leckman JF. Children's Yale-Brown Obsessive Compulsive Scale: reliability and validity. J Am Acad Child Adolesc Psychiatry. 1997; 36: 844-52. 
Shin MS, Choi H, Kim H, Hwang JW, Kim BN \& Cho SC. A study of neuropsychological deficit in children with obsessive-compulsive disorder. Eur Psychiatry. 2008; 23(7): 512- 520.

Shin NY, Lee TY, Kim E, Kwon JS. Cognitive functioning in obsessive-compulsive disorder: a meta-analysis. Psychol Med. 2014; 44: 1121-1130.

Skoog G, Skoog I. A 40-year follow-up of patients with obsessive-compulsive disorder. Arch Gen Psychiatry. 1999; 56(2):121-7.

Stein MB, Forde DR, Anderson G, Walker JR. Obsessive-compulsive disorder in the community: an epidemiologic survey with clinical reappraisal. $A m J$ Psychiatry. 1997; 154(8): 1120-1126.

Strauss E, Sherman EMS, Spreen O. A compendium of Neuropsychological Tests: Administration, Norms and Commentary (3rd ed.). New York: Oxford University Press; 2006.

Trentini CM, Yates DB, Heck VS. Escala de Inteligência Wechsler Abreviada (WASI): Manual profissional. São Paulo: Casa do Psicólogo; 2014.

Trites R. Grooved Pegboard Test - Model 32025 - Manual - User Instructions. Ontario, Canada: Lafayette Instrument; 2002.

van der Straten A, Huysler C, Wolters L, Denys D, van Wingen G. Long-term effects of cognitive behavioral therapy on planning and prefrontal cortex function in pediatric obsessive-compulsive disorder. Biol Psychiatry Cogn Neurosci Neuroimaging. 2018 Apr; 3 (4): 320-328. 
Watson HJ, Rees CS. Meta-analysis of randomized, controlled treatment trials for pediatric obsessive-compulsive disorder. J Child Psychol Psychiatry. 2008; 49(5), 489-498.

Wechsler D. Wechsler Abbreviated Scale of Intelligence (WASI). San Antonio, TX: Psychological Corporation; 1999.

Wechsler D. Manual for the Wechsler Memory Scale - Revised. San Antonio, TX: Psychological Corporation; 1987.

Wechsler D. Wechsler intelligence scale for children - Third edition (WISC-III): Manual. San Antonio: Psychological Corporation; 1991.

Zohar $\mathrm{AH}$. The epidemiology of obsessive-compulsive disorder in children and adolescents. Child Adolesc Psychiatr Clin Am. 1999 Jul; 8(3): 445-60. 